\title{
ETHNO-RACIAL DISPARITIES IN CANADA'S LABOUR MARKET: THE CASE OF RECENT GRADUATES
}

\author{
by \\ Ravinder Singh Mehmi

\begin{abstract}
A thesis
presented to Ryerson University

in partial fulfilment of the

requirements for the degree of

Master of Science in Management

in the program of

Master of Science in Management
\end{abstract}

Bachelor of Business Administration, University of Toronto, 2016

Toronto, Ontario, Canada, 2019

(C) Ravinder Singh Mehmi 2019 


\section{AUTHOR'S DECLARATION FOR ELECTRONIC SUBMISSION OF A THESIS}

I hereby declare that I am the sole author of this thesis. This is a true copy of the thesis, including any required final revisions, as accepted by my examiners.

I authorize Ryerson University to lend this thesis to other institutions or individuals for the purpose of scholarly research.

I further authorize Ryerson University to reproduce this thesis by photocopying or by other means, in total or in part, at the request of other institutions or individuals for the purpose of scholarly research.

I understand that my thesis may be made electronically available to the public 


\begin{abstract}
Ethno-Racial Disparities in Canada Labour Market: The Case of Recent Graduates. Master of Science in Management (MScM), 2019. Ravinder Singh Mehmi. Ted Rogers School of Management, Ryerson University.

This study explores the labour market outcomes of recent-graduate visible-minorities who did not obtain any non-Canadian educational credentials, of any level, prior to their graduation (e.g. "generation 1.5+"). Using the 2013 National Graduates Survey, which surveyed those who graduated from Canadian public-postsecondary institutions in the 2009-2010 academic year, this study assesses the incomes and (un)employment statuses of Canada's four largest ethno-racial groups - Whites, South Asians, Chinese, and Blacks. Approximately 93\% of the subsample under analysis is Canadian-born. The results show that, amongst those who held a full-time job at the time of the survey, the visible-minority subgroups do not experience any earnings penalties versus their White counterparts (by gender) — but rather some subgroups show earnings premiums. However, some visible-minority subgroups, such as the South Asian males, show substantially higher odds of being unemployed versus their White counterparts (by gender). Limitations and implications are discussed.
\end{abstract}




\section{ACKNOWLEDGEMENTS}

First and foremost, I wish to sincerely thank my supervisor, Dr. Rupa Banerjee, who guided me through my graduate studies with utmost patience and dedication. She has become one of the very few people in my life who I can say that I genuinely admire.

I am also extremely thankful to Dr. Danielle Lamb, not only for her valuable feedback as a member of my supervisory committee, but also for giving me the opportunity to become a Teaching Assistant. Without a doubt, this job is the best that I have ever worked in.

I also want to sincerely thank Dr. Murtaza Haider, who substantially increased my comfort with quantitative research methods - and thus enabled me to not just complete this thesis, but write it with confidence. I will be forever grateful for the lessons learned from this great man.

Moreover, I wish to extend my sincere thanks to Dr. Margaret Yap, for taking the time to diligently review my research and provide me with detailed feedback. I also want to thank her for giving me my very first Graduate Assistant position.

Finally, thank you to all the wonderful professors who I had the privilege to learn from throughout my time as a Ryerson University student; to Pat, Allison, and Carmina from Statistics Canada for patiently assisting me with my research; to all the staff \& administrators for always providing me with advice and guidance whenever I needed it; and to my fellow students \& colleagues for your dear companionship since day one. 


\section{STATISTICS CANADA DISCLAIMER}

This research was supported by funds to the Canadian Research Data Centre Network (CRDCN) from the Social Sciences and Humanities Research Council (SSHRC), the Canadian

Institute for Health Research (CIHR), the Canadian Foundation for Innovation (CFI), and Statistics Canada.

Although the research and analysis are based on data from Statistics Canada, the opinions expressed do not represent the views of Statistics Canada. 


\section{TABLE OF CONTENTS}

Author's Declaration for Electronic Submission of a Thesis. . . . . . . . . . . . ii

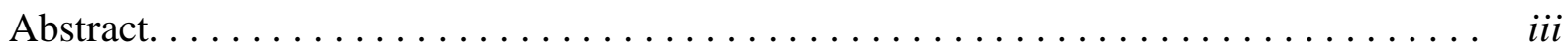

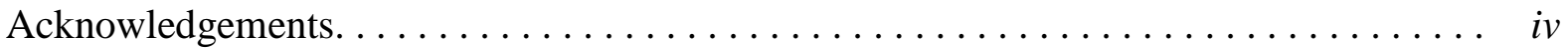

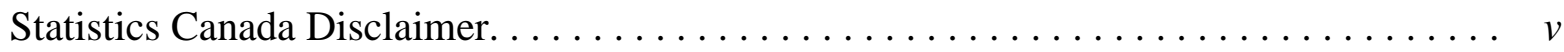

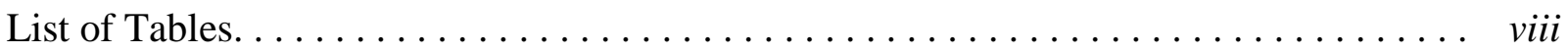

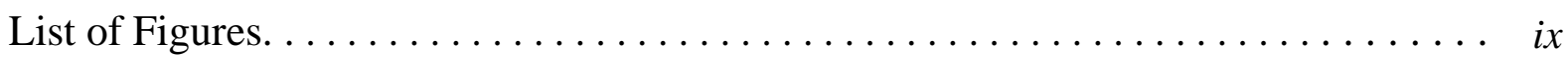

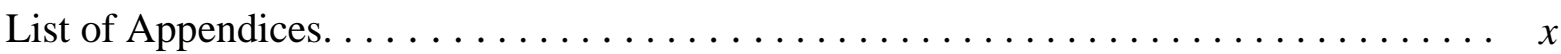

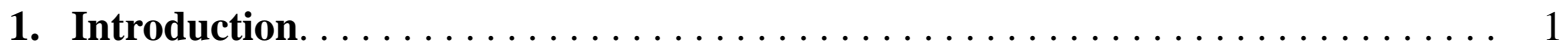

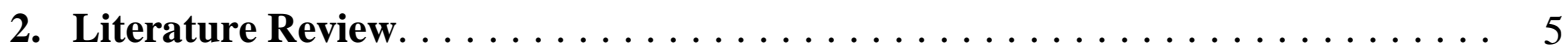

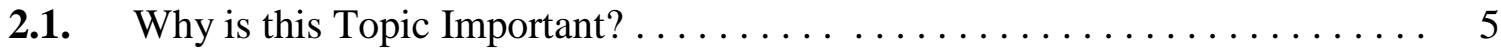

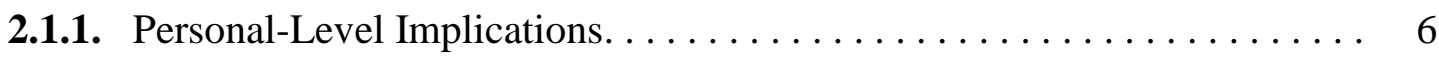

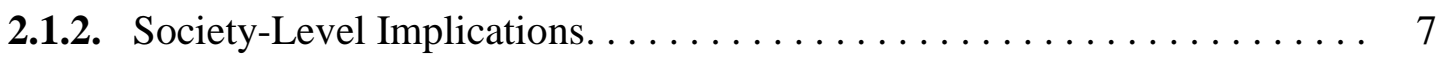

2.1.3. Organization-Level Implications. . . . . . . . . . . . . . . 9

2.2. A History of Ethno-Racial Disparities in Canada. . . . . . . . . . . . . . . 10

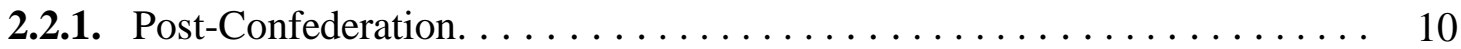

2.2.2. Immigration Reforms, Multiculturalism, and Employment Equity. . . . . 12

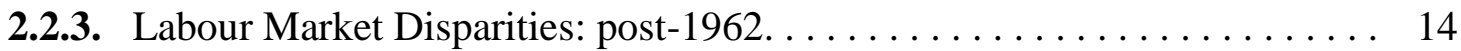

2.2.4. Labour Market Disparities: post-1990. . . . . . . . . . . . . . 15

2.3. Labour Market Outcomes in the $21^{\text {st }}$ Century. . . . . . . . . . . . . 17

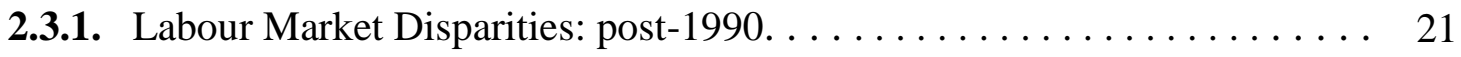

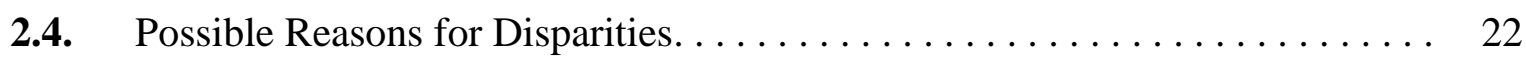

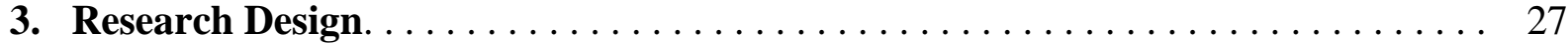

3.1. Previous Research on Recent Graduates. . . . . . . . . . . . . . . . 28

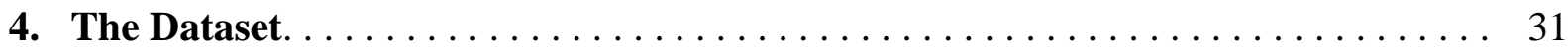

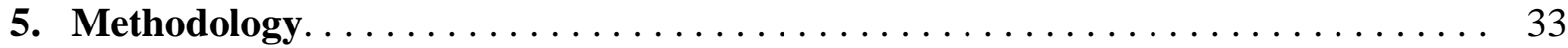

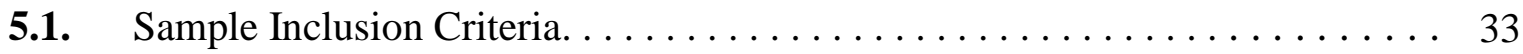

5.2. Dependent Variables. ......................... 36

5.3. Explanatory Variables of Interest. . . . . . . . . . 36

5.4. Control Variables. .......................... 37 


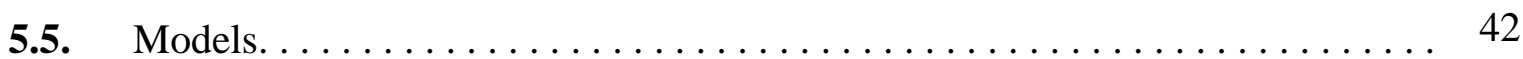

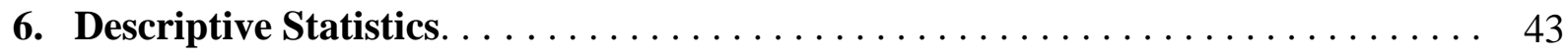

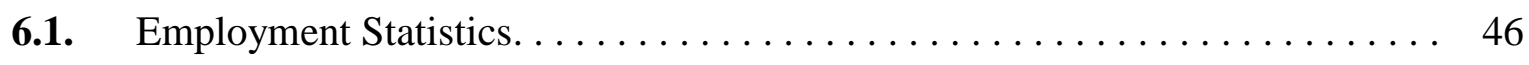

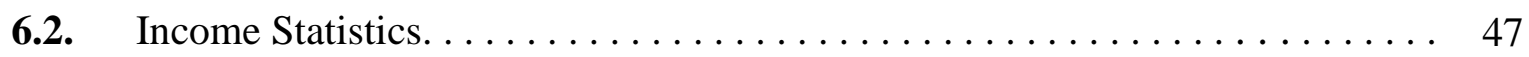

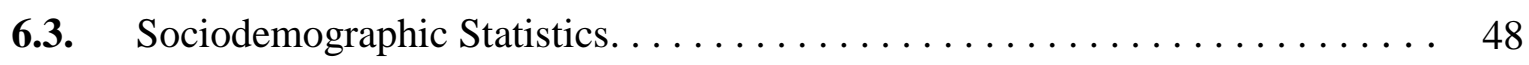

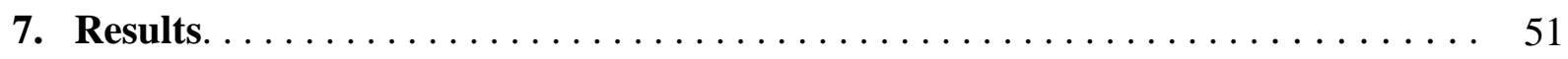

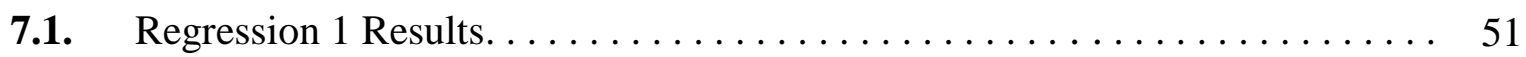

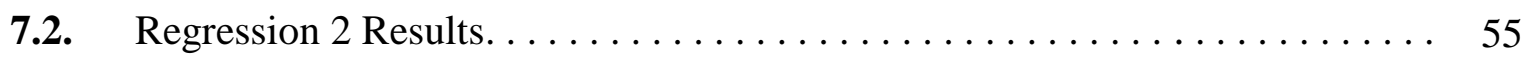

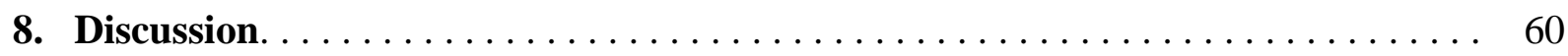

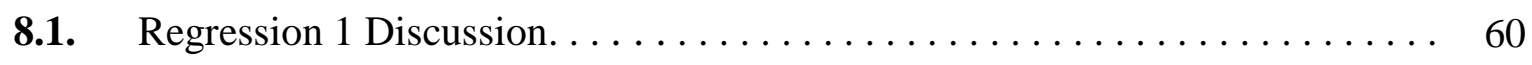

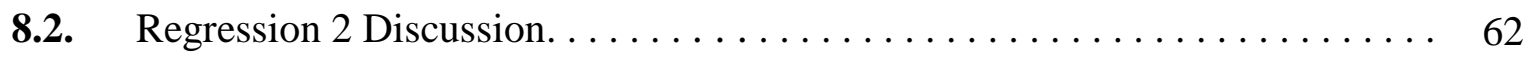

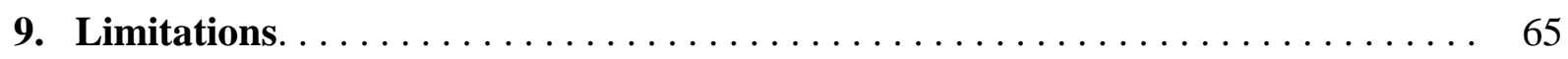

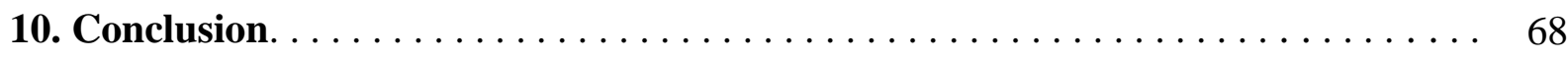

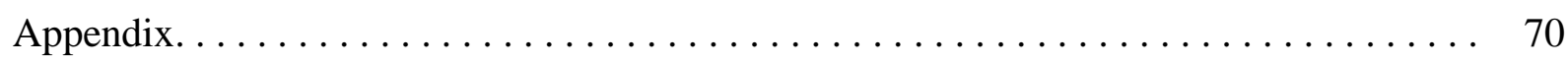

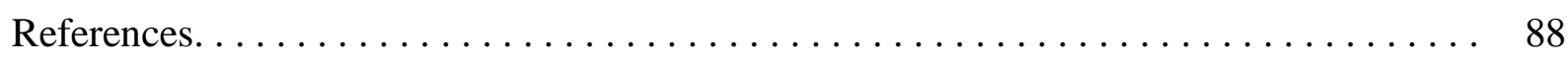




\section{LIST OF TABLES}

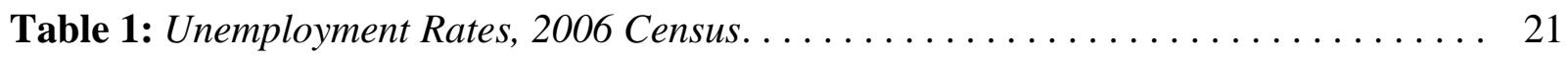

Table 2: Unemployment Rates, 2011 National Household Survey. . . . . . . . . . . . . . . 21

Table 3: Unemployment Rates, 2016 Census. . . . . . . . . . . . . . . . . 21

Table 4: Subsample Descriptive Statistics, 2013 National Graduates Survey. . . . . . . . . 44

Table 5: Unemployment Rates for Ages 20-34, 2011 National Household Survey. . . . . . 46

Table 6: Regression 1a: Gender-Pooled Analysis of Income, by Ethno-Racial Identity. . . 52

Table 7: Regression 1b: Gender-Split Analysis of Income, by Ethno-Racial Identity. . . . . 54

Table 8: Regression 2a: Gender-Pooled Analysis of Unemployment Odds-Ratios by

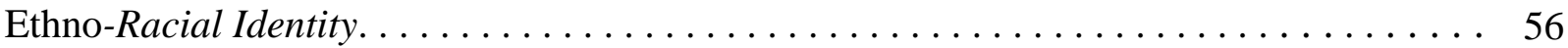

Table 9: Regression 2b: Gender-Split Analysis of Unemployment Odds-Ratios, by Ethno-

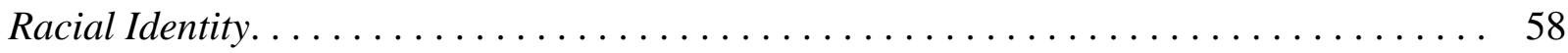




\section{LIST OF FIGURES}

Figure 1: 2013 National Graduates Survey Summary Statistics. . . . . . . . . . . . . . 31 


\section{LIST OF APPENDICES}

Appendix 1: Regression 1a: Gender-Pooled Analysis of Income . . . . . . . . . . . . 70

Appendix 2: Regression 1b: Males' Analysis of Income . . . . . . . . . . . . 73

Appendix 3: Regression 1b: Females' Analysis of Income. . . . . . . . . . . . 76

Appendix 4: Regression 2a: Gender-Pooled Analysis of Unemployment Odds-Ratios. . . 79

Appendix 5: Regression 2b: Males' Analysis of Unemployment Odds-Ratios. . . . . . . 82

Appendix 6: Regression 2b: Females' Analysis of Unemployment Odds-Ratios. . . . . . 85 


\section{INTRODUCTION}

As per Canada's 2016 Census, just over one in five residents of Canada identified themselves as visible-minorities, which includes most of those who do not proclaim any or only part White-European ancestry (Statistics Canada, 2017a). Statistics Canada projects that the proportion of visible-minorities could increase to over 30\% of Canada's population by 2031 (Statistics Canada, 2011a), led mostly by the South Asians, Chinese, Blacks, and Filipinos, in that order. This increase will be driven both by immigration, and the proliferation of second-and-higher generation members of visible-minority groups. With such a rapidly diversifying populace and the populations of individual ethno-racial groups increasing, many researchers have been studying how (or if) the various ethno-racial groups differ in their markers of socioeconomic status. A particular area of interest has been to compare their labour market outcomes such as earnings, because generally speaking, financial endowment is thought to be amongst the most important predictors for one's quality of life, at least in the economy-oriented societies of the $21^{\text {st }}$ century (Girardi Paskulin \& Molzahn, 2007; Headey et al., 2007; Senik, 2014). Therefore, it is important to understand if patterns of inferior labour market outcomes exist amongst particular groups, so that Canada can know which segment(s) of its population require attention.

To provide a preliminary perspective, the 2016 Census found that in the year 2015, visibleminorities had a median gross income of $\$ 25,514$ —versus $\$ 36,538$ for their non-visible-minority counterparts, and an average gross income of $\$ 36,955$ - versus $\$ 50,225$ for their non-visibleminority counterparts (Statistics Canada, 2017b). Moreover, this Census also showed that visibleminorities had an unemployment rate of $9.2 \%$-versus $7.3 \%$ for their non-visible-minority counterparts (Statistics Canada, 2017c). These statistics tell us that there are indeed disparities in labour market outcomes between visible-minorities (as a whole), and their White-European 
counterparts. The next step would be to pinpoint where exactly these disparities are coming from by creating subgroups based on the major differentiating criteria as identified by the researchwhich includes but is not limited to: gender, specific ethno-racial group, and generation-status. The existing literature which has made such subgroup distinctions has found that: the labour market disparities are larger between male groups; the income disparities between ethno-racial groups within each respective generation-status tend to decrease as the generations increase; Blacks experience the most labour market shortcomings overall; and the Chinese experience the least labour market shortcomings overall, if at all (Pendakur \& Pendakur, 1998, 2011, 2016; Skuterud, 2010; Yu, 2018). Note that these are generally the most common findings, but anomalies do arise depending on factors like: the survey used, the subsample, and/or the use of statistical controls. This paper will seek to contribute to this literature by answering the following question: how do the ethno-racial backgrounds of recent post-secondary graduates in Canada affect their labour-market outcomes? Particularly, the analysis will be limited to those who hold entirely Canadian educational credentials, dating back to elementary school (e.g. "generation 1.5+")—as this helps to dispel the "foreign human \& cultural capital" justifications which are commonly used to explain the (post-adolescent) immigrants' shortcomings (Pendakur \& Pendakur, 2016). The term "generation 1.5 " has been loosely defined as those who immigrated to the country as children, typically by the age of 14, though the exact age depends on the study (Boyd, 2002; Skuterud, 2010). Moreover, the socioeconomic outcomes of generation 1.5+ Canadians have been studied far less than those of first-generation Canadians, mainly due to sample size constraints, so this adds further importance to the research contributions of this paper. This is believed to be the first time that this topic will be explored using Canada's 2013 National Graduates Survey. I focus on recent postsecondary graduates rather than the general populace because they represent most of 
the new-entrants into Canada's labour market (Department of Finance, 2014; Kustec, 2012), so if any marginal changes to the socioeconomic statuses of Canada's ethno-racial groups are being made, recent graduates would be a major driving force. The other reason for focusing on recent graduates is because, their relative homogeneity in age and life/work experiences serve as natural controls when assessing labour market outcomes. Moreover, such a study on recent graduates would provide insight into not just the labour market outcomes of Canada's ethno-racial groups in general, but the outcomes of those in their early-careers - which represents a unique timeframe.

To clarify, this paper will adhere to the Canadian government's criteria for classifying ethno-racial groups, as debating about the objectivity in defining such groups is beyond the scope of this analysis. However, as will be discussed in the limitations, it is recognized that descriptions of ethno-racial identities are highly complex. Canada's two major mutually exclusive classifications are: 'visible-minority' and 'non-visible-minority'. Visible-minorities are defined by the Government as: "persons, other than Aboriginal peoples, who are non-Caucasian in race or non-white in colour" (Employment Equity Act, 1995). Thus, the general norm has been that, excluding Indigenous persons, those who deem themselves to have both a white skin-tone and European-only ancestry tend not to identify as visible-minorities, and if they establish that either one or both of those conditions are missing, then they do tend to identify as visible-minorities. However, when they are asked to identify with specific ethno-racial subgroups, a few anomalies arise. For instance, those with part European and part Arab descent, or part European and part Latin American descent are not supposed to be classified as visible-minorities, according to the Government's criterion (Statistics Canada, 2008). Nevertheless, for the purpose of my research, because these "part White" groups still do identify with another visible-minority (e.g. non-WhiteEuropean) subgroup, I will not categorize them into the "White" ethno-racial group, but rather 
label them "Other". Another important note is, due to the overlap between the (root) terms race and ethnicity along with the inconsistencies in defining them, this paper will use them interchangeably or as a combination-hence the term "ethno-racial". 


\section{LITERATURE REVIEW}

The ensuing review of literature will briefly provide a background of this topic, before continuing on to this paper's research contributions. Unless mentioned otherwise, only the studies deemed relevant to Canadian society will be discussed, which primarily means research from Canada, and also its OECD counterparts where applicable. The literature review will begin with a discussion about why this topic is important, namely the consequences of ethno-racial disparities in socioeconomic outcomes. Then, the discussion will shift to how Canada's ethno-racial diversity has evolved over time, along with a summary of the societal and labour market experiences of the various ethno-racial groups that have settled here-from Confederation up to the $21^{\text {st }}$ century. Finally, the literature review will briefly discuss the possible reasons for socioeconomic ethnoracial disparities in Canada.

\subsection{Why is this Topic Important?}

This is an important topic to research because, studies show that disparities in labour market outcomes, especially if they are driven by ethno-racial discrimination, can contribute to negative implications on both a personal level, and a societal level. Moreover, there are reasons why individual organizations may want to avoid contributing to such disparities through ethnoracial discrimination. To clarify, this paper will discuss 'ethno-racial discrimination' in the context of the following definition provided by the Ontario Human Rights Commission:

“...any distinction, conduct or action, whether intentional or not, but based on a person's race, which has the effect of imposing burdens on an individual or group, not imposed upon others or which withholds or limits access to benefits available to other members of society. Race need only be a factor for racial discrimination to have occurred." (OHRC, n.d.) 
Also, note that this discussion will highlight implications arising from both labourmarket/socioeconomic disparities in general, and from ethno-racial discrimination wherever it can be identified as a contributor to such disparities. Nevertheless, as will be discussed throughout this paper, a substantial amount of evidence does suggest that ethno-racial biases in Canada's labour market do play a significant role in exacerbating socioeconomic disparities between Canadians.

\subsubsection{Personal-Level Implications}

Comprehensive studies in Canada (and abroad) have shown that there are significant positive correlations between one's physical and mental healthiness and their income (Health Quality Ontario, 2016; Raphael, 2002). Likewise, many studies also show that the state of being unemployed is significantly correlated with poorer health outcomes (Canadian Public Health Association, 1996; Pharr et al., 2012). The physical health components that have been shown to be poorer amongst the unemployed and those with lower income include: heart health (Lee et al., 2009), various types of cancer (Conway et al., 2015), Parkinson's disease (Lix et al., 2009), and oral health (Ravaghi et al., 2013), to name a few. Similarly, mental health outcomes have also been shown to be poorer such as: clinical depression (Mckenzie et al., 2014; Wang et al., 2009), generalized anxiety disorder (Watterson et al., 2017), and substance abuse (Redonnet et al., 2012) among others. Moreover, those with lower income may be more prone to social isolation, which is further exacerbated if their disadvantage is influenced by ethno-racial discrimination (Wilson et al., 2011). As many of the papers cited above show, such health disparities have been shown to exist in Canada, even though it has universal healthcare. With less money to spend on healthsupporting items and activities (e.g. prescription medicine, private health services, etc.), it can

perhaps be inferred that the connection between lower income and poorer health is not just a correlation, but lesser financial endowment may also cause the factors that exacerbate poor health. 
To give another example, lower income can directly induce financial distress-which is directly related to greater physical health risks, such as heart attacks (Shah et al., 2012). Furthermore, there is evidence suggesting that physical and/or mental impairments impede one's career advancement due to less time spent at work, less productivity at work, and a lesser ability to develop human capital through education/training (Duguet \& Le Clainche, 2014; Zhang et al., 2016). Therefore, from an ethno-racial perspective, all of this implies that patterns of poorer labour market outcomes in particular ethno-racial groups may also contribute to patterns of poorer health outcomes in those same groups - perhaps even inducing a feedback loop with lower income inducing poor health, then the poor health inducing lower income.

\subsubsection{Society-Level Implications}

The first argument of society-level implications builds upon the health-related impacts above. To elaborate, it has been suggested that when people perceive discrimination on the basis of their ethno-racial background and/or religion, they become more likely to suffer from both physical and mental illnesses (Hyman, 2009). This is in addition to the poorer health experienced by those with lower income, as discussed above. So, declining health in general may affect the society in the form of: rising healthcare costs which are recovered by increasing taxation in public healthcare systems like Canada's (Canadian Institute for Health Information, 2011), rising health insurance costs which result in higher premiums for all policyholders, the exacerbation of doctor shortages (Esmail, 2016), economic slowdown due to lost productivity in the workplaces (Dollard \& Nesser, 2013), and increases of mental-illness-induced violent crime in the public (Hawkes, 2015; Weisburd et al., 2018), to name a few. To put this into perspective, one in five visibleminority members across Canada reported ethno-racial discrimination in the five years preceding 2014, versus just over one in ten for non-visible-minorities (Statistics Canada, 2018). Thus, a 
systemic reduction in such discrimination may help alleviate the aforementioned health consequences, and in turn the societal consequences of poorer health.

To provide another argument, it has been suggested that ethno-racial disparities in the labour market, especially if they are caused by ethno-racial discrimination, deter diverse groups of immigrants, putting the country or a specific region within it at a disadvantage in attracting and retaining skilled workers (Hou, 2007; OECD, 2014; Pruegger \& Cook, 2009). In fact, the United Nations' 2018 World Migration Report, shows that two of the top reasons why people migrate to another country is to escape persecution based on their ethno-racial identity and/or religion, and to have a chance to achieve greater economic prosperity (International Organization for Migration, 2017). Thus, they seek to escape to a country where they believe ethno-racial and religious discrimination are less likely, and their economic opportunities are greater than in their home nation. Drawing on this, if a country's labour market or its society in general shows evidence of discrimination on the grounds of one's ethno-racial background and/or religion (or any prohibited ground for that matter), it may deter talented immigrants from settling there and contributing to that economy, versus the countries they deem to be more welcoming.

Furthermore, throughout Canada and the United States, there is clear evidence that communities with significant differences in their average household incomes are also ethnoracially segregated (Breau et al., 2017; Reardon et al., 2015). For example, in Canada, the neighbourhoods with the lowest average incomes also tend to be those with the highest proportions of visible-minority residents (Breau et al., 2017). Such segregation may contribute to a disturbance in social cohesion, impairing the friendly coexistence of the ethno-racial groups (Bolt et al., 2010; Uslaner, 2010), not to the mention the widely documented correlation between lower income and crime (Statistics Canada, 2009). Nonetheless, although income disparities are not the only cause 
of a lack of social cohesion between ethno-racial groups, they have been objectively shown to make a notable difference (Musterd, 2005). To provide a specific example, an American study by Plummer et al. (2016) supports the argument that mitigating disparities in socioeconomic status between ethno-racial groups may improve their social cohesion. The study found that a similar socioeconomic status was amongst the top commonalities between friends of different races, and that "living in the same neighbourhood" was amongst the top catalysts for forming such friendships (Plummer et al., 2016). Thus, with greater socioeconomic disparities and the resulting neighbourhood segregation between ethno-racial groups, there may be an increased probability of social disharmony. Generally speaking, in modern Western nations, ethno-racial disharmony may induce: increases in overall crime and interracial conflicts (Krivo et al., 2009), more disagreements in government policies (Kinder \& Winter, 2001), and diminished overall economic growth (Alesina \& La Ferrara, 2005) to name a few.

\subsubsection{Organization-Level Implications}

From an organization-specific perspective, the economic argument made above regarding the 'attraction of talent' would apply here as well; if organizations have an apparently discriminatory environment, this may reduce the number of people willing to join them, leaving them with a smaller talent pool to select from (Avery \& McKay, 2006; Ng \& Burke, 2005). This may be particularly problematic for industries with labour shortages. To add to this, an empirical analysis on New York City firms by Pager (2016) showed that the firms who discriminated against job applicants on the basis of race were less likely to be in business six years later. Moreover, Raver \& Nishii (2010) show that ethno-racial discrimination within the workplace such as: hostile comments, isolation from work-related or social activities, withholding job-related information, and telling "ethnic jokes" lead to lower levels of organizational commitment, job satisfaction, and 
greater turnover intentions amongst the victims. Similar findings have been repeatedly affirmed in recent studies, including ones that show deteriorations in the mental and physical health of discriminated employees (Triana et al., 2015). This literature also shows that from the business perspective, these types of consequences suffered by discriminated employees can lead the company to incur noteworthy financial losses — some specific reasons for which are: recruitment and training costs for new employees (Hancock et al., 2013), opportunity costs of lost-productivity and absenteeism (Triana et al., 2013), and/or the costs of defending litigations and the corresponding costs of a damaged reputation (Goldman, 2006). To provide an example, a 'damaged reputation' may lead to consumer boycotts, which can impair a firm's financial performance (Makarem \& Jae, 2015; van den Broek et al., 2017).

Overall, the preceding discussion clearly indicates that it is in the best interest of individuals, the society, and organizations if ethno-racial disparities in labour market outcomes are mitigated, especially if ethno-racial discrimination is one of the causes.

\subsection{A History of Ethno-Racial Disparities in Canada}

\subsubsection{Post-Confederation}

In the many years after Confederation, Canada's immigration policies were designed to target only White Britons and White Americans (Verbeeten, 2007), while also refraining from any prohibitions against the French and Catholics (Immigration, Refugees, \& Citizenship Canada, n.d.). In contrast, citizens of the other European nations, though not explicitly welcomed, were not prohibited either, and people of colour were not even considered (Verbeeten, 2007). The following quote from Prime Minister William Mackenzie King in a 1942 Parliament session affirms Canada's overt preference to remain a "White-European" country: 
"There will, I am sure, be general agreement with the view that the people of Canada do not wish, as a result of mass immigration, to make a fundamental alteration in the character of our population. Large-scale immigration from the Orient would change the fundamental composition of the Canadian population." (Mackenzie King, 1947).

This systemic favouritism towards the ethnic English was also reflected in the labour market of the time. The limited amount of literature suggests that the minority groups in postConfederate Canada (e.g. the non-English), particularly the French and the Aboriginals, did indeed face poorer labour market outcomes than the majority British-English descendants. For example, the historical accounts suggest that the French dominated the logging industry, which represented a 'lower-class' of occupations that was correlated with poverty (Newton, 2016). As an affirmation of discrimination towards the French, popular author, Madison Grant, commented in 1917 that the French Canadians are "a poor and ignorant community of little more importance to the world at large than are the Negroes in the South" (Newton, 2016). This was his opinion of the French Canadians' inferior ability to make economic contributions-likening them to the African Blacks who were generally considered the most inferior race by White-Europeans of the time (Christensen \& Weinfeld, 1993).

Regarding the Aboriginals, some well-known examples of widespread, state-supported discrimination included: forced assimilation to English culture through residential schools (Zalcman, 2016), forced relocation to economically and infrastructurally underdeveloped "reserved lands" (Denov \& Campbell, 2002), and widespread barriers to higher education and job opportunities (Fan et al., 2017), all of which directly diminished their socioeconomic outcomes. Similar situations were also experienced by other sizeable coloured groups, namely the early Black Canadians, and the early Chinese Canadians. Even as so-called "free Blacks" after the abolishment 
of slavery, most of the Black Canadians were only able to find work in menial labour jobs (McFarquhar, 2007), were frequently denied access to higher education merely for being Black, and overall were prevented from assimilating into the mainstream society because the majority European descendants perceived them as second-class, and sometimes even subhuman citizens (Christensen \& Weinfeld, 1993; Thornhill, 2008). The Chinese settlers, who were brought into Canada as indentured labourers to help construct the railroads encountered similar state-supported discrimination. The nation in general became discontent with the Chinese' presence in their society, which lead to widespread anti-Chinese protests, and the government imposing "head taxes" to prevent them from settling in Canada (Canadian Museum of Immigration, n.d. -a; Mar, 2007). It is important to note that the government in Canada did not legislate any 'prohibited grounds of discrimination' until the Bill of Rights in the 1960 (Canadian Museum of Immigration,

n.d. -b), which meant that disfavouring people based on their ethno-racial backgrounds was technically not illegal.

\subsubsection{Immigration Reforms, Multiculturism, and Employment Equity}

The turning point for Canadian ethno-racial demographics came in 1962, when the Minister of Citizenship and Immigration, Ellen Fairclough, introduced legislation to admit immigrants based mainly on their skillsets without discriminating on their ethno-racial backgrounds or nationalities (Canadian Museum of Immigration, n.d. -b). The primary reasons for such reform were: to help supply the increasingly urban, service-sector economy with skilled immigrants, and to conform to the emerging post-Holocaust human rights policies in the Western world (Canadian Museum of Immigration, n.d. -b; Gabriel, 2015; Triadafilopoulos, 2010). This immigration reform was supplementary to Canada's adoption of the Bill of Rights in 1960, which prohibited discrimination on the basis of: race, religion, colour, national origin, and sex. From there on, 
additional legislations continued to reinforce these laws, which were aimed at establishing and enforcing prohibited grounds of discrimination throughout the entirety of Canada's society. Some notable examples include: the Canadian Multiculturalism Policy in 1971, the Canadian Human Rights Act in 1977, the Charter of Rights \& Freedoms in 1982, and the Canadian Multiculturalism Act in 1988, all of which added more protections on ethno-racial grounds to Canada's social, political and economic organizations, primarily to serve those of non-European descent—a rapidly growing population (Canadian Museum of Immigration, n.d. -a).

Moreover, in 1986, the federal government introduced the Employment Equity Act (EEA), then later amended it in 1995. This Act formalized the concept of "visible-minorities"-who became one of four protected groups along with women, Aboriginals, and persons with disabilities. The goal of this Act was to mitigate the labour market disparities amongst these historically disadvantaged groups — in other words, to require the federally-regulated organizations (and federal contractors) and to encourage the other organizations to proportionally (to demographic makeup) employ these protected groups, and to provide 'equal pay for equal work' (Employment Equity Act, 1995; Lum, 1995). In accordance with this new official method of defining ethno-racial classifications, the 1996 Census showed that $11.2 \%$ of the population proclaimed visible-minority status, with the most populous groups being the: Chinese, South Asians, Blacks, Arabs/West Asians, and Filipinos (Statistics Canada, 1998). Moreover, just under $4 \%$ of the population proclaimed full or partial Aboriginal descent. This meant that the new "majority" became officially defined as all those with only (and sometimes partial) WhiteEuropean descent, who constituted the remaining $85 \%$ of the population. The ensuing discussion will focus only on comparing visible-minorities to the majority, separating the "visible-minorities" into subgroups where enough literature exists on a subgroup. 


\subsubsection{Labour Market Disparities: post-1962}

Despite Canada's series of legal reforms as mentioned above, the earliest studies that compared the labour market outcomes of Canada's various ethno-racial groups using specific measures indicated that: non-White-Europeans (as a whole) generally had lower average \& median earnings (but not amongst the self-employed), higher unemployment rates, and lower returns-toeducation than their European-descent counterparts (Daenzer, 1991; Herberg, 1990; Maxim, 1992; McDade, 1988). The common explanations for the penalties experienced by these minority groups were that, the vast majority of them were immigrants with foreign credentials incompatible with Canada's labour market, and/or they had an insufficient understanding of Canadian culture and language. The other common explanation was that these minorities, especially Blacks and South Asians, experienced more 'taste-based' ethno-racial discrimination in the labour market (Boyd, 1992; Christofides \& Swidinsky, 1994; Daenzer, 1991; Herberg, 1990; Maxim, 1992; McDade \& Institute for Research on Public Policy, 1988). Moreover, Howland \& Sakellariou (1993) downplayed the theory that a large part of these ethno-racial disparities was due to most visibleminorities concentrating in lower-paying occupations, by showing that such disparities existed even within narrowly-defined occupational fields (Howland \& Sakellariou, 1993).

Given that, when the study samples were separated by gender, generation status, and ethnoracial identity, some novel conclusions arose. For example, the visible-minorities born in Canada generally did not experience the penalties seen in their first-generation counterparts (Boyd, 1992), and when separating by gender, the disparities amongst the female minority groups existed but were lower compared to those amongst the male minority groups (Christofides \& Swidinsky, 1994). Other more specific exceptions included: raw Statistics Canada data from 1970 showing that although all White-European subgroups did earn more than the Asian-subgroup amongst 
immigrants, the Asians became one of the top-earning groups amongst the Canadian-born (Richmond \& Verma, 1978); a 1974 report from Canada's Department of Manpower \& Immigration showing that the incomes of West-Indian immigrant-families were higher than those of the Greek and Italian immigrant-families (Clairmont \& Wien, 1976); the 1981 Census showing that amongst university-educated immigrant males, and amongst university-educated Canadianborn males, the Portuguese had lower incomes than all visible-minority subgroups except the Southeast Asians (Winn, 1985). Regarding these earlier studies, it is important to note that they used little or no statistical controls, and often made speculations on specific ethno-racial groups using small sample sizes, hence the inconsistencies in the earlier literature.

\subsubsection{Labour Market Disparities: post-1990}

By the 1990s, more detailed and extensive statistics began to emerge that allowed the researchers to make statistically significant and more statistically-controlled conclusions on individual ethno-racial groups, even when separating males from females, and immigrants from the Canadian-born. Although the disparities between visible-minorities as a whole and the majority still existed, novel conclusions could now be made thanks to higher populations of individual visible-minority groups, and the emergence of generation 1.5+. Beginning with the 1991 Census, Pendakur \& Pendakur (1998) found that amongst Canadian-born males, the Chinese and Blacks earned significantly less than the British descendants, with insufficient sample sizes for the other visible-minority subgroups. However, all immigrant visible-minority subgroups amongst males showed significantly less earnings than the Canadian-born British descendants. To compare, immigrant European males (except Greeks and Balkans) earned almost as much as the Canadianborn British descendants. Amongst females, all visible-minority immigrant subgroups (except Chinese) earned less than the Canadian-born British females, but all of the Canadian-born visible- 
minority subgroups did not show such a disparity, though the sample sizes for most of them were too small. Similar to the males, the immigrant European subgroups (except Spanish) amongst females earned almost as much as the Canadian-born British females.

In another study, Hum \& Simpson (1999) were able to conduct a similar analysis using the 1993 Survey of Labour and Income Dynamics, but this time with bigger subgroup sample sizes. They subdivided the 'visible-minority' group into six distinct categories to compare with those of White-European descent, in subsamples split by: males \& females, and immigrants \& Canadianborn. They found that amongst males born in Canada, only Blacks faced a significant earnings penalty, with no significant evidence of penalties in other visible-minority groups. Also, there was no significant evidence of penalties amongst any of the Canadian-born female groups. However, amongst immigrant males, the Southeast Asian, Black, Chinese, and Indo-Pakistani subgroups faced significant earnings penalties_ — and amongst immigrant females, only the Southeast Asians showed a significant earnings penalty versus the White-European females.

Similar trends continued into the 1996 Census as well, with Swidinsky \& Swidinsky (2002) showing the following: amongst immigrant males, Blacks experienced the greatest earnings penalties, and South Asians followed by the Chinese experienced the least. Amongst Canadianborn males, Blacks were the only group showing a statistically significant earnings penalty. Amongst immigrant females, Blacks were the only group showing a statistically significant earnings penalty. Amongst the Canadian-born females, there were no statistically significant results. Another key finding was that amongst both males and females, earnings generally increased as the age-at-immigration decreased. Note that other visible-minority subgroups are not being discussed because they did not yield statistically significant results, primarily due to insufficient sample sizes. 
To summarize, the key takeaways from the labour market outcomes of Canada's ethnoracial groups towards the end of the $20^{\text {th }}$ century are as follows. Visible-minorities as a whole experienced significant penalties in earnings versus their White-European counterparts. In addition to earning less from employment despite controlling for several sociodemographic factors, visibleminorities as a whole also experienced greater rates of unemployment (although the studies comparing unemployment rates are limited). To elaborate, it was found that the greatest penalties were amongst visible-minority immigrants, namely those who immigrated at a higher age. Later analyses of individual ethno-racial groups showed that Blacks experienced the greatest penalties amongst both immigrants and amongst natives, as well as amongst males and amongst females. In contrast, the Chinese generally experienced the least penalties amongst immigrants, and showed little evidence of penalties amongst the Canadian-born, especially the females. Amongst South Asians, both males and females showed varied results, with earnings penalties generally experienced by the immigrants, and mostly insignificant results yielded from the Canadian-born groups. In everyone overall, the earnings disparities were smaller amongst the females, compared to the males. Most of these groups experiencing earnings disparities did so despite the fact that the authors controlled for several sociodemographic variables. Thus, most studies hinted at ethnoracial discrimination as a major contributor to these disparities. It is important to note that these conclusions hold true according to most of the analyses - some studies are inconsistent mainly because of differences in the sample cases studied and differences in analytical methods such as the control variables used.

\subsection{Labour Market Outcomes in the $21^{\text {st }}$ Century}

As per Canada's first Census of the millennium, in 2001, the proportion of Canadians proclaiming visible-minority status had expectedly increased, to approximately $13.5 \%$ (Statistics 
Canada, 2001). The largest individual groups were still (from largest to smallest): the Chinese, South Asians, Blacks, and Filipinos who collectively represented nearly $10 \%$ of Canada's population. Moreover, as these groups became increasingly populous in Canada, the Canadianborn and generation 1.5 members of these groups also increased in population, which paved the way for more significant conclusions on their socioeconomic outcomes. To begin, Skuterud (2010) analyzed the earnings of generations 1.5, 2, \& 3+ Chinese, South Asians, Blacks, and non-visibleminorities (Whites) using the 2001 and 2006 Canadian Censuses. He showed that in 2001, all generations within each of the three visible-minority subgroups earned significantly less than the third-and-higher generation White males, even when 'occupational' controls were included. Also, while the Chinese and Blacks showed evidence of upwards intergenerational advancement, South Asians showed intergenerational degeneration. Similar earnings penalties for each of the three visible-minority groups were found in the 2006 Census as well, except that South Asians now also showed evidence of upwards intergenerational advancement. Generally speaking, and barring some minor subgroup exceptions, Blacks had the highest penalties, while the Chinese had the lowest. These conclusions were also generally applicable to the female subgroups, although the disparities were not as large and were also less significant, especially for the Chinese.

Similar findings were echoed by Pendakur \& Pendakur (2011), who compared earnings amongst only the Canadian-born ethno-racial groups. Using the 2006 Census, they showed that compared to British-origin men, all male visible-minority subgroups faced significant earnings penalties. In order from greatest deficit to least, they were: Blacks (of all origins), Southeast Asians, South Asians, Latinos, Arabs/West Asians, Other Asians, and Chinese. Compared to British-origin females, the female visible-minority subgroups showing significant earnings penalties were (from greatest deficit to least): Blacks (of all origins), and Arabs/West Asians. The 
Chinese females, followed by the Other Asian females showed significant earnings premiums, while the remaining subgroups were statistically insignificant. Again, the disparities between the female groups were not as large as between the male groups. Another novel conclusion from Pendakur \& Pendakur's (2011) study was that, generally speaking, the earnings penalties of the visible-minority subgroups had not improved since the 1996 Census. To add to this, Hou \& Coulombe (2010) also analyzed the 2006 Census and showed that the visible-minorities' earnings penalties mostly come from the private sector, with public sector penalties only being seen in Black men and in Black women.

A subsequent analysis by Pendakur \& Pendakur (2016) used the 2006 Census again, but this time they separated the visible-minority subgroups into age-at-arrival cohorts. They found that versus Canadian-born White males, each of the immigrant male visible-minority subgroups faced significant earnings penalties regardless of the age at which they immigrated to Canada, and that these penalties increased as the age-at-arrival increased. The Canadian-born Black males and the Canadian-born South Asian males also experienced significant penalties, while the Canadian-born Chinese males were insignificant. Versus the Canadian-born White females, all of the immigrant and Canadian-born Black females faced earnings penalties, the South Asian females only showed a significant penalty if they immigrated as adults, and the generation $1.5+$ Chinese females showed earnings premiums, while a significant penalty was seen in those Chinese females who immigrated after the age of 30. Generally speaking, the earnings penalties of the female subgroups were again lower in magnitude compared to those of their male counterparts.

The next comprehensive national survey was the 2011 National Household Survey (NHS), which was not mandatory, unlike the prior Censuses. Therefore, several biases may exist in this survey because as identified by Block et al. (2014), certain subgroups such as low-earners may 
have been less likely to participate. However, since my research is based on the also nonmandatory 2013 National Graduates Survey, it would be informative to review the 2011 NHS. Nonetheless, after limiting the NHS sample to only those with a bachelor's degree, and controlling for other sociodemographic characteristics, Yu (2018) found that amongst immigrants, Black males faced the greatest earnings penalties, followed by Chinese males, followed by South Asian males_versus non-visible-minority males. No female immigrant groups showed significant evidence of earnings differences versus non-visible-minority females. Amongst the Canadian-born males, Blacks were the only group showing a significant earnings penalty, while the Chinese males were the only group showing a significant earnings premium. Amongst the Canadian-born females, the Chinese women showed an earnings premium, the only significant result.

To summarize, the earnings analyses from the $21^{\text {st }}$ century allowed for more significant conclusions on generation $1.5+$ visible-minorities. Amongst generation $1.5+$ males, Blacks experienced the greatest earnings penalties, followed by South Asians, and the Chinese experienced the lowest, if at all. Amongst male immigrants, the conclusions did not change much since the 1990s with almost all visible-minority subgroups showing earnings penalties. Amongst generation 1.5+ females, Blacks experienced the greatest earnings penalties, with mostly insignificant results for the South Asian females, and mostly earnings premiums for the Chinese females. Amongst female immigrants, the earnings penalties were mostly experienced by Blacks, while the South Asian and Chinese females only experienced penalties if they arrived later in their adult years. Once again, the females' penalties were lower in magnitude compared to the males' penalties. Overall, the earnings analyses discussed above justify the need to separate generation $1.5+$ from the first-generation when analyzing their incomes - as the former's disparities appear to be much smaller in magnitude. 


\subsubsection{Unemployment Rates}

It is not enough to simply compare earnings since this narrows the focus, only to those who were employed - and not those who did not have a job to begin with. The following charts compare the most recent Canada-wide data on the unemployment rates of Canada's most populous ethnoracial groups, derived from the 2006 Census, the 2011 National Household Survey, and the 2016 Census, respectively. The "count" rows show the number of respondents who were "in the labour market'.

Table 1: Unemployment Rates, 2006 Census (Statistics Canada, 2006):

\begin{tabular}{|c|c|c|c|c|c|c|c|c|}
\hline \multicolumn{9}{|c|}{ NON-IMMIGRANTS } \\
\hline \multirow{2}{*}{ South Asian } & \multicolumn{2}{c|}{ Chinese } & \multicolumn{2}{c|}{ Black } & \multicolumn{2}{c|}{ Non-Visible-Minority } \\
\cline { 2 - 9 } & Female & Male & Female & Male & Female & Male & Female & Male \\
\hline Count & 46,420 & 48,125 & 51,340 & 56,435 & 54,835 & 53,345 & $6,149,025$ & $6,793,540$ \\
\hline Rate & $9.9 \%$ & $10.8 \%$ & $7.4 \%$ & $8.4 \%$ & $11.4 \%$ & $13.1 \%$ & $6.1 \%$ & $6.5 \%$ \\
\hline
\end{tabular}

\begin{tabular}{|c|c|c|c|c|c|c|c|c|}
\hline \multicolumn{9}{|c|}{ IMMIGRANTS } \\
\hline \multirow{2}{*}{ South Asian } & \multicolumn{2}{c|}{ Chinese } & \multicolumn{2}{c|}{ Black } & \multicolumn{2}{c|}{ Non-Visible-Minority } \\
\cline { 2 - 9 } & Female & Male & Female & Male & Female & Male & Female & Male \\
\hline Count & 238,725 & 309,505 & 247,215 & 257,255 & 140,785 & 135,055 & 693,315 & 825,280 \\
\hline Rate & $10.8 \%$ & $6.3 \%$ & $7.9 \%$ & $6.8 \%$ & $10.5 \%$ & $8.9 \%$ & $5.8 \%$ & $4.5 \%$ \\
\hline
\end{tabular}

Table 2: Unemployment Rates, 2011 National Household Survey (Statistics Canada, 2011b):

\begin{tabular}{|c|c|c|c|c|c|c|c|c|}
\hline \multicolumn{10}{|c|}{ NON-IMMIGRANTS } \\
\hline \multirow{2}{*}{ South Asian } & \multicolumn{2}{c|}{ Chinese } & \multicolumn{2}{c|}{ Black } & \multicolumn{2}{c|}{ Non-Visible-Minority } \\
\cline { 2 - 9 } & Female & Male & Female & Male & Female & Male & Female & Male \\
\hline Count & 61,645 & 64,750 & 62,990 & 68,820 & 66,610 & 65,420 & $6,330,205$ & $6,901,970$ \\
\hline Rate & $11.6 \%$ & $13.2 \%$ & $9.5 \%$ & $9.3 \%$ & $13.5 \%$ & $15.9 \%$ & $6.7 \%$ & $7.9 \%$ \\
\hline
\end{tabular}

\begin{tabular}{|c|c|c|c|c|c|c|c|c|}
\hline \multicolumn{10}{|c|}{ IMMIGRANTS } \\
\hline \multirow{2}{*}{ South Asian } & \multicolumn{2}{c|}{ Chinese } & \multicolumn{2}{c|}{ Black } & \multicolumn{2}{c|}{ Non-Visible-Minority } \\
\cline { 2 - 9 } & Female & Male & Female & Male & Female & Male & Female & Male \\
\hline Count & 288,400 & 366,075 & 266,420 & 268,500 & 163,320 & 157,415 & 666,155 & 767,845 \\
\hline Rate & $12.3 \%$ & $7.8 \%$ & $8.7 \%$ & $7.1 \%$ & $12.3 \%$ & $11.4 \%$ & $6.7 \%$ & $6.1 \%$ \\
\hline
\end{tabular}

Table 3: Unemployment Rates, 2016 Census (Statistics Canada, 2016):

\begin{tabular}{|c|c|c|c|c|c|c|c|c|}
\hline \multicolumn{8}{|c|}{ NON-IMMIGRANTS } \\
\hline & \multicolumn{2}{|c|}{ South Asian } & \multicolumn{2}{c|}{ Chinese } & \multicolumn{2}{c|}{ Black } & \multicolumn{2}{c|}{ Non-Visible-Minority } \\
\cline { 2 - 9 } & Female & Male & Female & Male & Female & Male & Female & Male \\
\hline Count & 86,550 & 92,935 & 80,790 & 87,070 & 93,610 & 89,795 & $6,298,665$ & $6,851,940$ \\
\hline Rate & $11.2 \%$ & $11.9 \%$ & $8.0 \%$ & $9.0 \%$ & $12.9 \%$ & $16.2 \%$ & $6.4 \%$ & $8.4 \%$ \\
\hline
\end{tabular}




\begin{tabular}{|c|c|c|c|c|c|c|c|c|}
\hline \multicolumn{9}{|c|}{ IMMIGRANTS } \\
\hline \multirow{2}{*}{ South Asian } & \multicolumn{2}{c|}{ Chinese } & \multicolumn{2}{c|}{ Black } & \multicolumn{2}{c|}{ Non-Visible-Minority } \\
\cline { 2 - 9 } & Female & Male & Female & Male & Female & Male & Female & Male \\
\hline Count & 343,110 & 441,860 & 298,190 & 291,685 & 199,870 & 198,290 & 647,035 & 755,220 \\
\hline Rate & $11.0 \%$ & $6.7 \%$ & $7.6 \%$ & $6.8 \%$ & $11.2 \%$ & $10.8 \%$ & $6.2 \%$ & $6.0 \%$ \\
\hline
\end{tabular}

These statistics make it clear that visible-minorities are more likely to be unemployed than non-visible-minorities, with Blacks and South Asians having the highest rates of unemployment, especially if they are Canadian-born. Generally, immigrants of every ethno-racial group seem to have better employment rates than their Canadian-born counterparts, perhaps because Canada's non-immigrants are generally much younger than the immigrants — and Canada's youths have long had higher unemployment rates than everyone else (Bernard, 2013; Statistics Canada, 2011c). However, immigrants may be more likely to be underemployed due to barriers like foreigncredential devaluation (Guo, 2009). Moreover, all of the Chinese subgroups, and the immigrant South Asian males have the lowest unemployment rates amongst the visible-minority subgroups. Nevertheless, it is difficult to draw substantive conclusions from unemployment rates because, being employed may not necessarily be a "positive" outcome if the individual is underemployed, and being unemployed may not necessarily be a "negative" outcome if the individual is highly selective in applying for and accepting jobs.

\subsection{Possible Reasons for Disparities}

Prior to the legal reforms to explicitly prohibit ethno-racial discrimination across Canada, such discrimination by the majority, or racism, was a plausible explanation for the socioeconomic shortcomings of minority ethno-racial groups. However, even after the introduction of several legal reforms as discussed above, the ethno-racial disparities continued to manifest. This section will review some potential explanations for why these disparities may exist, particularly for those visible-minorities who have Canadian credentials and experiences (generation 1.5+). Note that this discussion focuses mainly on larger factors that previous studies generally have not controlled for. 
However, it is important to acknowledge that even when the usual controls are included (e.g. human capital, sociodemographic characteristics, etc.), there is also the possibility of variation within the individual control variables. Thus, such unaccounted-for variation may be a contributor to differences in labour market outcomes. Nevertheless, this discussion will not delve into the various ways with which people can differ within the control variables, as such a discussion would go beyond the scope of this paper (e.g. even if level of study is held constant, there will still be differences in field, majors/minors, grades, school reputation, and so on.).

Firstly, the explanation that ethnic minorities face disproportionate ethno-racial discrimination is highly plausible given the results of controlled experiments from many Western countries, which show that minority ethno-racial groups are disfavoured on the basis of their ethnoracial, cultural, and/or religious identities. The reason for focusing on controlled experiments is because they make it difficult to implicate other unaccounted-for explanatory variables. To provide some examples, job-application experiments in Canada and other Western countries have shown that resumes of people with names that belong to the dominant culture and/or religion (e.g. Anglo/Christian in Canada) receive significantly more call-backs than do the equivalent resumes of people who have names associated with a minority culture and/or religion-and so the minorities' call-backs improve if they "Whiten" their names. Even the minority resumes without any foreign experiences are subject to such discrimination (Bertrand \& Mullainathan, 2003; Kang et al., 2016; Oreopoulos, 2011; Wright et al., 2013). Similar ethno-racial biases have been shown beyond the resume-screening stages and into the interview stages — where experiments have shown that ethnic minorities, particularly those with foreign accents, "foreign" body language styles, and/or darker skin are significantly more likely to be viewed unfavourably by the interviewers even when they have greater job-relevant credentials (Bye et al., 2014; Derous et al., 2017; 
Manroop et al., 2013; Segrest Purkiss et al., 2006). Beyond the job application process and into the job itself, experiments have shown that minority ethno-racial groups may be more prone to receiving lower performance ratings for the same performance level, particularly if their raters are of the majority ethno-racial group (Lynn \& Sturman, 2011; Stauffer \& Buckley, 2005). In Canada as a whole, because Whites hold more senior-level positions in organizations than minority groups (Reitz e. al., 2011), they are probably the major force influencing this discrimination against the non-White groups. Such experiments help support the well-documented "Glass Ceiling" and "Sticky Floor" effects, which show that visible-minorities are significantly less likely to advance in the organizational hierarchies than their White counterparts (Yap \& Konrad, 2009).

Whether the ethno-racial discrimination discussed above is the result of conscious or unconscious attitudes is a topic to be explored by psychological study — but that does not change the essential point, that ethnic minorities are subject to unfair judgements as their ethno-racial background becomes a determining factor for their occupational and thus labour market outcomes. In addition to scientific racism, under which particular groups are disfavoured due to beliefs that their ethno-racial backgrounds, or other closely related factors such as religion, are "inferior" (Jackson \& Weidman, 2005), theories about similarity-attraction from social psychology provide another perspective for such bias. That is, people are more likely to be attracted to those with similar attitudes, beliefs, personality traits, and thus ethno-racial identities, simply because one's comfort is greater amidst such familiar people (Lintott, 2015; Montoya \& Horton, 2012). This perspective implies that 'unfamiliar' people may not necessarily be considered "inferior", but rather too different for comfort (Lintott, 2015). Given that, a "minority" in any society may, by definition, be subject to less favourable socioeconomic outcomes, simply because the "majority" would rather connect with other members of that majority due to their commonalities. In other 
words, the minority groups would find less people willing to associate with them because they are less likely to encounter people similar to them, as opposed to the majority group (Hou \& Balakrishnan, 1996) - this phenomenon has also been used to explain ethnic minorities' lack of social capital (Nakhaie, 2007). Perhaps such similarity-attraction is why employees have been shown to have better occupational outcomes when their managers are of the same ethno-racial backgrounds (Giuliano et al., 2011; Zatzick et al., 2003). Moreover, there is evidence to support that having social ties in organizations may result in higher starting salaries and greater chances of promotion (Seibert et al., 2001; Seidel et al., 2000).

Finally, there are other often-overlooked explanatory variables that may need to be included in the analyses for labour market outcomes, before attributing the aforementioned labour market disparities solely to ethno-racial discrimination. For example, the specific number of hours worked has been seldom controlled-for when comparing the earnings of different groups. Broad classifications have been used instead, usually in the form of "part-time" and "full-time". This is highly problematic because various analyses show that increases in hours-worked, within these "part-time" and within these "full-time" categories, have notable increases in income (Francis, 2006; Gicheva, 2013). For example, according to 2000-2002 data from the US-based National Bureau of Economic Research, a male who worked 55 hours per week earned 24.5\% more than an equivalent male working normal hours (Francis, 2006). Most Statistics Canada datasets would classify both of these cases as "full-time" workers, which is evidently flawed. From an ethno-racial perspective, because there is some evidence that groups differ in their hours-worked (in the US at least), even when accounting for full/part-time status (Bureau of Labor Statistics, 2018; Tom, 2015), the notion that ethno-racial disparities in income may partly be explained by differences in hours-worked should be further explored. Moreover, with regards to (un)employment status, many 
of the existing studies fail to account for the "choosiness" of job seekers — which basically denotes the level of selectivity job seekers exercise when applying for and accepting jobs, or opting to work at all. Though studies comparing the levels of choosiness for job seekers of different ethnoracial groups are scarce, general studies do show that such choosiness can be a significant determinant of whether people are unemployed or not (Dunn, 2015; Jayasingam et al., 2016). Thus, it is important that the aforementioned explanatory variables be further explored when assessing labour market outcomes. 


\section{RESEARCH DESIGN}

The overarching research question of this paper-"how do the ethno-racial backgrounds of recent post-secondary graduates in Canada affect their labour-market outcomes?"-will be explored using the 2013 National Graduates Survey (NGS). Given the stark differences between the labour market outcomes and other sociodemographic features of first-generation visibleminority immigrants versus their child-immigrant and native-born counterparts, this study will focus on the latter (generation 1.5+) for analysis - a more detailed explanation for this will be provided shortly. The "visible-minorities" will be divided into the three most-populous subgroups - the Chinese, South Asians, and Blacks, who will be compared to their White counterparts, separately by gender. Those who identify with other groups and/or multiple groups will be amassed into a category of their own. The two labour market outcomes in question are: annual employment income and (un)employment status. The combination of these two outcome variables make this study unique because, most of the past research on this topic focused solely on comparing income. Such analyses can be misleading because they only consider those who had obtained employment to begin with. Adding controlled comparisons of (un)employment status can produce a more informative description of the conditions of labour market participants. The analyses of annual earnings will be conducted using OLS Multiple Regression, and the analyses of employment statuses will be conducted using odds ratios derived from Binary Logistic Regression.

\section{Race \& Gender Variables}

In most of the past research on this topic, the entire samples were split so that the male visible-minority subgroups were compared to White males, and the female visible-minority subgroups were compared to the White females. To better contribute to the literature, I will include a slightly different approach to my analyses. Particularly, I will not split the sample by male and 
female at first, but rather create a distinct variable for males of each respective ethno-racial group, and females of each respective ethno-racial group (e.g. a pooled model) — with White males as the reference category. My pooled analysis is simply to view the outcomes of all subgroups in comparison to White males, who are historically the most advantaged group in the labour market. Given that, I also acknowledge the importance of being able to compare my results to past studies. Therefore, I will still provide analyses for each outcome variable, separated by gender. Separating the analyses by gender also helps to view the relationship between the dependent and independent variables without having these variables' values influenced by the other gender.

\subsection{Previous Research on Recent Graduates}

Previous labour market studies on Canada's recent (however the authors define "recent") graduates do exist, but they differ from my research in several ways. First of all, most of them do not subdivide the visible-minority category into its subgroups, which is highly important due to the amount of heterogeneity within this single label. Secondly, the ones that do make more detailed subgroup distinctions base their research on very specific subsamples from which only "niche" conclusions can be made — such as region specific (Krahn \& Maximova, 2005), university specific (Grayson, 2004), occupational industry specific ( $\mathrm{Li}, 2012)$, level of education specific (Twa et al., 2017), or field of study specific (Stenstrom et al., 2013) among others. These types of studies are not as helpful in making conclusions on ethno-racial disparities in Canada's labour market as a whole, because they are too narrow.

Despite those limitations, the following are some conclusions from a few studies which are the most similar to mine. Firstly, Walters et al. (2004) used the 1995 NGS to show that the nonvisible-minorities had no significant earnings difference versus the visible-minorities (as a whole), but without any controls, the visible-minorities showed a significant earnings advantage. However, 
when they compared unemployment rates, they found that the visible-minorities were slightly more likely to be unemployed versus their (gendered) non-visible-minority counterparts. Next, Krahn \& Maximova (2005) used the 1997 Alberta University Graduate Survey and showed that without any controls, the non-visible-minorities generally had an earnings advantage, but with controls, that advantage mostly disappeared. Using the 2000 NGS, Walters \& Zarifa (2008) showed that after controlling for several sociodemographic variables, the visible-minorities faced a significant earnings penalty. Similarly, Frank \& Walters (2012) used the 2005 NGS but focused only on Ontario's graduates. They produced similar results, with the visible-minority group facing a significant earnings penalty in the fully-controlled models.

As seen by these previous analyses, although inconsistent, there does seem to be some evidence of earnings penalties for recent graduate visible-minorities, especially in more recent analyses. However, these studies did not separate the "visible-minority" variable into its subcategories, and most of them did not account for the generation-status of respondents either. This makes it difficult to derive useful conclusions, as this paper has discussed.

\section{Hypotheses}

In accordance with the findings from most of the other national surveys leading up to the 2013 NGS, I expect that my study will find that significant ethno-racial disparities do exist in earnings and in (un)employment status. However, because my sample is narrowed down to recent graduates who were full-time students just three years prior (and relatively younger), I expect these disparities to be smaller because of the greater homogeneity in life experiences that such a sample would have. Given that, amongst males, I predict that the Black males will once again be the only (statistically significant) subgroup with an earnings penalty versus White males, irrespective of controls. Amongst the females, I predict all subgroups will have an earnings penalty versus White 
males irrespective of controls. However, versus White females, I predict that the Black females will be the only subgroup with an earnings penalty, and the Chinese females the only subgroup with an earnings premium, again irrespective of controls. This is simply in accordance with the previous literature, particularly Yu's (2018) findings using the 2011 NHS, which was also a nationwide non-mandatory survey like the 2013 NGS.

For the second outcome of (un)employment status, I predict that all visible-minority male and female subgroups will show significantly higher odds of being unemployed versus White males. When separating females, I predict that all visible-minority female subgroups will show significantly higher odds of being unemployed versus White females. Not only does the raw data from previous nationwide surveys support this, but I make this prediction even if all my controls are applied, because of the aforementioned experiments showing that ethnic minority job applicants receive significantly fewer call-backs despite having equivalent resumes, and that such ethno-racial discrimination continues even if they are invited to an interview. 


\section{THE DATASET}

The 2013 NGS was a nation-wide survey administered to 28,715 respondents who had graduated from a Canadian postsecondary institution in the 2009-2010 academic year. The survey was done approximately three years after these graduation dates, via telephone on a voluntary basis. The respondents were asked detailed questions regarding their labour market outcomes at several time points, including: before graduation, immediately after graduation, and at the time of the survey. They were also asked questions regarding their academic program that commenced in 2010 (e.g. relative GPA ranking, field of study, type/level of credential obtained), and their sociodemographic characteristics (e.g. marital status, residence, ethnic origin, etc.). The following chart from Statistics Canada provides a brief summary of some basic characteristics of the survey's respondents. Note that the 'number of graduates' figures have been multiplied by the weight variable assigned to this dataset by Statistics Canada:

Figure 1: 2013 National Graduates Survey Summary Statistics

\begin{tabular}{|c|c|c|}
\hline Level of Study & Statistics & 2010 \\
\hline \multirow{6}{*}{ College } & Number of graduates & 136,300 \\
\hline & Females (percent) & 56 \\
\hline & Average age at graduation (years) & 28 \\
\hline & Median age at graduation (years) & 24 \\
\hline & Under age 25 at graduation (percent) & 55 \\
\hline & Pursued further education after graduation (percent) & 35 \\
\hline \multirow{5}{*}{ Bachelor's } & $\begin{array}{l}\text { Number of graduates } \\
\text { Females (percent) }\end{array}$ & $\begin{array}{c}194,600 \\
61\end{array}$ \\
\hline & Average age at graduation (years) & 26 \\
\hline & Median age at graduation (years) & 24 \\
\hline & Under age 25 at graduation (percent) & 59 \\
\hline & Pursued further education after graduation (percent) & 48 \\
\hline \multirow{6}{*}{ Master's } & Number of graduates & 48,200 \\
\hline & Females (percent) & 62 \\
\hline & Average age at graduation (years) & 32 \\
\hline & Median age at graduation (years) & 28 \\
\hline & Under age 25 at graduation (percent) & 16 \\
\hline & Pursued further education after graduation (percent) & 31 \\
\hline \multirow{6}{*}{ Doctorate } & Number of graduates & 6,200 \\
\hline & Females (percent) & 51 \\
\hline & Average age at graduation (years) & 34 \\
\hline & Median age at graduation (years) & 32 \\
\hline & Under age 25 at graduation (percent) & $\mathrm{F}$ \\
\hline & Pursued further education after graduation (percent) & 16 \\
\hline
\end{tabular}


To reiterate, there are a few purposes for using the 2013 National Graduates Survey to study ethno-racial disparities in the labour market. Firstly, there are not many studies which compare the ethno-racial groups' labour market outcomes when they are all recent graduates, which is a unique timeframe. Note that I loosely use the phrase "early-career" because over half of the $2013 N G S^{\prime}$ respondents were under the age of 25 at the time of their graduations. It is important to study this demographic because, most of the new entrants into Canada's labourmarket are postsecondary "school leavers" (Employment \& Social Development Canada, 2015). Thus, if any changes to the currently known patterns in Canadians' labour market outcomes are being made, an ideal place to look would be at the root- the "root" being new entrants into the labour market—or in other words, the 'future' of Canada's labour market. This is partly because, research suggests that one's early-career labour market success has a strong influence on their later-career labour market success (Schmillen \& Umkehrer, 2017; Stumpf \& Tymon, 2012; Verbruggen et al., 2015). Therefore, if certain ethno-racial groups have poorer (or better) outcomes as new postsecondary graduates, this relative inferiority (or superiority) may continue indefinitely. There are also other issues unique to recent graduates such as student-loan debts, which can be helped by early-career success. Another reason for focusing on recent graduates is that, this demographic is relatively younger and more homogenous in terms of skills and knowledge than the society as a whole-which naturally mitigates the impact(s) of other unaccounted-for explanatory variables (e.g. life experiences) when analyzing their outcomes. For example, in the 2013 NGS, the median age-at-survey for college-level and bachelor-level graduates (who makeup $86 \%$ of the entire weighted survey) was 27 , each. Generally speaking, these younger subjects would not be expected to have large disparities between themselves in terms of their professional experiences, especially if they were full-time students just three years prior. 


\section{METHODOLOGY}

\subsection{Sample Inclusion Criteria}

Before beginning the analysis, I will establish my subsample (cases) for analysis. The following list presents the specific variables used to exclude unwanted cases from the dataset, and the rationales for doing so. The goal is to reduce the (non-ethno-racial) heterogeneity between the sample's cases as much as possible, while also keeping the sample size sufficiently large for robust statistical analyses, wherever possible.

- Any education completed in a non-Canadian institution prior to 2010 graduation? Those who answered "none" were retained, and the rest filtered out. This question had options dating back to elementary school, which is why I use it as my "generation 1.5+" filter. In other words, anyone who finished elementary school or any level of schooling above that in a non-Canadian institution were filtered out. Using this filter helps to mitigate the "foreign human capital" argument that is often made to justify the (immigrant) ethnic minorities' shortcomings. Moreover, $93 \%$ of the subsample that remained after applying this filter was born in Canada, which helps to dispel the "foreign cultural capital" arguments as well.

- The reason for not using only those born and raised in Canada (e.g. entirely secondgeneration) instead is because, then the sample size becomes too small for statistical robustness. Regardless, research has suggested that roughly speaking, generation 1.5 does not differ substantially in their labour market outcomes, versus their Canadianborn counterparts - but they do differ substantially from those who arrive in their later teen or adult years (Fortin et al., 2016; Pendakur \& Pendakur, 2016). There is also evidence to show that those who immigrate by age 12 show almost no linguistic shortcomings (Johnson \& Newport, 1989). 
- Were you enrolled in your academic program on a full-time basis, part-time basis, or combination of both? Only those who were enrolled on an entirely full-time basis were retained. The reason for this was to further reduce the heterogeneity in the cases' explanatory characteristics by limiting the subsample only to the "traditional" full-time-only students. Specifically, the students who were not entirely enrolled full-time may have been spending more time obtaining other skills and experiences—most notably through employment (Fortin \& Ragued, 2017; Geel \& Backes-Gellner, 2012). Although there is a variable to account for one's length of work experience (when predicting labour market outcomes), other aspects would be difficult to account for, such as: volunteer experiences, knowledge and abilities obtained, and networks developed among others. On the other hand, there is also evidence that certain students who work while in school may end up with poorer labour market outcomes after graduation (Fortin \& Ragued, 2017; Hordosy et al., 2018). Therefore, to reduce any positive or negative biases in the analyses of labour market outcomes, I have decided to eliminate such people altogether.

- Did you take any leaves-of-absence during the academic program? Only those who did not were retained. The reason for eliminating those who did take any leaves is identical to the rationale for eliminating those who had studied as part-time students, as explained above.

- Currently residing in USA? This filter removed all those who lived in the United States, so that only those living in Canada were retained. The reason for this was simply to focus the research on the graduates participating in Canada's labour market. Allowing any foreign elements into the equation may introduce unwanted bias.

To summarize, after applying all the discussed selection criteria, the new subsample represents approximately $65 \%$ of the entire original dataset. Moreover, in this subsample, 
approximately $93 \%$ of cases are Canadian-born, and the remaining $7 \%$ are immigrants. The subsample can be defined as: recent graduates who completed no level of education in a nonCanadian institution prior to their 2009-2010 graduation, were enrolled entirely as full-time students during the said academic program, took no leaves of absence during this academic program, and were residents of Canada at the time of the survey.

The following filter will only be used for the analyses on annual employment income:

- Employed as full-time or part-time workers? this question asked each respondent if they were employed as full-time or part-time workers at the time of the survey. Those who were parttime were filtered out for the income analyses only. There are many reasons for this, with the underlying purpose being to reduce the heterogeneity in the cases' income-determiningcharacteristics because part-time workers would naturally be earning less. Moreover, adding part-time status as a control variable instead would apply a constant affect to the ethno-racial groups' coefficients, ignoring the unique ways in which part-time status could be affecting the different ethno-racial groups. To avoid such problems from heterogeneity in my subsample, and for overall simplicity, I will constrain my conclusions to only full-time workers.

- This filter was removed from the analyses on (un)employment status, which means that both the unemployed and the part-timers were added back. All types of workers were labelled as "employed", rather than only full-time workers because, outright unemployment is still a far-cry from part-time employment.

Furthermore, this dataset's weight variable as assigned by Statistics Canada was rescaled by dividing the weight assigned to each case, by the mean of all cases' weights. This method allows the cases to keep their relative weights constant, without inflating the total number of respondents. This method is in accordance with Statistics Canada's reporting standards. Statistics Canada 
estimates and assigns weights to each respondent in its surveys to help make the survey more representative of the population covered — and not simply representative of the survey sample.

\subsection{Dependent Variables}

The following is a list and descriptions of the respective variables that correspond to each of the labour market outcomes being investigated:

- Annualized Employment Income: this question asked respondents their gross annualized earnings from the occupation(s) held during the survey. This variable includes everyone who was employed in any capacity, including self-employed. This variable does not include any non-employment income- which I do not need because I am assessing earnings from the labour market only. The annual employment earnings which were in CAD, were converted into their natural logarithms.

- (Un)employment Status: this question asked all respondents whether they were employed, unemployed, or not in the labour force. For the entire dataset, those who were not in the labour force were converted into "missing cases" and deleted from all analyses. This variable was recoded into the following binary format: employed $(0) \&$ unemployed $(1)$.

\subsection{Explanatory Variables of Interest}

The following is a list of the explanatory variables, the ethno-racial classifications of respondents, which will be used for answering the research question. Along with Whites, distinct dummy variables were only created for the top-three most populous visible-minority groups in Canada (and in this survey) while all those who identified with other groups, or with multiple groups were cumulated into the Other category. Again, approximately $3 \%$ of the survey's respondents did not identify with any ethno-racial group, so they are not in any of the analyses. The original questions were recoded as follows (split by gender): 
- Identify as White (1), or not (0)

- Identify as South Asian (1), or not (0)

- Identify as Chinese (1), or not (0)

○ Identify as Black (1), or not (0)

- Identify as anything else/combination of more than one (1), or not (0)

\subsection{Control Variables}

The following is a list of all the control variables, and where necessary, the rationale for including them. Note that for categorical variables, the respective reference categories (for regressions) are in bold.

- Months of FT work experience before graduation (continuous): This variable was derived from questions that asked the respondents if they had ever worked full-time before their 2010 graduation, and if so, to state the cumulative length of such experiences in 'months' or 'years' (answers in 'years' were converted back into 'months'). This variable was included to account for those who may have a labour market advantage (or disadvantage) after graduation due to their previous labour market experiences.

- Enrollment in school after graduation that is above the high school level, and would take 3 or more months to finish if taken full-time? $\rightarrow$ " 0 " if no; " 1 " if yes: This variable was included mainly because, those who did pursue further education after their 2010 graduation would probably have entered the labour market later than those who did not, and/or have obtained less work experience as a result of being preoccupied with school.

- Self-Employed? $\rightarrow$ " 0 " if no; " 1 " if yes: This is an essential control variable because, there are completely different processes involved in becoming self-employed versus employedthis paper focuses on the latter. Moreover, Maxim (1992) found that visible-minorities had 
lower wage-labour income than Whites, but no such income disparities were seen amongst the self-employed.

- Fields of study: This question asked respondents to select an option that best corresponds to their primary field of study in the program from which they graduated in 2010. The reason for holding this variable constant is because one's educational field alone has been shown to be a strong predictor of their labour market outcomes (Lemieux, 2014). Due to the wide range of answers to this question, and a small number of responses for some options, I condensed the derived variables into the following ten binary categories:

○ "Social \& Behavioural Sciences, Law" $\rightarrow$ "0" for no; "1" for yes

$\bigcirc$ “Business, Management, \& Public Administration" $\rightarrow$ " 0 " for no; "1" for yes

○ “Architecture, Engineering \& Related Technologies" $\rightarrow$ "0” for no; "1 " for yes

○ "Health \& Related Fields" $\rightarrow$ "0" for no; " 1 ” for yes

○ "Education" $\rightarrow$ "0" for no; "1" for yes

○ "Physical/Life Sciences \& Tech, Natural Resources" $\rightarrow$ "0" for no; "1" for yes

○ "Mathematics, Computer \& Information Sciences" $\rightarrow$ " 0 " for no; " 1 " for yes

○ "Humanities" $\rightarrow$ " 0 ” for no; " 1 ” for yes

○ "Visual/Performing Arts, Communications Tech" $\rightarrow$ "0” for no; "1" for yes

○ "Personal/Protective/Transportation Services, Other" $\rightarrow$ "0” for no; " 1 " for yes

- Region of residence: A total of six binary categories were derived from the question asking respondents where they were residing at the time of the interview ('job location' was not used instead because the self-employed were not asked that). Although the question included options of outside Canada, only those who answered with a Canadian province or territory were retained. The rationale for controlling for region-of-residence is because: the income 
levels and employment rates differ between Canada's provinces (and broader regions for that matter), and also because certain ethno-racial groups are known to be concentrated in very specific regions (Statistics Canada, 2017d; Statistics Canada, 2017e). Thus, it must be ensured that the analyses do not falsely imply that an ethno-racial group has good (or bad) outcomes, when it's their residence location that is influencing them rather than their ethno-racial status. Due to small sample sizes, Nova Scotia, New Brunswick, Prince Edward Island, and Newfoundland were amalgamated into "Atlantic Canada"; Manitoba, Saskatchewan, and Alberta were amalgamated into "Prairies"; and Nunavut, Yukon, and Northwest Territories were amalgamated into "Northern Territories":

$$
\begin{aligned}
& \text { ○ "Atlantic Canada" } \rightarrow \text { "0" for no; "l" for yes } \\
& \text { ○ "Quebec" } \rightarrow \text { "0" for no; "1" for yes } \\
& \circ \text { “Ontario" } \rightarrow \text { “0” for no; " } 1 \text { " for yes } \\
& \text { ○ "Prairies" } \rightarrow \text { “0” for no; " } 1 \text { " for yes } \\
& \text { ○ "British Columbia" } \rightarrow \text { "0" for no; "l" for yes } \\
& \text { ○ "Northern Territories" } \rightarrow \text { "0" for no; "1" for yes }
\end{aligned}
$$

- Education level attained in 2010: The level of one's credentials has also been shown to be a strong predictor of their labour market outcomes (Frank \& Walters, 2012), and moreover, Abada et al. (2009) has shown that educational attainment differs between Canada's generation 1.5+ ethno-racial groups. This question provided the respondent with several options, which resulted in too little responses for some of the options. Thus, they were all condensed into three broader categories. Those who obtained college-level certificates, diplomas, apprenticeships, or trade school credentials were cumulated into one binary variable. The next binary variable combined those who attained a bachelor's degree or a post- 
graduate certificate. Finally, those who attained a credential at the level of a master's degree or anything higher were cumulated into one binary variable. They are labelled as follows:

○ "Less than Bachelors" $\rightarrow$ "0" for no; "1" for yes

○ “Bachelors, Post-grad Certificate/Diploma $\rightarrow$ "0" for no; "1" for yes

○ “Masters, PhD, Professional $\rightarrow$ "0" for no; " 1 ” for yes

- Self-reported academic ranking: This question asked each respondent to estimate the percentile in which their grade-point-average ranked amongst their graduating class. Because of self-reporting biases, and the fact that StatsCan did not verify what the respondents' actual grades were, this question likely did not yield accurate responses. However, this question may instead be measuring the respondents' tendencies towards embellishment (or a lack thereof), while still hinting at their academic ranking (because someone with a high or low GPA would probably acknowledge that in a rough sense). Job application studies show that the making of embellishing statements, otherwise referred to as 'ingratiation', may result in greater chances of success in job applications (Varma et al., 2006). Moreover, a positive correlation between a high GPA and career success has also been documented (Jones \& Jackson, 1990; Roth \& Clark, 1998). Therefore, holding such characteristics constant would account for any ethnoracial differences in this area. The responses to this question were sorted into the following three binary categories:

○ "Ranked in the top $10 \%$ " $\rightarrow$ "0" for no; " 1 " for yes

○ "Ranked in the top 25\%, but below the top $10 \%$ " $\rightarrow$ " 0 " for no; " 1 " for yes

$\bigcirc \quad$ “Ranked below the top 25\%" $\rightarrow$ “0” for no; " 1 " for yes

- Marital status: This question asked respondents to select one option that corresponds to them best. All of the options were condensed into the following three categories due to sample size 
constraints for some individual options. The reason for including this control variable is that differences in relationship status/history have been shown to impact labour market outcomes (Zagorsky, 2005).

○ "Married or Common-Law" $\rightarrow$ "0" for no; " 1 " for yes

○ "Prev. Married: Widowed, Separated, or Divorced" $\rightarrow$ "0" for no; " 1 " for yes

$\bigcirc \quad$ “Never Married" $\rightarrow$ "0" for no; "1" for yes

- Has dependent children? $\rightarrow$ " 0 ” for no; " 1 ” for yes: This question simply asked respondents if they had adolescent dependents or not. There is evidence of earnings penalties for women with dependent children, as they take on this extra responsibility (Zhang, 2009).

Before continuing, another point about control variables should be added. Unlike some previous studies, this study will not control for certain 'occupational controls' namely industry, and occupational level because, as explained by various researchers including Pendakur \& Pendakur (2002) and Skuterud (2010), these are 'labour market outcomes' in themselves, as they are closely tied to earnings and other labour market outcomes. So, controlling for them may end up 'concealing' the effects of ethno-racial discrimination. Instead, I have controlled for field of study which as explained above, is a strong predictor of labour market outcomes, but is not a "labour market outcome" in and of itself. Nevertheless, some of the fields of study showed relatively greater collinearity (than between other independent variables) with their occupationalfield counterparts. This is perhaps expected because recent Statistics Canada data has shown that roughly three quarters of both employed men and women aged 25 to 34 are in occupations that are either "closely related" or "somewhat related" to their education (Yuen, 2010). 


\subsection{Models}

\section{Regression 1a: (Pooled Model)}

$\ln ($ Earnings $)=\beta_{0}+\beta_{1}$ SouthAsianMale $+\beta_{2}$ ChineseMale $+\beta_{3}$ BlackMale $+\beta_{4}$ OtherMale + $\beta_{5}$ WhiteFemale $+\beta_{6}$ SouthAsianFemale $+\beta_{7}$ ChineseFemale $+\beta_{8}$ BlackFemale + $\beta_{9}$ OtherFemale $+\ldots \beta_{n} X_{n}+\varepsilon i$

Regression 1b: (Split by Gender)

$\ln ($ Earnings $)=\beta_{0}+\beta_{1}$ SouthAsian $+\beta_{2}$ Chinese $+\beta_{3}$ Black $+\beta_{4}$ Other $+\ldots \beta_{n} X_{n}+\varepsilon i$

Regression 2a: (Pooled Model)

Logit $($ Unemployed $)=\beta_{0}+\beta_{1}$ SouthAsianMale $+\beta_{2}$ ChineseMale $+\beta_{3}$ BlackMale $+\beta_{4}$ OtherMale

$+\beta_{5}$ WhiteFemale $+\beta_{6}$ SouthAsianFemale $+\beta_{7}$ ChineseFemale $+\beta_{8}$ BlackFemale + $\beta_{9}$ OtherFemale $+\ldots \beta_{n} X_{n}$

\section{Regression 2b: (Split by Gender)}

Logit $($ Unemployed $)=\beta_{0}+\beta_{1}$ SouthAsian $+\beta_{2}$ Chinese $+\beta_{3}$ Black $+\beta_{4}$ Other $+\ldots \beta_{n} X_{n}$

Note that I will enter the control variables sequentially, in a "block-wise" manner, so that each regression will have several "blocks" (or "models"). I will mostly focus on the fullycontrolled blocks, and only discuss the notable developments in the preceding blocks. Nonetheless, I will still show all models of each regression in the Appendix, so that future researchers can get an idea of the impacts that the successively-added control variables may be having. 


\section{DESCRIPTIVE STATISTICS}

The following are several sets of descriptive statistics from the dataset, with all of the aforementioned subsample data filters applied except that these statistics have not filtered out parttime workers. Statistics corresponding to each of the control variables mentioned above have been included, along with commentary following the chart. Note that approximately $3 \%$ of the entire survey's respondents did not have a response for any of the ethno-racial subgroups. 
Table 4: Subsample Descriptive Statistics, 2013 National Graduates Survey

\begin{tabular}{|c|c|c|c|c|c|c|c|c|c|c|}
\hline & \multicolumn{2}{|c|}{ White } & \multicolumn{2}{|c|}{ South Asian } & \multicolumn{2}{|c|}{ Chinese } & \multicolumn{2}{|c|}{ Black } & \multicolumn{2}{|c|}{ Other } \\
\hline & Male & Female & Male & Female & Male & Female & Male & Female & Male & Female \\
\hline \multicolumn{11}{|l|}{ Unemployed } \\
\hline Rate & $6.2 \%$ & $4.6 \%$ & $19.4 \%$ & $6.1 \%$ & $6.2 \%$ & $4.8 \%$ & $8.8 \%$ & $4.3 \%$ & $10.8 \%$ & $9.2 \%$ \\
\hline Total in LF & 6246 & 8156 & 217 & 245 & 241 & 311 & 68 & 185 & 493 & 662 \\
\hline \multicolumn{11}{|l|}{ Employee Type } \\
\hline Employee & $93.4 \%$ & $94.6 \%$ & $96.6 \%$ & $97.8 \%$ & $92.1 \%$ & $96.3 \%$ & \multicolumn{2}{|c|}{$96.7 \%$} & $94.3 \%$ & 92.8 \\
\hline Self-Employed & $6.6 \%$ & $5.4 \%$ & $3.4 \%$ & $2.2 \%$ & $7.9 \%$ & $3.7 \%$ & \multicolumn{2}{|c|}{$3.3 \%$} & $5.7 \%$ & 7.2 \\
\hline Total Response & 5848 & 7780 & 175 & 230 & 227 & 296 & \multicolumn{2}{|c|}{$239^{1}$} & 440 & 601 \\
\hline \multicolumn{11}{|l|}{ PT/FT Employee } \\
\hline PT \% & $8.5 \%$ & $18.3 \%$ & $9.8 \%$ & $13.0 \%$ & $6.2 \%$ & $18.6 \%$ & $8.1 \%$ & $34.1 \%$ & $12.1 \%$ & $18.1 \%$ \\
\hline Total Response & 5861 & 7783 & 174 & 231 & 226 & 296 & 62 & 176 & 439 & 601 \\
\hline \multicolumn{11}{|l|}{ Employment Income (CAD) } \\
\hline Mean & 53,943 & 43,824 & 53,066 & 44,765 & 57,485 & 67,808 & 47,559 & 37,864 & 56,730 & 42,546 \\
\hline Median & 48,000 & 40,000 & 47,000 & 42,000 & 46,800 & 49,400 & 43,000 & 33,280 & 45,000 & 41,860 \\
\hline (Ln) Mean & 10.71 & 10.51 & 10.75 & 10.60 & 10.82 & 10.63 & 10.59 & 10.41 & 10.71 & 10.49 \\
\hline (Ln) Median & 10.78 & 10.60 & 10.76 & 10.65 & 10.75 & 10.81 & 10.67 & 10.41 & 10.71 & 10.64 \\
\hline Total Response & 5464 & 7368 & 163 & 213 & 193 & 260 & 60 & 166 & 389 & 561 \\
\hline \multicolumn{11}{|l|}{ Exp. Before Grad } \\
\hline Months, Mean & 44.39 & 37.63 & 7.62 & 9.73 & 9.37 & 12.66 & 23.28 & 25.44 & 29.37 & 20.00 \\
\hline Months, Median & 17.00 & 12.00 & 0 & 0 & 0 & 0 & 6.00 & 9.00 & 12.00 & 4.00 \\
\hline Total Response & 6636 & 8796 & 231 & 298 & 281 & 375 & 82 & 193 & 563 & 717 \\
\hline \multicolumn{11}{|l|}{ FT School Since Grad? } \\
\hline No & $61.4 \%$ & $59.1 \%$ & $48.1 \%$ & $54.7 \%$ & $54.1 \%$ & $52.5 \%$ & $60.2 \%$ & $56.2 \%$ & $49.4 \%$ & $51.9 \%$ \\
\hline Yes & $38.6 \%$ & $40.9 \%$ & $51.9 \%$ & $45.3 \%$ & $45.9 \%$ & $47.5 \%$ & $39.8 \%$ & $43.8 \%$ & $50.6 \%$ & $48.1 \%$ \\
\hline Total Response & 6699 & 8907 & 231 & 298 & 281 & 375 & 83 & 194 & 569 & 728 \\
\hline \multicolumn{11}{|l|}{ Field of Study* } \\
\hline SocSci \& Law + Humanities & $15.6 \%$ & $24.2 \%$ & $6.1 \%$ & $32.8 \%$ & $10.3 \%$ & $28.1 \%$ & $13.3 \%$ & $34.0 \%$ & $18.9 \%$ & $24.1 \%$ \\
\hline Business/Admin & $16.6 \%$ & $20.8 \%$ & $33.0 \%$ & $36.5 \%$ & $33.5 \%$ & $11.2 \%$ & $31.3 \%$ & $23.7 \%$ & $25.9 \%$ & $24.3 \%$ \\
\hline Engineer/Arch. + Math/CompSci & $37.5 \%$ & $4.8 \%$ & $37.8 \%$ & $3.7 \%$ & $27.8 \%$ & $7.2 \%$ & $22.9 \%$ & $3.1 \%$ & $24.7 \%$ & $5.2 \%$ \\
\hline Health + Education & $9.0 \%$ & $33.5 \%$ & $3.5 \%$ & $10.7 \%$ & $11.0 \%$ & $30.7 \%$ & $13.3 \%$ & $30.4 \%$ & $15.1 \%$ & $27.2 \%$ \\
\hline
\end{tabular}

${ }^{1}$ The Black males and Black females are combined because their individual sample sizes were too small to meet Statistics Canada's vetting requirements. 


\begin{tabular}{|c|c|c|c|c|c|c|c|c|c|c|}
\hline Science/Tech & $7.8 \%$ & $6.3 \%$ & $12.2 \%$ & $11.7 \%$ & $12.5 \%$ & $13.6 \%$ & $10.8 \%$ & $2.1 \%$ & $6.0 \%$ & $6.6 \%$ \\
\hline Arts/ComTech + Others & $13.5 \%$ & $10.3 \%$ & $7.4 \%$ & $4.7 \%$ & $5.0 \%$ & $9.1 \%$ & $8.4 \%$ & $6.7 \%$ & $9.5 \%$ & $12.5 \%$ \\
\hline Total Response & 6699 & 8912 & 230 & 299 & 281 & 374 & 83 & 194 & 571 & 727 \\
\hline \multicolumn{11}{|l|}{ Level of Education } \\
\hline$<$ Bachelor & $55.3 \%$ & $46.5 \%$ & $42.2 \%$ & $26.8 \%$ & $33.1 \%$ & $20.5 \%$ & $69.1 \%$ & $50.5 \%$ & $46.7 \%$ & $37.8 \%$ \\
\hline Bachelor/PG & $37.2 \%$ & $43.3 \%$ & $50.0 \%$ & $66.6 \%$ & $58.0 \%$ & $68.9 \%$ & $23.4 \%$ & $42.8 \%$ & $45.1 \%$ & $53.6 \%$ \\
\hline$\geq$ Master & $7.5 \%$ & $10.2 \%$ & $7.8 \%$ & $6.7 \%$ & $8.9 \%$ & $10.6 \%$ & $7.4 \%$ & $6.7 \%$ & $8.2 \%$ & $8.7 \%$ \\
\hline Total Response & 6671 & 8898 & 230 & 299 & 281 & 376 & 81 & 194 & 570 & 728 \\
\hline \multicolumn{11}{|l|}{ Academic Rank } \\
\hline Top $10 \%$ & $41.2 \%$ & $41.6 \%$ & $19.6 \%$ & $30.7 \%$ & $36.8 \%$ & $28.6 \%$ & $26.5 \%$ & $27.4 \%$ & $36.9 \%$ & $32.0 \%$ \\
\hline Top $25 \%$ & $41.6 \%$ & $41.9 \%$ & $49.8 \%$ & $37.3 \%$ & $37.2 \%$ & $42.9 \%$ & $42.6 \%$ & $59.9 \%$ & $42.5 \%$ & $42.5 \%$ \\
\hline Below Top $25 \%$ & $17.2 \%$ & $16.4 \%$ & $30.6 \%$ & $32.0 \%$ & $26.0 \%$ & $28.6 \%$ & $30.9 \%$ & $12.7 \%$ & $20.6 \%$ & $25.5 \%$ \\
\hline Total Response & 6146 & 7641 & 209 & 241 & 223 & 245 & 68 & 157 & 501 & 584 \\
\hline \multicolumn{11}{|l|}{ Residence* } \\
\hline Atlantic Canada + Quebec & $44.1 \%$ & $38.2 \%$ & $1.7 \%$ & $4.4 \%$ & $2.5 \%$ & $5.2 \%$ & $24.1 \%$ & $43.8 \%$ & $23.3 \%$ & $22.0 \%$ \\
\hline Ontario & $33.4 \%$ & $37.9 \%$ & $62.2 \%$ & $76.8 \%$ & $53.2 \%$ & $58.9 \%$ & $68.7 \%$ & $49.5 \%$ & $47.9 \%$ & $56.3 \%$ \\
\hline Prairies $+\mathrm{BC}+$ Territories & $22.5 \%$ & $23.9 \%$ & $36.1 \%$ & $18.8 \%$ & $44.3 \%$ & $35.9 \%$ & $7.2 \%$ & $6.8 \%$ & $28.8 \%$ & $21.7 \%$ \\
\hline Total Response & 6641 & 8830 & 230 & 293 & 280 & 365 & 83 & 192 & 559 & 718 \\
\hline \multicolumn{11}{|l|}{ Marital Status* } \\
\hline Widow/Sep./Div. + Never Married & $60.5 \%$ & $53.6 \%$ & $78.4 \%$ & $75.2 \%$ & $87.6 \%$ & $80.3 \%$ & $84.1 \%$ & $86.5 \%$ & $68.9 \%$ & $69.4 \%$ \\
\hline Married/Common-Law & $39.5 \%$ & $46.4 \%$ & $21.6 \%$ & $24.8 \%$ & $12.4 \%$ & $19.7 \%$ & $15.9 \%$ & $13.5 \%$ & $31.1 \%$ & $30.6 \%$ \\
\hline Total Response & 6691 & 8902 & 231 & 298 & 282 & 375 & 82 & 193 & $\mathbf{5 7 0}$ & 728 \\
\hline \multicolumn{11}{|l|}{ Dependent Kids? } \\
\hline No & $85.3 \%$ & $79.6 \%$ & $96.1 \%$ & $84.3 \%$ & $96.1 \%$ & $91.0 \%$ & $90.2 \%$ & $77.7 \%$ & $88.4 \%$ & $89.7 \%$ \\
\hline Yes & $14.7 \%$ & $20.4 \%$ & $3.9 \%$ & $15.7 \%$ & $3.9 \%$ & $9.0 \%$ & $9.8 \%$ & $22.3 \%$ & $11.6 \%$ & $10.3 \%$ \\
\hline Total Response & 6699 & 8912 & 231 & 299 & 281 & 376 & 82 & 193 & 570 & 728 \\
\hline
\end{tabular}

* Some individually-coded categories have been combined by a "+” symbol for the purpose of presenting these descriptive statistics, because some ethno-racial subgroups had insufficient respondents in a single category. Again, this was done to comply with Statistics Canada's vetting requirements. 


\subsection{Employment Statistics}

Note that the following discussion is only a summary of the raw descriptive statistics, so readers can get an overview of the subsample's characteristics. Thus, the comparisons between the ethno-racial groups are not being suggested to have statistical significance.

The raw statistics show that amongst visible-minority males, South Asians are the primary influencers of the high unemployment rate, with Others having a distant second-highest rate, and Blacks having the third highest. The Chinese and White males have identical rates. Amongst the females, there is a much smaller spread, with the differences in unemployment rates being negligible between the Whites, Chinese, and Blacks. The Other females have noticeably the highest rate, and South Asians have the second-highest. The major takeaway from these statistics is the exceptionally high unemployment rate for South Asian males. To cross-check with another dataset, the following table presents data from the 2011 NHS, with all of my subgroups roughly defined. The filter criteria are: non-immigrants aged 20 to 24 , and 25 to 34 who have obtained an education at the bachelor's level or above:

Table 5: Unemployment Rates for Ages 20-34, 2011 National Household Survey (Statistics Canada, 2013):

\begin{tabular}{|c|c|c|c|}
\hline \multicolumn{2}{|c|}{} & Unemployed \% (Aged 20-24) & Unemployed \% (Aged 25 - 34) \\
\hline \multirow{2}{*}{ White } & Male & $15.6 \%$ & $4.2 \%$ \\
\cline { 2 - 4 } & Female & $11.8 \%$ & $4.2 \%$ \\
\hline \multirow{3}{*}{ South Asian } & Male & $17.9 \%$ & $5.6 \%$ \\
\cline { 2 - 4 } & Female & $16.4 \%$ & $6.0 \%$ \\
\hline \multirow{2}{*}{ Chinese } & Male & $18.6 \%$ & $4.3 \%$ \\
\cline { 2 - 4 } & Female & $16.1 \%$ & $4.9 \%$ \\
\hline \multirow{2}{*}{ Black } & Male & $24.3 \%$ & $5.8 \%$ \\
\cline { 2 - 4 } & Female & $14.9 \%$ & $6.5 \%$ \\
\hline
\end{tabular}

This data presents a different picture, with Blacks having the highest unemployment rate amongst visible-minority males, and also amongst visible-minority females. Nevertheless, the 
unemployment rates for all visible-minorities appear to be significantly higher than their White counterparts in the NHS data as well, along with the smaller spread between female groups again. The fact that my dataset is confined to only those who graduated from a Canadian publicpostsecondary institution in 2009-2010, is perhaps the biggest factor contributing to such differences versus this other national survey. Note that the my NGS subsample lies in between the two NHS age brackets presented above, with the median age being 27 for my subsample.

Moving on to employment characteristics, the most notable remarks regarding selfemployment rates are that, amongst males, the Chinese have the highest rate, and South Asians have the lowest. Amongst females, the Others have the highest rate, and South Asians have the lowest. Regarding the part-time employment rates, the females in general have higher rates than males. The most notable statistic is the exceptionally high rate in the Black females. Notably, Black females have the lowest unemployment rate, but the highest part-time employment rate. Nonetheless, the NGS describes part-time status as "less than 30 hours per week" which leaves a large range, and self-employment is not precisely defined either which may leave a host of possibilities (e.g. are employees who only earn commissions considered self-employed?).

\subsection{Income Statistics}

This discussion will only consider the non-log-transformed figures, as both the mean and median are presented, and the medians would not be skewed by outliers. Amongst the males, there are negligible differences between Whites and South Asians (though South Asians have the highest unemployment). The Chinese appear to have the highest average incomes — which do not reflect on their median incomes though, and Blacks appear to have the lowest average and median incomes. The Other males have the second-highest average income, but the second-lowest median income. Amongst the females, South Asians appear to have slightly higher incomes than Whites, 
the Chinese appear to have the highest of all, and Blacks have the lowest of all. In fact, this data shows that the Chinese females earn more than all of the other groups, irrespective of gender. In contrast, the Black females seem to be the lowest-earning group in the entire table, probably driven by them having the highest part-time-employment rate. It is important to note that Blacks have the lowest sample size, which impairs the significance of their data, as will be seen in the regression models shortly. The Other females have the second-lowest average income, while their median income is comparable to the White and South Asian females. Nevertheless, it is difficult to draw inferences on the Other groups' incomes because, they represent a cumulation of various ethnoracial groups and mixed-race individuals of various combinations. Roughly speaking, these subgroups' raw incomes seem to be consistent with literature presented above.

\subsection{Sociodemographic Statistics}

The raw statistics from the rest of the variables in the chart help to assess the factors that may be driving the differences in the ethno-racial groups' employment outcomes. Beginning with months of full-time work experience before graduation, it appears that Whites have the most of such experiences, Others and Blacks have the second most, and South Asians and Chinese have the least — in both genders. Furthermore, every visible-minority subgroup appears to have pursued additional full-time education after their 2009-2010 graduation in higher rates than Whites, though Blacks are closest to Whites in this regard. The South Asian males have the highest rate versus all the other subgroups, which is perhaps one contributor to their high unemployment rate-because they might have been 'job seeking' for the shortest amount of time.

Next, there are vast differences in the ethno-racial groups' fields of study. Note that some of the individual categories were combined despite being coded into distinct variables, due to sample size constraints for some ethno-racial subgroups. Most of these fields have been combined 
on the basis of curriculum similarities, but Health and Education have been combined because both of these fields are overwhelmingly female (Turcotte, 2011), and Engineering/Architecture and Math/Computer-Science (e.g. STEM) have been combined because both of these fields are overwhelmingly male (Hango, 2013). However, these will be added individually in the regression models. Given that, the following is a brief summary of these statistics. The most popular fields for males, irrespective of ethno-racial group, appear to be both Business/Administration and STEM - by a large margin. Their least popular ones vary by subgroup. For females, there is more variability in the most popular fields, but overall, Health + Education, Business/Administration, and Social Sciences \& Law + Humanities are the most popular categories. The least popular is STEM for all female subgroups. Again, this is generally reflective of general demographic differences between males' and females' educational fields.

Moving down to level of education, the highlights are that: amongst males, the Chinese appear to have the greatest proportion with a bachelor's degree or higher. In contrast, the Black males appear to have the lowest proportion in this area. Amongst females, the Chinese have the greatest proportion with a bachelor's degree or higher, followed closely by South Asians. The Black females have the lowest proportion in this area. Narrowing in on males with a master's or higher, the Chinese males and Other males have the highest proportions, with negligible differences between the remaining male groups. Amongst females with a master's or higher, the Chinese females and White females have the highest proportions, while the Black females and South Asian females have the lowest. Another important observation is that Blacks, followed by Whites have the greatest proportions in those with less than a bachelor's degree, within both genders. The primary conclusion from these statistics is that, Blacks have the lowest educational credentials, while the Chinese have the highest. Also, females appear to achieve higher credentials 
than the males across the board. This seems to be reflective of previous research on this topic (Abada et al., 2009).

In the category of self-reported academic rankings, Whites make the highest claims amongst males, while South Asians make the lowest. Amongst females, Blacks and Whites make the highest claims, and South Asians and Chinese make the lowest. As explained above, this variable is perhaps also an indicator of the tendency to embellish rather than actual academic ranking, because Statistics Canada did not validate the graduates' answers to this question.

For residence locations, again some individually-coded categories were combined to resolve the descriptive statistics' sample size constraints. These combined categories are now roughly, "eastern Canada" consisting of Atlantic Canada + Quebec, Ontario on its own, and “western Canada" consisting of Prairies $+B C+$ Territories. The key takeaways are that, all of the visible-minorities have the highest proportions of themselves residing in Ontario. Blacks also have a sizeable proportion of themselves residing in "eastern Canada", but not so much in "western Canada", and vice versa for the Chinese and South Asians. The Others have less of a spread between "eastern" and "western" Canada. In contrast, Whites are mostly concentrated in "eastern Canada", followed closely by Ontario, and a sizeable portion still left in "western Canada". These relative figures are consistent with Statistics Canada's data (Statistics Canada, 2017d).

Finally, the family status statistics mainly suggest that Whites have a higher proportion of those who are married or in a common-law relationship, and the Chinese and Blacks have the highest proportion of those who are single (never married, or previously married). Also, amongst males, Whites followed by the Others have the highest proportions with dependent children —and amongst females, Blacks followed by Whites have the highest proportions with dependent children. 


\section{RESULTS}

\subsection{Regression 1 Results}

Before discussing the substance of the fully-controlled regression models in the next chapter, the findings from the preceding successive blocks (e.g. models) as presented in the Appendix will be briefly highlighted. This is to give the reader and future researchers an idea of the possible impacts that these successive sets of control variables may be having. Note that, in regressions with a log-transformed dependent variable, although the coefficients for continuous independent variables can be interpreted as a percentage-increase or percentage-decrease (after being multiplied by 100) that a one-unit increase in that independent variable causes in the dependent variable, this is not the case for categorical (dummy) independent variables. To elaborate, the coefficient for a dummy independent variable (denoted by $B$ ) must first be converted before being interpreted as a percentage-increase or percentage-decrease in the dependent variable — using the following formula (Halvorsen \& Palmquist, 1980):

$$
[\exp (B)-1] \times 100
$$

For each dummy independent variable, this percentage-increase or percentage-decrease is relative to the respective reference categories. For example, in my analyses, the "reference category" for the ethno-racial groups is always either 'White males' or 'White females'. 
statistics presented above - and this region has one of the lowest incomes in Canada (Statistics Canada, 2017f). After adding controls for education level in Model 5, there are a few developments. Notably, the Chinese males begin to show a significant negative coefficient for the first time, and the Other males' previously significant positive coefficient is no longer significant. Also, notice the remarkable increase in magnitude of the Black males' coefficient, and decrease in the Chinese females' coefficient_although they are still insignificant. Again, this may be reflective of the fact that amongst generation $1.5+$, the Blacks have the lowest educational credentials, and the Chinese have the highest (Abada et al., 2009) — and thus this higher human capital probably allows the Chinese to avoid earnings penalties, while the Blacks' lower human capital contributes to their earnings penalties. Next, controlling for academic ranking in Model 6 produces negligible changes, but when the 'family status' controls are added in Model 7, the Black males' positive coefficient gains significance, though at the $\mathrm{p}<0.1$ level. Also, the Black females' coefficient, although still negative, reaches its highest magnitude thus far. Note that the Chinese females are the only female subgroup without a significant earnings penalty versus the White males, and with the exception of the Blacks males, no other male subgroup has a significant coefficient in the final model. 
Table 7: Regression 1b: Gender-Split Analysis of Income, by Ethno-Racial Identity

MALES:
\begin{tabular}{|l|l|l|}
\hline N= 5,267 & \multicolumn{2}{c|}{ Fully-Controlled $\left(\mathrm{R}^{2}=.161\right)$} \\
\hline \multicolumn{2}{|c|}{ Variables } & \multicolumn{2}{c|}{ B.E. B } \\
\hline Male Ethno-Racial Groups: & \multicolumn{2}{c|}{} \\
\hline South Asian Male & -.025 & .044 \\
\hline Chinese Male & -.038 & .041 \\
\hline Black Male & $.125^{*}$ & .075 \\
\hline Other Male & .030 & .029 \\
\hline Reference = White Male & - & - \\
\hline
\end{tabular}

FEMALES:

\begin{tabular}{|c|c|c|}
\hline$N=5,882$ & \multicolumn{2}{|c|}{ Fully-Controlled $\left(\mathrm{R}^{2}=.241\right)$} \\
\hline Variables & B & S.E. B \\
\hline \multicolumn{3}{|c|}{ Female Ethno-Racial Groups: } \\
\hline South Asian Female & .047 & .033 \\
\hline Chinese Female & $.111 * * *$ & .035 \\
\hline Black Female & .024 & .042 \\
\hline Other Female & -.033 & .022 \\
\hline Reference $=$ White Female & - & - \\
\hline \multicolumn{3}{|c|}{$* \mathrm{p}<0.1 ; * * \mathrm{p}<0.05 ; * * * \mathrm{p}<0.01$} \\
\hline \multicolumn{3}{|c|}{$\begin{array}{c}\text { Sample Filters: only FT workers; no education completed outside of } \\
\text { Canada; were always FT students during academic program; } \\
\text { residing in Canada }\end{array}$} \\
\hline \multicolumn{3}{|c|}{$\begin{array}{l}\text { (Including controls for: employment experiences, field of study, } \\
\text { residence region, education level, academic self-ranking, and family } \\
\text { status variables-see full tables in Appendices } 11.2 \& 11.3 \text { ) }\end{array}$} \\
\hline
\end{tabular}

Expectedly, there are negligible differences in the male subgroups' coefficients (and model-to-model changes) between the gender-pooled Regression la (Appendix 1) and the malesonly Regression 1 (Appendix 2), because the same White males are the reference category in both analyses. Thus, Appendix 2 will not be exclusively summarized as doing so would be redundant.

\section{Earnings: Females Only}

Moving on to the female-only earnings model in Appendix 3, with the first set of controls in Model 2, only the Chinese females have a significant earnings premium over the White females, while the other subgroups are insignificant. After the field of study controls are added in Model 3, the South Asian females join the Chinese females in having a significant earnings premium over the White females, though the change from Model 2 is unremarkable. However, when residence 
location is controlled for in Model 4, the South Asian females lose their significance, and the Chinese females show a drop in their coefficient's magnitude for the first time. As remarked earlier, this may be partially explained by the fact that Whites (males and females) have greater proportions of themselves residing in the lower income regions of Canada. Next, when education level is controlled for in Model 5, the Chinese females still show an earnings premium versus White females, but there has been a substantial drop in their coefficient's magnitude. Moreover, the Other female's negative coefficient becomes significant. Again, this may be because the Chinese have higher education credentials (Abada et al., 2009), so holding them constant in such an analysis may "deflate" their relative earnings. Finally, there are negligible changes in Model 6 with the addition of academic ranking controls. In the final Model 7, the Chinese females remain as the only subgroup with a significant coefficient (positive). Moreover, although insignificant, the Black females show their largest coefficient yet—which may be hinting at parallels with their male counterparts. The earnings advantage for Chinese females is consistent with previously documented trends in the overall generation $1.5+$ population.

\section{2. $\quad$ Regression 2 Results}

This discussion will highlight the findings in the successive models from the (un)employment analyses seen in Appendices 11.3 through 11.6. The numbers of interest are the exponentiated coefficients under the $\operatorname{Exp}(B)$ columns, which are otherwise called odds-ratios. These odds-ratios are interpreted as: the relative odds of being unemployed when the predictor variable in question is increased by one unit (versus the reference category, for categorical variables). Note that I focus this explanation in the context of the categorical (binary) ethno-racial variables that I coded. For odds-ratios greater than 1, the interpretation would be "those in the corresponding predictor variable (e.g. the binary value $=1$ ) have $x$ times greater odds of being 
the South Asian males, followed by the Other males, followed by the Other females - and now also followed by the Chinese males have significantly higher odds. All other subgroups are insignificant. This marginal change may suggest that everyone who is not a White male could have graduated from fields of study with better employment prospects than the fields in which White males studied - although this is difficult to ascertain from the descriptive statistics. Furthermore, when residence locations are controlled for in Model 4, there is a general worsening in the oddsratios of all non-White and non-Black subgroups, irrespective of significance. Like the income models, the reason for this marginal change is perhaps because Whites and Blacks have greater proportions living in Atlantic Canada, where not only are the incomes lower, but the unemployment rates are also generally higher (Statistics Canada, n.d.). A similar marginal change occurs after education level controls in Model 5 as well, with all of the non-White and non-Black subgroups' odds-ratios worsening, irrespective of significance. Referring back to the descriptive statistics, this may be due to the fact that Whites and Blacks have higher proportions than everyone else with less than a bachelor's degree. Next, when academic ranking is controlled for in Model 6, there is generally a small improvement in the subgroups' odds-ratios, irrespective of significance. Looking at the descriptive statistics again, this is probably influenced by the fact that Whites proclaim higher academic rankings than the visible-minorities do, which could be helping their employment prospects (see studies cited in section 5.4) - so when this variable is held constant, the visible-minorities' employment rates show a marginal improvement. Finally, in Model 7, after adding the 'family status' controls, there is another marginal improvement in all of the non-White subgroups' odds-ratios, irrespective of significance. This is probably because the visible-minorities have lower rates of marriage/common-law as seen in the descriptive statisticsand the regression does show lower odds of unemployment for the Married/Common-Law 
variable. Note that the marginal improvements in the results of the non-White subgroups seen in Models $6 \& 7$ were also seen in the corresponding earnings models (generally speaking, irrespective of significance)—which may hint that Whites benefit from their higher self-reported academic rank, and their higher rates of marriage/common-law status. Overall, the significant results in the final employment-status model show: South Asian males, followed by Other males, followed by Other females, followed by Chinese males all have higher odds of being unemployed versus the White males - and the remaining subgroups are insignificant.

Table 9: Regression 2b: Gender-Split Analysis of Unemployment Odds-Ratios, by Ethno-Racial Identity

MALES:

\begin{tabular}{|c|c|c|c|}
\hline Employed $=6,099 ;$ Unemployed $=394$ & \multicolumn{3}{|c|}{ Fully-Controlled (Pseudo $\mathrm{R}^{2}=.107$ ) } \\
\hline \multirow{2}{*}{$\begin{array}{c}\text { Variables } \\
\text { Male Ethno-Racial Groups: }\end{array}$} & B & S.E. B & $\operatorname{Exp}(\mathbf{B})$ \\
\hline & & & \\
\hline South Asian Male & 1.991 & 217 & $7.324 * * *$ \\
\hline Chinese Male & .729 & .318 & $2.074 * *$ \\
\hline Black Male & .511 & .499 & 1.667 \\
\hline Other Male & .981 & .191 & $2.667 * * *$ \\
\hline Reference $=$ White Male & - & - & - \\
\hline
\end{tabular}

FEMALES:

\begin{tabular}{|l|l|}
\hline Employed $=7,588 \cdot$ Unemployed $=376$ & Fully-Controlled $\left(\right.$ Pseudo $\left.\mathrm{R}^{2}=.068\right)$
\end{tabular}

\begin{tabular}{|c|c|c|c|}
\hline Variables & B & S.E. B & $\operatorname{Exp}(B)$ \\
\hline \multicolumn{4}{|c|}{ Female Ethno-Racial Groups: } \\
\hline South Asian Female & .367 & .313 & 1.443 \\
\hline Chinese Female & -.623 & .519 & .536 \\
\hline Black Female & -.126 & .393 & .881 \\
\hline Other Female & .754 & .168 & $2.126 * * *$ \\
\hline Reference $=$ White Female & - & - & - \\
\hline
\end{tabular}

$* \mathrm{p}<0.1 ; * * \mathrm{p}<0.05 ; * * * \mathrm{p}<0.01$

Sample Filters: no education completed outside of Canada; were only FT students during academic program; residing in Canada

(Including controls for: employment experiences, field of study, residence region, education level, academic self-ranking, and family status variables-see full tables in Appendices 11.5 \& 11.6)

(Un)employment: Females Only 
Once again, the males-only analysis in Appendix 5 will not be discussed because, there are negligible differences in the male subgroups' odds-ratios (and model-to-model changes) between the gender-pooled Regression $2 a$ (Appendix 4) and the males-only Regression $2 b$ (Appendix 5), as the same White males are the reference category in both analyses. So, moving on to the femalesonly analysis in Appendix 6, the ethno-racial subgroups' odds-ratios do not appear to show many remarkable developments from model to model. To elaborate, the Other females are the only subgroup with significantly higher odds of being unemployed versus the White females, while the rest of the subgroups remain insignificant from Model 1 through to Model 7. Nonetheless, although insignificant throughout, the Black females' odds-ratio does improve gradually across the models - so this may evoke the attention of future researchers. 


\section{DISCUSSION}

\subsection{Regression 1 Discussion}

\section{Male Earnings}

The fully-controlled income model for males shows that only the Black males have an earnings premium over White males, as Regression $1 b$ in Appendix 2 shows them having an annual income that is $13.3 \%[(\exp (0.125)-1) \times 100]$ higher than that of White males-while the other groups are statistically insignificant. Thus, my hypothesis that Black males will be the male subgroup with the greatest earning penalty versus White males, is rejected. This novel finding is the opposite of what previous research on ethno-racial earnings disparities has shown, in which Black males (regardless of generation status) have been the most disadvantaged group. However, this finding should be interpreted with caution for a number of reasons. Firstly, the Black males' result is based on a very small sample size, and their coefficient is only significant at the $p<0.1$ level. Moreover, this dataset mainly concerns the respondents' early-career labour outcomes, as they are young, recent graduates. Therefore, the discriminatory effects of the "Glass Ceiling" or the "Sticky Floor" as discussed above may not have had time to manifest yet. Nevertheless, this finding warrants additional research, perhaps by replicating this model using a larger sample size, and viewing those in their early-careers and those in their later-careers separately. Another important consideration is that, as the full model in Appendix 2 shows, the Black males' coefficient begins taking shape after the educational controls are added, then gains significance after adding the 'family status' controls. This may suggest that the Black males' early-career earnings are largely influenced by their educational achievements, which again, would need to be further validated with larger datasets. Overall, there appears to be no evidence of a "White male advantage" over the visible-minority males, at least according to this dataset. 


\section{Female Earnings}

Amongst females, the fully-controlled model in Appendix 3 shows only one significant (at $\mathrm{p}<0.01)$ coefficient — the Chinese females' earning an $11.7 \%[(\exp (0.111)-1) \times 100]$ higher income than the White females. The other female visible-minority subgroups are insignificant. This partially supports my hypothesis, as the Chinese females show the hypothesized earnings premium, but the Black females do not show the hypothesized (significant) earnings penalty. This premium for my sample's Chinese females is not surprising as the recent literature, like Pendakur \& Pendakur (2016) and Yu (2018), have found earnings premiums for Canadian-born Chinese females versus their White female counterparts. However, my analysis suggests that the Chinese females may be enjoying an earnings premium even amongst only those in their early-careers. Also, when looking at the fully-controlled pooled income model (Appendix 1), all visible-minority female subgroups show an earnings penalty versus the White males, except for the Chinese females who are insignificant. However, with minimal controls, this pooled income model shows an earnings premium for Chinese females over White males. This means that my hypothesis that every female subgroup will show an earnings penalty versus White males, is rejected-due to this exception of Chinese females. Thus, future researchers may want to compare Chinese females to White males, rather than only to White females, as this may yield novel conclusions.

To summarize, these results for the males and females overall suggest that the visibleminorities who are entirely educated in Canada up to the completion of a postsecondary credential, may not be facing any earnings penalties versus their White (gendered) counterparts — at least as full-time employees in their early-careers. A more extensive dataset is needed to validate this finding, especially because my earnings analyses did not yield many significant coefficients. 


\section{2. $\quad$ Regression 2 Discussion}

\section{Male Unemployment Rates}

The fully-controlled results in Regression $2 b$ (Appendix 5), show higher unemployment odds for the South Asian males, Other males, and the Chinese males. The Black males remain insignificant, probably due to their small sample size. Thus, barring the insignificant result for Black males, my hypothesis is otherwise supported. The South Asian males' show the largest odds of being unemployed versus White males, with an odds-ratio of 7.324 (at $\mathrm{p}<0.01$ ) in the fullycontrolled model. For context, the interpretation of this is that the odds of South Asian males being unemployed are 7.324 times greater than the White males' odds, ceteris paribus - this is not to be confused with probability. All of this may suggest that although the (recent graduate) male visibleminorities do not show significant evidence of earnings penalties, they may be at a significant disadvantage when it comes to obtaining employment in the first place. The government statistics presented earlier also showed the visible-minority male subgroups overall as having higher unemployment rates than the White males, irrespective of generation status-but my analysis shows that this trend persists despite adding several statistical controls. This finding may be explained by the results from previous experiments such as the one done by Oreopoulos (2011), which show ethno-racial discrimination against ethnic minorities throughout the job application process. Alternatively, the studies reviewed above also suggest that unemployment can be a result of the applicants' own 'choosiness' in job applications, lifestyle choices, and the like (Dunn, 2015; Jayasingam et al., 2016). Thus, it would help to identify such causes in future research. Like the income analysis, it would be useful to repeat this analysis using larger datasets, with a focus on those in their early-careers. Particularly, if the magnitude of the South Asian males' disadvantage is shown to be persistent, then they should receive additional attention to figure out the causes. 


\section{Female Unemployment Rates}

Next, the females' fully-controlled models in Appendix 6 show that only the Other females have significantly higher odds of being unemployed versus the White females, while the rest of the subgroups are insignificant. Specifically, they show 2.126 times higher odds of being unemployed versus the White females $(\mathrm{p}<0.01)$. The lack of significance for the rest of the female subgroups leads me to mostly reject my hypothesis, that every female subgroups will show significantly higher odds of being unemployed versus White females. Again, it is not feasible to make substantive conclusions on this finding because this Other category is too heterogenoushowever the analysis does show that a disparity exists. Moreover, the lack of statistical significance for the other subgroups may indicate that a larger sample size is needed. Nevertheless, like amongst the males, the government statistics above do show higher unemployment rates for visibleminority females, versus the White females.

To provide the other perspective, in the pooled model in Appendix 4, the females' oddsratios are predicted versus White males, rather than versus White females. Firstly, the raw model shows that both the White females and the Chinese females have lower odds of being unemployed versus the White males, while the Other females have higher odds of being unemployed versus the White males. The remaining female subgroups are insignificant. The fully-controlled model shows that only the Other females yield a significant odds-ratio (2.078 times higher odds of being unemployed versus White males; at $\mathrm{p}<0.01$ ), indicating that they not only have higher odds of being unemployed versus White females, but also versus White males. This leads me to mostly reject my hypothesis, that every female subgroup will show significantly higher odds of being unemployed versus White males. Nonetheless, this disadvantage in the Other females warrants 
further attention. It would help to first split this group into more ethno-racial categories, then assess which subgroup(s) is driving the disadvantage.

Overall, these results suggest that it is the visible-minority males, especially the South Asians, who warrant the most attention in future research on the ethno-racial groups' unemployment rates. Most of the previous literature has shown that separating by gender, the male visible-minorities experience greater earnings disparities than do their female counterparts. Now this study suggests that male visible-minorities may also experience poorer employment prospects than visible-minority females, whether separating by gender or not. 


\section{LIMITATIONS}

\section{Limitations Inherent to Survey}

Firstly, the 2013 National Graduates Survey was conducted on a voluntary basis, although repeated efforts were made by Statistics Canada to encourage the selected participants to partake in the survey. This may create bias in my study if particular types of people were less (or more) likely to participate. Moreover, the respondents were all graduates from a single academic year, which limits the scope of my entire sample population. Next, the $N G S$ has a narrow scope as the proportion of Canadians aged 25-64 with either college or university credentials has only been around half in recent years. This means that the NGS does not account for a large portion of (nonimmigrant) new entrants into Canada's labour market—who include high school graduates, and those who never graduated high school (Statistics Canada, 2017g). Thus, future researchers should consider deriving more informative and robust conclusions by including these other 'early-career' individuals. Finally, like any survey that relies on unverified self-reported data, the respondents may have provided inaccurate or untruthful responses. In my study, this may have especially created problems if respondents reported inaccurate incomes, and/or inaccurate (un)employment statuses - not to mention the inconsistencies in the reporting of one's ethno-racial identity, as ethnic/racial groups have seldom been objectively defined.

\section{Limitations with Subsample}

The removal of part-time workers from the income models may be concealing the overall earnings penalties (or premiums) of groups who have larger (or smaller) proportions employed part-time - which is especially important if that part-time employment is involuntary. Moreover, the removal of those graduates who were part-time students or took any leaves of absence during their academic program may have created biases_again, if more (or less) members of particular 
ethno-racial groups fall into these categories, and if these categories also have different labour market outcomes. Next, the sample sizes are very small for some subgroups, particularly the Black males. This may be a problem especially when applying the unemployment rates to the small samples, because then the number of unemployed respondents becomes very small. Moreover, the Other subgroup, although relatively large in size, is very heterogenous and thus the findings from this category are difficult to assign to any particular ethno-racial subgroups.

A similar argument can be made for the other ethno-racial groups as well-for example, studies have shown different labour market outcomes for Blacks of Caribbean descent versus Blacks of African descent (Skuterud, 2010), and within South Asians, different outcomes have been found for those of distinct national origins such as Indian, Pakistani, Sri Lankan, etc. (Raza \& Erfani, 2015). There is also some evidence of differences in labour market outcomes between the White-European subgroups when they are separated by their national origins (Stelcner, 2000). These are limitations that would be best addressed by larger surveys, where each of the distinct subgroups have sufficient sample sizes for statistical robustness. However, this may lead into the other issue regarding what exactly constitutes a "distinct" ethno-racial subgroup. Logically speaking, the division of humans into specific ethnicities or races would produce infinite categories because each human has a unique admixture of genetics and environmental experiences. Perhaps that is why there appears to be no consensus amongst legal bodies on how to objectively define the various ethnic and racial subdivisions of humans, further adding to the confusion (Peery, 2017). This is a complex limitation which would likely require systemic changes to the ways that researchers study ethno-racial groups. 


\section{Limitations with Analyses}

Regarding the analyses in particular, the default use of listwise-deletion when adding control variables to regressions may create bias as well. This is because, particular types of people may have provided replies for only some of the variables in the regression instead of all of them, which causes them to be removed altogether. This also has the exacerbating effect of further reducing the sample size. Another issue, particularly with the income analyses is that there were many respondents who reported themselves as 'employed' but did not provide an income. This can impair my conclusions as well, especially if a higher proportion of a particular ethno-racial group(s) did not provide their income. Another point to note is that approximately $3 \%$ of the entire survey's respondents did not identify with a specific ethno-racial group(s), leading to their removal from my subsample. Again, this may bias the analyses if a greater proportion of a particular ethnoracial group(s) chose not to identify with a label provided by the $N G S$.

Regarding the exclusion of 'occupational' controls from the analyses as discussed earlier, this may be a limitation if the ethno-racial groups did go into different 'occupational industries' and attain different 'occupational levels', without facing discrimination (e.g. racism). Although there is mild collinearity between some fields of study and occupational industries, they are not perfectly collinear. To address this, I tested the impact of adding the occupational industries to the controls in the earnings models, both with the fields of study and without. Although there were no remarkable differences from the conclusion made in this paper overall, there was a slight increase in the magnitudes and significance levels of the visible-minority subgroups' coefficients. This is perhaps because of the "controlling away" of labour market discrimination that the previous researchers cited above have remarked about. 


\section{CONCLUSION}

Overall, this study suggests that amongst those who completed no level(s) of education outside Canada, graduated with a postsecondary credential in 2010, and held a full-time job three years later, the visible-minorities overall show no significant evidence of earnings penalties versus their White (gendered) counterparts—but rather some subgroups may have earnings premiums. However, this is tainted by the fact that all of the visible-minority subgroups with significant results, especially the South Asian males, show substantially higher odds of being unemployed versus their White (gendered) counterparts. This is very similar to what Walters et al. (2004) found using the $1995 N G S$-albeit without subdividing the 'visible-minority' variable. To reiterate, in their fully-controlled models, they found no significant differences in earnings between nonvisible-minorities and visible-minorities, but they did find evidence for a higher probability of unemployment in visible-minorities (for both genders). This may be suggestive of a longstanding pattern of poorer employment prospects for visible-minorities (at least in their early-careers), so this further builds a case for the replication of these studies. Moreover, this study has hinted that (amongst postsecondary graduates in their early-careers) the Black males may not experience an earnings penalty after controlling for several sociodemographic variables especially educational achievements. To the best of my knowledge, this has not been found in previous studies on similar topics, so this finding should especially be further explored. Overall, due to the small sample sizes in this study, along with the survey covering a narrow population segment, the findings in this paper's analyses are perhaps better construed as "hints" for future researchers, rather than "conclusions" in and of themselves.

With that said, this study stresses the importance of analyzing the ethno-racial groups' unemployment rates, and not just focusing on their earnings. Much of the previous research has 
shown that generation 1.5+ visible-minorities, especially the Chinese and South Asians, show far lower earnings disparities than those experienced by their first-generation counterparts. However, that is for those who obtain employment in the first place. If the findings of this study hold true, then policies should be targeted towards helping visible-minorities (particularly recent graduates) finding employment first, before focusing on subsequent concerns about pay equity, the "Glass Ceiling", the "Sticky Floor", etc. An ideal place to start can be with the widespread implementation of 'blind hiring' practices where removing "ethnic" indicators from minorities' resumes can increase their chances of obtaining an interview (Aslund \& Skans, 2012). Then in the interview stages, conducting more formalized and structured interviews may help reduce racial bias (de Kock \& Hauptfleisch, 2018). Moreover, the federal government can consider better enforcement of Employment Equity legislation, and perhaps consider extending it to sectors other than just the federal-public sector, because there is some evidence that this policy has benefitted visibleminorities (Jain \& Lawler, 2004). 


\section{APPENDIX}

Appendix 1: Regression 1a: Gender-Pooled Analysis of Income

Regression 1 (OLS): (Ln)Annualized Income-at-Survey; $\mathrm{n}=11,149$; using listwise-deletion method

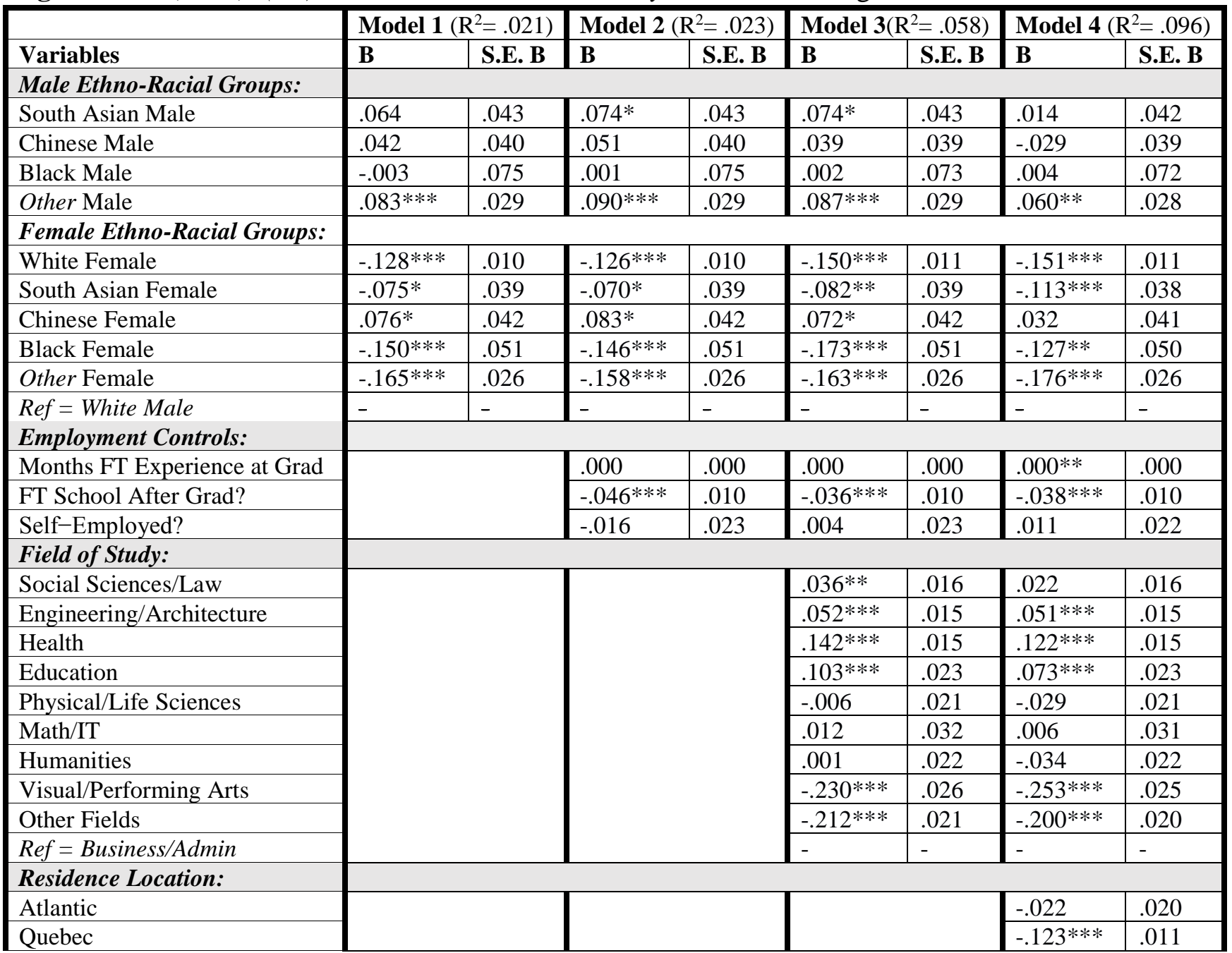




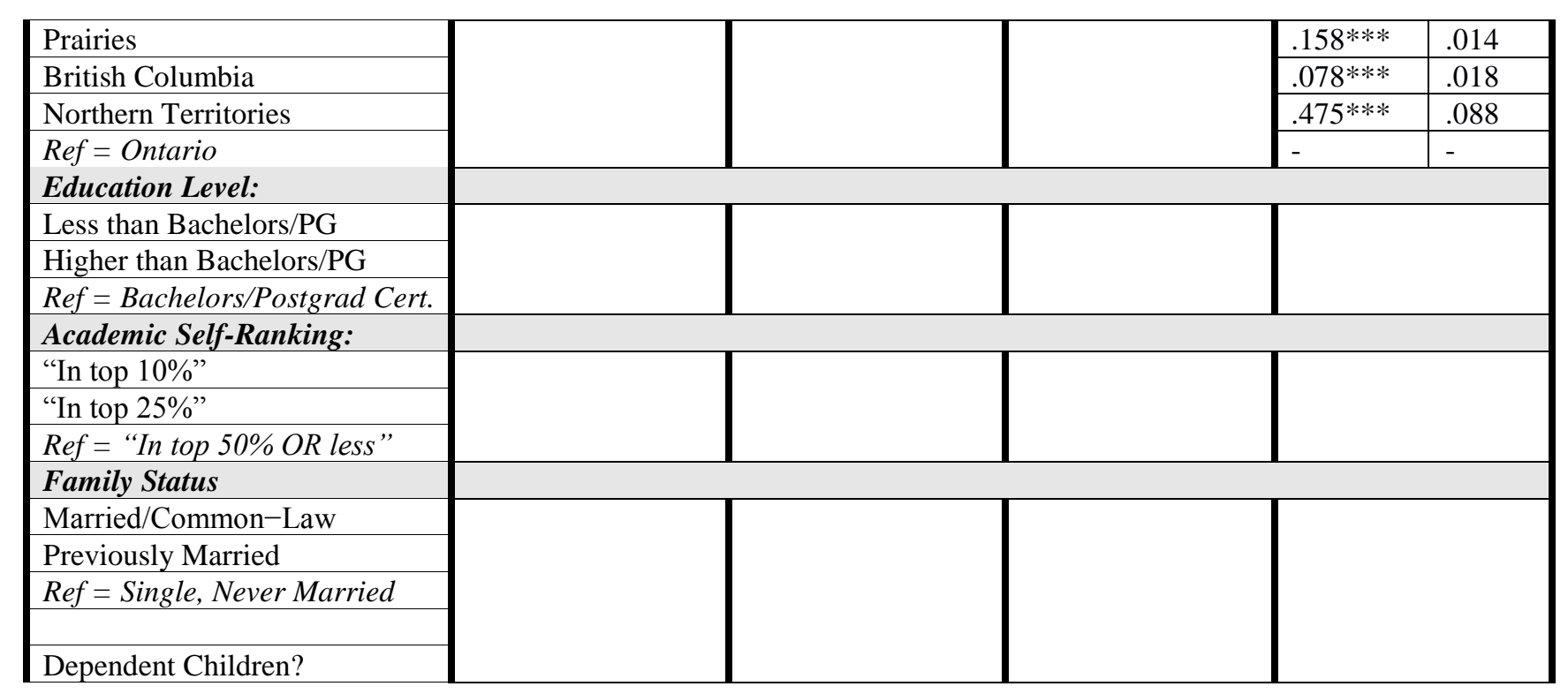

\begin{tabular}{|c|c|c|c|c|c|c|}
\hline \multirow[b]{2}{*}{ Variables } & \multicolumn{2}{|c|}{ Model $5\left(\mathrm{R}^{2}=.196\right)$} & \multicolumn{2}{|c|}{ Model $6\left(\mathrm{R}^{2}=.198\right)$} & \multicolumn{2}{|c|}{ Model $7\left(\mathrm{R}^{2}=.205\right)$} \\
\hline & B & S.E. B & B & S.E. B & B & S.E. B \\
\hline \multicolumn{7}{|l|}{ Male Ethno-Racial Groups: } \\
\hline South Asian Male & -.048 & .040 & -.037 & .040 & -.036 & .039 \\
\hline Chinese Male & $-.062 *$ & .037 & $-.062 *$ & .037 & -.044 & .037 \\
\hline Black Male & .092 & .068 & .112 & .068 & $.118 *$ & .068 \\
\hline Other Male & .023 & .027 & .028 & .027 & .028 & .027 \\
\hline \multicolumn{7}{|l|}{ Female Ethno-Racial Groups: } \\
\hline White Female & $-.143 * * *$ & .010 & $-.145 * * *$ & .010 & $-.150 * * *$ & .010 \\
\hline South Asian Female & $-.111 * * *$ & .036 & $-.111 * * *$ & .036 & $-.103 * * *$ & .036 \\
\hline Chinese Female & -.043 & .039 & -.043 & .039 & -.034 & .039 \\
\hline Black Female & $-.135 * * *$ & .047 & $-.131 * * *$ & .047 & $-.106 * *$ & .047 \\
\hline Other Female & $-.185 * * *$ & .024 & $-.184 * * *$ & .024 & $-.177 * * *$ & .024 \\
\hline Ref $=$ White Male & - & - & - & - & - & - \\
\hline \multicolumn{7}{|l|}{ Employment Controls: } \\
\hline Months FT Experience at Grad & $.000 * * *$ & .000 & $.000 * * *$ & .000 & $.000 * * *$ & .000 \\
\hline FT School After Grad? & $-.041 * * *$ & .009 & $-.043 * * *$ & .009 & $-.036 * * *$ & .009 \\
\hline Self-Employed? & $-.036 *$ & .021 & -.034 & .021 & -.032 & .021 \\
\hline
\end{tabular}




\begin{tabular}{|c|c|c|c|c|c|c|}
\hline \multicolumn{7}{|l|}{ Field of Study: } \\
\hline Social Sciences/Law & $-.044 * * *$ & .015 & $-.042 * * *$ & .015 & $-.041 * * *$ & .015 \\
\hline Engineering/Architecture & $.137 * * *$ & .014 & $.134 * * *$ & .014 & $.130 * * *$ & .014 \\
\hline Health & $.129 * * *$ & .014 & $.131 * * *$ & .014 & $.126 * * *$ & .014 \\
\hline Education & -.030 & .022 & -.035 & .022 & $-.037 *$ & .022 \\
\hline Physical/Life Sciences & $-.099 * * *$ & .020 & $-.097 * * *$ & .020 & $-.098 * * *$ & .020 \\
\hline Math/IT & .006 & .030 & .006 & .030 & .008 & .029 \\
\hline Humanities & $-.131 * * *$ & .021 & $-.131 * * *$ & .021 & $-.133 * * *$ & .021 \\
\hline Visual/Performing Arts & $-.222 * * *$ & .024 & $-.223 * * *$ & .024 & $-.219 * * *$ & .024 \\
\hline Other Fields & $-.068 * * *$ & .020 & $-.069 * * *$ & .020 & $-.069 * * *$ & .019 \\
\hline Ref $=$ Business $/$ Admin & - & - & - & - & - & - \\
\hline \multicolumn{7}{|l|}{ Residence Location: } \\
\hline Atlantic & $-.034 *$ & .019 & $-.034 *$ & .019 & $-.038 * *$ & .019 \\
\hline Quebec & $-.102 * * *$ & .011 & $-.097 * * *$ & .011 & $-.106 * * *$ & .011 \\
\hline Prairies & $.154 * * *$ & .013 & $.156 * * *$ & .013 & $.152 * * *$ & .013 \\
\hline British Columbia & $.063 * * *$ & .017 & $.061 * * *$ & .017 & $.056 * * *$ & .016 \\
\hline Northern Territories & $.416 * * *$ & .083 & $.415^{* * *}$ & .083 & $.399 * * *$ & .083 \\
\hline Ref $=$ Ontario & - & - & - & - & - & - \\
\hline \multicolumn{7}{|l|}{ Education Level: } \\
\hline Less than Bachelors/PG & $-.284 * * *$ & .010 & $-.295 * * *$ & .011 & $-.288 * * *$ & .011 \\
\hline Higher than Bachelors/PG & $.256 * * *$ & .017 & $.248 * * *$ & .017 & $.234 * * *$ & .017 \\
\hline Ref = Bachelors/Postgrad Cert. & - & - & - & - & - & - \\
\hline \multicolumn{7}{|l|}{ Academic Self-Ranking: } \\
\hline "In top $10 \% "$ & & & $.065 * * *$ & .013 & $.063 * * *$ & .013 \\
\hline "In top $25 \% "$ & & & $.030 * *$ & .012 & $.030 * *$ & .012 \\
\hline Ref $=$ "In top 50\% OR less" & & & - & - & - & - \\
\hline \multicolumn{7}{|l|}{ Family Status } \\
\hline Married/Common-Law & & & & & $.083 * * *$ & .010 \\
\hline Previously Married & & & & & -.046 & .029 \\
\hline Ref $=$ Single, Never Married & & & & & - & - \\
\hline Dependent Children? & & & & & -.015 & .013 \\
\hline
\end{tabular}


Appendix 2: Regression 1b: Males' Analysis of Income

Regression 1b (OLS): (Ln)Annualized Income-at-Survey; $\mathrm{n}=5267$; using listwise-deletion method

\begin{tabular}{|c|c|c|c|c|c|c|c|c|}
\hline \multirow{2}{*}{ Variables } & \multicolumn{2}{|c|}{ Model $1\left(\mathrm{R}^{2}=.002\right)$} & \multicolumn{2}{|c|}{ Model $2\left(\mathrm{R}^{2}=.006\right)$} & \multicolumn{2}{|c|}{ Model 3( $\left.\mathrm{R}^{2}=.036\right)$} & \multicolumn{2}{|c|}{ Model 4 $\left(\mathrm{R}^{2}=.091\right)$} \\
\hline & B & S.E. B & B & S.E. B & B & S.E. B & B & S.E. B \\
\hline \multicolumn{9}{|l|}{ Male Ethno-Racial Groups: } \\
\hline South Asian Male & .064 & .046 & $.077 *$ & .046 & $.088^{*}$ & .046 & .011 & .045 \\
\hline Chinese Male & .042 & .043 & .051 & .043 & .045 & .043 & -.038 & .042 \\
\hline Black Male & -.003 & .080 & .002 & .080 & .010 & .079 & .010 & .077 \\
\hline Other Male & $.083 * * *$ & .031 & $.091 * * *$ & .031 & $.084 * * *$ & .031 & .048 & .031 \\
\hline Ref $=$ White Male & - & - & - & - & - & - & - & - \\
\hline \multicolumn{9}{|l|}{ Employment Controls: } \\
\hline Months FT Experience at Grad & & & .000 & .000 & .000 & .000 & $.000 * *$ & .000 \\
\hline FT School After Grad? & & & $-.073 * * *$ & .016 & $-.074 * * *$ & .016 & $-.080 * * *$ & .016 \\
\hline Self-Employed? & & & .008 & .034 & .019 & .033 & .019 & .032 \\
\hline \multicolumn{9}{|l|}{ Field of Study: } \\
\hline Social Sciences/Law & & & & & $.093 * * *$ & .028 & $.064 * *$ & .028 \\
\hline Engineering/Architecture & & & & & $.049 * *$ & .021 & $.040 * *$ & .020 \\
\hline Health & & & & & $.156^{* * * *}$ & .034 & $.125 * * *$ & .033 \\
\hline Education & & & & & $.122 * *$ & .049 & .056 & .048 \\
\hline Physical/Life Sciences & & & & & -.025 & .032 & $-.053 *$ & .032 \\
\hline Math/IT & & & & & -.012 & .042 & -.028 & .041 \\
\hline Humanities & & & & & .013 & .039 & -.046 & .038 \\
\hline Visual/Performing Arts & & & & & $-.277 * * *$ & .043 & $-.329 * * *$ & .042 \\
\hline Other Fields & & & & & $-.178^{* * *}$ & .030 & $-.172 * * *$ & .030 \\
\hline Ref $=$ Business $/$ Admin & & & & & - & - & - & - \\
\hline \multicolumn{9}{|l|}{ Residence Location: } \\
\hline Atlantic & & & & & & & -.036 & .032 \\
\hline Quebec & & & & & & & $-.162 * * *$ & .017 \\
\hline Prairies & & & & & & & $.216^{* * * *}$ & .022 \\
\hline British Columbia & & & & & & & $.072 * * *$ & .027 \\
\hline Northern Territories & & & & & & & $.349 * * *$ & .128 \\
\hline Ref $=$ Ontario & & & & & & & - & - \\
\hline \multicolumn{9}{|l|}{ Education Level: } \\
\hline \multicolumn{9}{|l|}{ Less than Bachelors/PG } \\
\hline \multicolumn{9}{|l|}{ Higher than Bachelors/PG } \\
\hline Ref $=$ Bachelors $/$ Postgrad Cert. & & & & & & & & \\
\hline Academic Self-Ranking: & & & & & & & & \\
\hline
\end{tabular}




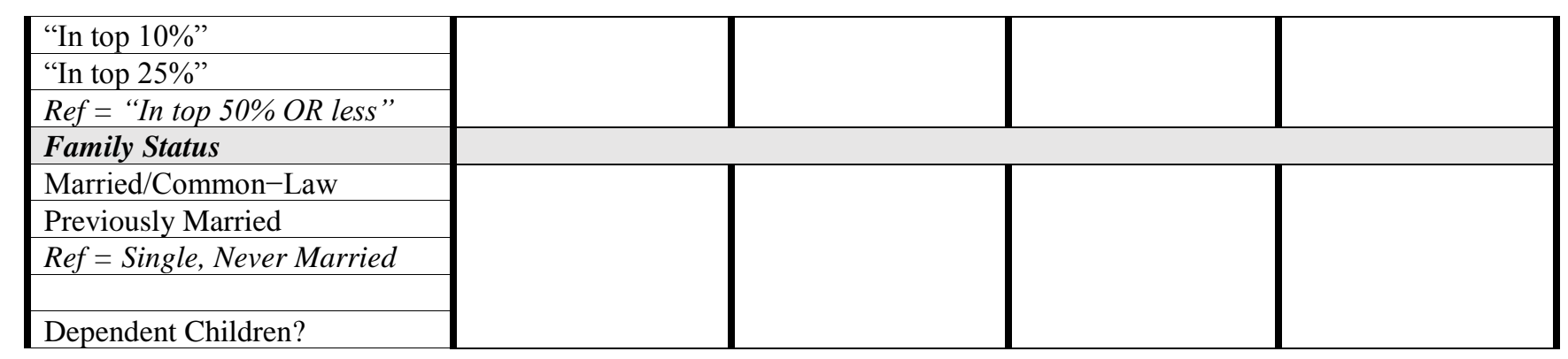

\begin{tabular}{|c|c|c|c|c|c|c|}
\hline \multirow[b]{2}{*}{ Variables } & \multicolumn{2}{|c|}{ Model $5\left(\mathrm{R}^{2}=.149\right)$} & \multicolumn{2}{|c|}{ Model $6\left(\mathrm{R}^{2}=.152\right)$} & \multicolumn{2}{|c|}{ Model $7\left(\mathrm{R}^{2}=.161\right)$} \\
\hline & B & S.E. B & B & S.E. B & B & S.E. B \\
\hline \multicolumn{7}{|l|}{ Male Ethno-Racial Groups: } \\
\hline South Asian Male & -.042 & .044 & -.028 & .044 & -.025 & .044 \\
\hline Chinese Male & -.062 & .041 & -.061 & .041 & -.038 & .041 \\
\hline Black Male & .091 & .075 & .120 & .075 & $.125^{*}$ & .075 \\
\hline Other Male & .024 & .030 & .031 & .030 & .030 & .029 \\
\hline Ref $=$ White Male & - & - & - & - & - & - \\
\hline \multicolumn{7}{|l|}{ Employment Controls: } \\
\hline Months FT Experience at Grad & $.000 * * *$ & .000 & $.000 * * *$ & .000 & $.000 *$ & .000 \\
\hline FT School After Grad? & $-.069 * * *$ & .015 & $-.071 * * *$ & .015 & $-.061 * * *$ & .015 \\
\hline Self-Employed? & -.006 & .031 & .000 & .031 & .012 & .031 \\
\hline \multicolumn{7}{|l|}{ Field of Study: } \\
\hline Social Sciences/Law & -.001 & .027 & .003 & .027 & .000 & .027 \\
\hline Engineering/Architecture & $.144 * * *$ & .020 & $.138 * * *$ & .020 & $.132 * * *$ & .020 \\
\hline Health & $.122 * * *$ & .032 & $.119 * * *$ & .032 & $.107 * * *$ & .032 \\
\hline Education & -.016 & .047 & -.020 & .047 & -.016 & .046 \\
\hline Physical/Life Sciences & $-.084 * * *$ & .031 & $-.083 * * *$ & .031 & $-.087 * * *$ & .030 \\
\hline Math/IT & .011 & .039 & .010 & .039 & .011 & .039 \\
\hline Humanities & $-.117 * * *$ & .037 & $-.123 * * *$ & .037 & $-.128 * * *$ & .037 \\
\hline Visual/Performing Arts & $-.254 * * *$ & .041 & $-.256 * * *$ & .041 & $-.246 * * *$ & .041 \\
\hline Other Fields & -.029 & .030 & -.029 & .030 & -.032 & .030 \\
\hline Ref $=$ Business $/$ Admin & - & - & - & - & - & - \\
\hline \multicolumn{7}{|l|}{ Residence Location: } \\
\hline Atlantic & -.036 & .031 & -.034 & .031 & -.034 & .031 \\
\hline Quebec & $-.139 * * *$ & .017 & $-.133 * * *$ & .017 & $-.136 * * *$ & .017 \\
\hline Prairies & $.208 * * *$ & .022 & $.213 * * *$ & .022 & $.215 * * *$ & .021 \\
\hline
\end{tabular}




\begin{tabular}{|c|c|c|c|c|c|c|}
\hline British Columbia & $.063 * *$ & .026 & $.062 * *$ & .026 & $.057 * *$ & .026 \\
\hline Northern Territories & $.363 * * *$ & .124 & $.369 * * *$ & .124 & $.356^{* * *}$ & .123 \\
\hline Ref $=$ Ontario & - & - & - & - & $2=$ & - \\
\hline \multicolumn{7}{|l|}{ Education Level: } \\
\hline Less than Bachelors/PG & $-.248 * * *$ & 017 & $-.267 * * *$ & .018 & $-.260 * * *$ & .018 \\
\hline Higher than Bachelors/PG & $.235 * * *$ & .030 & $.219 * * *$ & .030 & $.197 * * *$ & .030 \\
\hline Ref $=$ Bachelors/Postgrad Cert. & - & - & - & - & - & - \\
\hline \multicolumn{7}{|l|}{ Academic Self-Ranking: } \\
\hline "In top 10\%" & & & $.090^{* * * *}$ & .020 & $.081^{* * * *}$ & .020 \\
\hline "In top 25\%" & & & $.050 * * *$ & .019 & $.044 * *$ & .019 \\
\hline Ref = "In top 50\% OR less" & & & - & - & - & - \\
\hline \multicolumn{7}{|l|}{ Family Status } \\
\hline Married/Common-Law & & & & & $.100 * * *$ & .016 \\
\hline Previously Married & & & & & .008 & 058 \\
\hline Ref $=$ Single, Never Married & & & & & - & - \\
\hline Dependent Children? & & & & & .023 & .022 \\
\hline
\end{tabular}

${ }^{*} \mathrm{p}<0.1 ; * * \mathrm{p}<0.05 ; * * * \mathrm{p}<0.01$ 
Appendix 3: Regression 1b: Females' Analysis of Income

Regression 1b (OLS): (Ln)Annualized Income-at-Survey; $\mathrm{n}=5882$; using listwise-deletion method

\begin{tabular}{|c|c|c|c|c|c|c|c|c|}
\hline & \multicolumn{2}{|c|}{ Model $1\left(\mathrm{R}^{2}=.005\right)$} & \multicolumn{2}{|c|}{ Model 2 $\left(\mathrm{R}^{2}=.007\right)$} & \multicolumn{2}{|c|}{ Model 3( $\left.\mathrm{R}^{2}=.055\right)$} & \multicolumn{2}{|c|}{ Model $4\left(\mathrm{R}^{2}=.080\right)$} \\
\hline Variables & B & S.E. B & B & S.E. B & B & S.E. B & B & S.E. B \\
\hline \multicolumn{9}{|l|}{ Female Ethno-Racial Groups: } \\
\hline South Asian Female & .053 & .037 & .057 & .037 & $.070 *$ & .036 & .047 & .036 \\
\hline Chinese Female & $.204 * * *$ & .039 & $.210^{* * * *}$ & .039 & $.210 * * *$ & .039 & $.178^{* * *}$ & .038 \\
\hline Black Female & -.023 & .048 & -.021 & .048 & -.021 & .047 & .015 & .046 \\
\hline Other Female & -.037 & .024 & -.032 & .024 & -.017 & .024 & -.026 & .024 \\
\hline Ref $=$ White Female & - & - & - & - & - & - & - & - \\
\hline \multicolumn{9}{|l|}{ Employment Controls: } \\
\hline Months FT Experience at Grad & & & $.000^{*}$ & .000 & 0.00 & .000 & 0.000 & .000 \\
\hline FT School After Grad? & & & $-.023 *$ & .013 & -.007 & .013 & -.007 & .012 \\
\hline Self-Employed? & & & -.046 & .031 & -.014 & .031 & -.005 & .030 \\
\hline \multicolumn{9}{|l|}{ Field of Study: } \\
\hline Social Sciences/Law & & & & & .004 & .019 & -.002 & .019 \\
\hline Engineering/Architecture & & & & & $.082 * * *$ & .029 & $.085^{* * *}$ & .029 \\
\hline Health & & & & & $.139 * * *$ & .017 & $.127 * * *$ & .017 \\
\hline Education & & & & & $.096^{* * *}$ & .025 & $.079^{* * *}$ & .025 \\
\hline Physical/Life Sciences & & & & & .012 & .028 & -.008 & .028 \\
\hline Math/IT & & & & & .070 & .054 & .069 & .054 \\
\hline Humanities & & & & & -.004 & .026 & -.024 & .026 \\
\hline Visual/Performing Arts & & & & & $-.202 * * *$ & .031 & $-.212 * * *$ & .030 \\
\hline Other Fields & & & & & $-.257 * * *$ & .029 & $-.245 * * *$ & .028 \\
\hline $\operatorname{Ref}=$ Business $/$ Admin & & & & & - & - & - & - \\
\hline \multicolumn{9}{|l|}{ Residence Location: } \\
\hline Atlantic & & & & & & & -.012 & .024 \\
\hline Quebec & & & & & & & $-.084 * * *$ & .015 \\
\hline Prairies & & & & & & & $.113^{* * *}$ & 018 \\
\hline British Columbia & & & & & & & $.089 * * *$ & .023 \\
\hline Northern Territories & & & & & & & $.581 * * *$ & 121 \\
\hline Ref $=$ Ontario & & & & & & & - & - \\
\hline \multicolumn{9}{|l|}{ Education Level: } \\
\hline Less than Bachelors/PG & & & & & & & & \\
\hline $\begin{array}{l}\text { Higher than Bachelors/PG } \\
\text { Ref }=\text { Bachelors/Postgrad Cert. }\end{array}$ & & & & & & & & \\
\hline
\end{tabular}




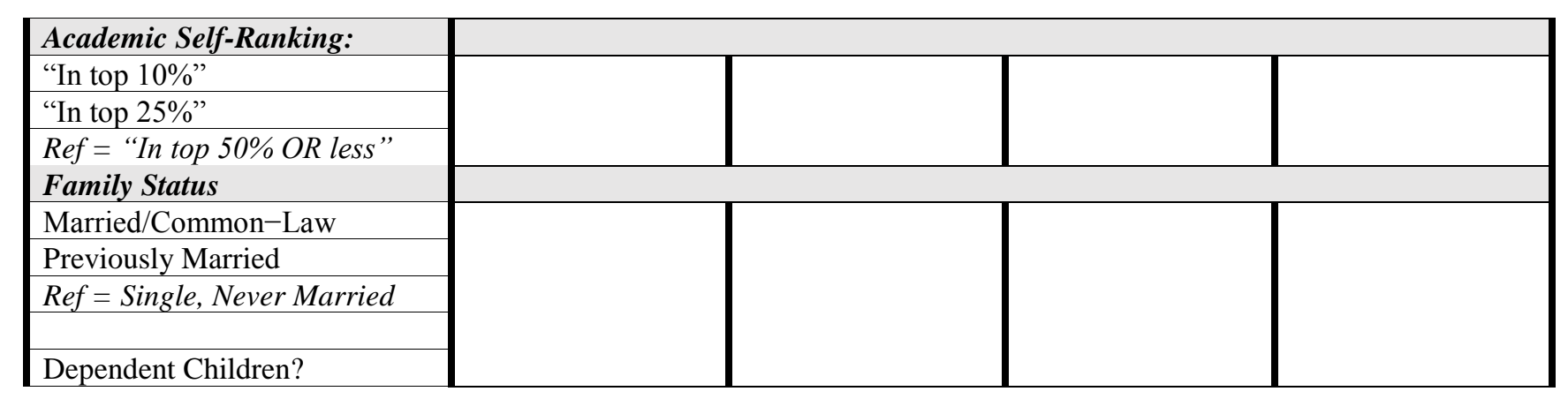

\begin{tabular}{|c|c|c|c|c|c|c|}
\hline \multirow[b]{2}{*}{ Variables } & \multicolumn{2}{|c|}{ Model $5\left(\mathrm{R}^{2}=.234\right)$} & \multicolumn{2}{|c|}{ Model $6\left(\mathrm{R}^{2}=.235\right)$} & \multicolumn{2}{|c|}{ Model $7\left(\mathrm{R}^{2}=.241\right)$} \\
\hline & B & S.E. B & B & S.E. B & $\mathbf{B}$ & S.E. B \\
\hline \multicolumn{7}{|l|}{ Female Ethno-Racial Groups: } \\
\hline South Asian Female & .034 & .033 & .036 & .033 & .047 & .033 \\
\hline Chinese Female & $.098 * * *$ & .035 & $.100 * * *$ & .035 & $.111 * * *$ & .035 \\
\hline Black Female & -.007 & .042 & -.002 & .042 & .024 & .042 \\
\hline Other Female & $-.044 * *$ & .022 & $-.042 *$ & .022 & -.033 & .022 \\
\hline Ref $=$ White Female & - & - & - & - & - & - \\
\hline \multicolumn{7}{|l|}{ Employment Controls: } \\
\hline Months FT Experience at Grad & $.000 * * *$ & .000 & $.000 * * *$ & .000 & $.000 * * *$ & .000 \\
\hline FT School After Grad? & $-.020 *$ & .012 & $-.022 *$ & .012 & -.018 & .012 \\
\hline Self-Employed? & $-.069 * *$ & .028 & $-.071 * *$ & .028 & $-.074 * * *$ & .028 \\
\hline \multicolumn{7}{|l|}{ Field of Study: } \\
\hline Social Sciences/Law & $-.072 * * *$ & .017 & $-.070 * * *$ & .017 & $-.069 * * *$ & .017 \\
\hline Engineering/Architecture & $.086 * * *$ & .026 & $.089 * * *$ & .026 & $.085 * * *$ & .026 \\
\hline Health & $.126^{* * *}$ & .015 & $.129 * * *$ & .015 & $.125 * * *$ & .015 \\
\hline Education & $-.049 * *$ & .023 & $-.052 * *$ & .023 & $-.053 * *$ & .023 \\
\hline Physical/Life Sciences & $-.116 * * *$ & .026 & $-.115 * * *$ & .026 & $-.116 * * *$ & .025 \\
\hline Math/IT & -.009 & .049 & -.007 & .049 & -.011 & .049 \\
\hline Humanities & $-.142 * * *$ & .024 & $-.140 * * *$ & .024 & $-.142 * * *$ & .024 \\
\hline Visual/Performing Arts & $-.217 * * *$ & .028 & $-.217 * * *$ & .028 & $-.217 * * *$ & .028 \\
\hline Other Fields & $-.132 * * *$ & .026 & $-.132 * * *$ & .026 & $-.132 * * *$ & .026 \\
\hline Ref $=$ Business $/$ Admin & - & - & - & - & - & - \\
\hline \multicolumn{7}{|l|}{ Residence Location: } \\
\hline Atlantic & -.034 & .022 & -.035 & .022 & $-.040 *$ & .022 \\
\hline Quebec & $-.067 * * *$ & .013 & $-.064 * * *$ & .013 & $-.073 * * *$ & .013 \\
\hline
\end{tabular}




\begin{tabular}{|c|c|c|c|c|c|c|}
\hline Prairies & $.112 * * *$ & .016 & $.113 * * *$ & .016 & $.103 * * *$ & .016 \\
\hline British Columbia & $.063 * * *$ & .021 & $.061 * * *$ & .021 & $.054 * * *$ & .021 \\
\hline Northern Territories & $.460 * * *$ & .111 & $.454 * * *$ & .111 & $.449 * * *$ & .110 \\
\hline Ref $=$ Ontario & - & - & - & - & - & - \\
\hline \multicolumn{7}{|l|}{ Education Level: } \\
\hline Less than Bachelors/PG & $-.311 * * *$ & .013 & $-.317 * * *$ & .013 & $-.306 * * *$ & .013 \\
\hline Higher than Bachelors/PG & $.265 * * *$ & .019 & $.261 * * *$ & .019 & $.256 * * *$ & .019 \\
\hline Ref $=$ Bachelors/Postgrad Cert. & - & - & - & - & - & - \\
\hline \multicolumn{7}{|l|}{ Academic Self-Ranking: } \\
\hline "In top $10 \% "$ & & & $.044 * * *$ & .016 & $.046 * * *$ & .016 \\
\hline "In top $25 \% "$ & & & .015 & .015 & .018 & .015 \\
\hline Ref $=$ "In top 50\% OR less" & & & - & - & - & - \\
\hline \multicolumn{7}{|l|}{ Family Status } \\
\hline Married/Common-Law & & & & & $.067 * * *$ & .012 \\
\hline Previously Married & & & & & -.051 & .032 \\
\hline Ref $=$ Single, Never Married & & & & & - & - \\
\hline Dependent Children? & & & & & $-.048 * * *$ & .015 \\
\hline
\end{tabular}

${ }^{*} \mathrm{p}<0.1 ; * * \mathrm{p}<0.05 ; * * * \mathrm{p}<0.01$ 
Appendix 4: Regression 2a: Gender-Pooled Analysis of Unemployment Odds

Regression 2 (Binary Logistic): Employed(0)/Unemployed(1); Employed (and Self-Employed) $\rightarrow \mathrm{n}=13,687$; Unemployed $\rightarrow \mathrm{n}=770$

\begin{tabular}{|c|c|c|c|c|c|c|c|c|c|c|c|c|}
\hline \multirow[b]{2}{*}{ Variables } & \multicolumn{3}{|c|}{ Model 1 (Pseudo $\mathrm{R}^{2}=.019$ ) } & \multicolumn{3}{|c|}{ Model 2 (Pseudo $\mathrm{R}^{2}=.027$ ) } & \multicolumn{3}{|c|}{ Model 3 (Pseudo $\left.\mathrm{R}^{2}=.051\right)$} & \multicolumn{3}{|c|}{ Model 4 (Pseudo $\mathrm{R}^{2}=.058$ ) } \\
\hline & B & S.E. B & $\operatorname{Exp}(B)$ & B & S.E. B & $\operatorname{Exp}(B)$ & B & S.E. B & $\operatorname{Exp}(B)$ & B & S.E. B & $\operatorname{Exp}(B)$ \\
\hline \multicolumn{13}{|l|}{ Male Ethno-Racial Groups: } \\
\hline South Asian Male & 1.483 & .189 & $4.406 * * *$ & 1.553 & .190 & $4.727 * * *$ & 1.659 & .194 & $5.254 * * *$ & 1.790 & .199 & $5.989 * * *$ \\
\hline Chinese Male & .265 & .294 & 1.304 & .338 & .295 & 1.402 & .525 & .297 & $1.691 *$ & .689 & .302 & $1.992 * *$ \\
\hline Black Male & .518 & .481 & 1.679 & .578 & .482 & 1.782 & .682 & .485 & 1.978 & .670 & .487 & 1.955 \\
\hline Other Male & .604 & .178 & $1.830 * * *$ & .617 & .179 & $1.854 * * *$ & .774 & .181 & $2.168 * * *$ & .844 & .183 & $2.326 * * *$ \\
\hline \multicolumn{13}{|l|}{ Female Ethno-Racial Groups: } \\
\hline White Female & -.197 & .084 & $.821 * *$ & -.197 & .084 & $.821 * *$ & -.012 & .093 & .988 & -.012 & .094 & .988 \\
\hline South Asian Female & .094 & .303 & 1.098 & .190 & .304 & 1.209 & .411 & .309 & 1.508 & .485 & .311 & 1.625 \\
\hline Chinese Female & -.985 & .511 & $.373 *$ & -.914 & .512 & $.401 *$ & -.781 & .515 & .458 & -.689 & .516 & .502 \\
\hline Black Female & -.114 & .386 & .892 & -.110 & .386 & .896 & .083 & .391 & 1.086 & .044 & .392 & 1.045 \\
\hline Other Female & .603 & .160 & $1.827 * * *$ & .626 & .161 & $1.871 * * *$ & .760 & .167 & $2.137 * * *$ & .799 & .168 & $2.222 * * *$ \\
\hline Ref $=$ White Male & - & - & - & - & - & - & - & - & - & - & - & - \\
\hline \multicolumn{13}{|l|}{ Employment Controls: } \\
\hline Months FT Experience at Grad & & & & .003 & .000 & $1.003 * * *$ & .003 & .000 & $1.003 * * *$ & .003 & .000 & $1.003 * * *$ \\
\hline FT School After Grad? & & & & .342 & .077 & $1.408 * * *$ & .394 & .080 & $1.483 * * *$ & .394 & .080 & $1.483 * * *$ \\
\hline \multicolumn{13}{|l|}{ Field of Study: } \\
\hline Social Sciences/Law & & & & & & & -.111 & .154 & .895 & -.089 & .155 & .915 \\
\hline Engineering/Architecture & & & & & & & .568 & .128 & $1.765 * * *$ & .565 & .128 & $1.759 * * *$ \\
\hline Health & & & & & & & -.320 & .160 & $.726 * *$ & -.297 & .160 & $.743^{*}$ \\
\hline Education & & & & & & & 1.004 & .158 & $2.728 * * *$ & 1.043 & .159 & $2.839 * * *$ \\
\hline Physical/Life Sciences & & & & & & & .443 & .170 & $1.557 * * *$ & .477 & .171 & $1.611 * * *$ \\
\hline Math/IT & & & & & & & .281 & .273 & 1.324 & .281 & .273 & 1.324 \\
\hline Humanities & & & & & & & .648 & .157 & $1.911 * * *$ & .699 & .159 & $2.012 * * *$ \\
\hline Visual/Performing Arts & & & & & & & .549 & .191 & $1.732 * * *$ & .576 & .191 & $1.780 * * *$ \\
\hline Other Fields & & & & & & & .935 & .144 & $2.547 * * *$ & .914 & .144 & $2.495 * * *$ \\
\hline Ref $=$ Business $/$ Admin & & & & & & & - & - & - & - & - & - \\
\hline \multicolumn{13}{|l|}{ Residence Location: } \\
\hline Atlantic & & & & & & & & & & .413 & .151 & $1.512 * * *$ \\
\hline Quebec & & & & & & & & & & .186 & .092 & $1.205 * *$ \\
\hline Prairies & & & & & & & & & & -.509 & .146 & $.601 * * *$ \\
\hline British Columbia & & & & & & & & & & -.116 & .146 & .890 \\
\hline Northern Territories & & & & & & & & & & -1.251 & 1.519 & .286 \\
\hline Ref $=$ Ontario & & & & & & & & & & - & - & - \\
\hline
\end{tabular}




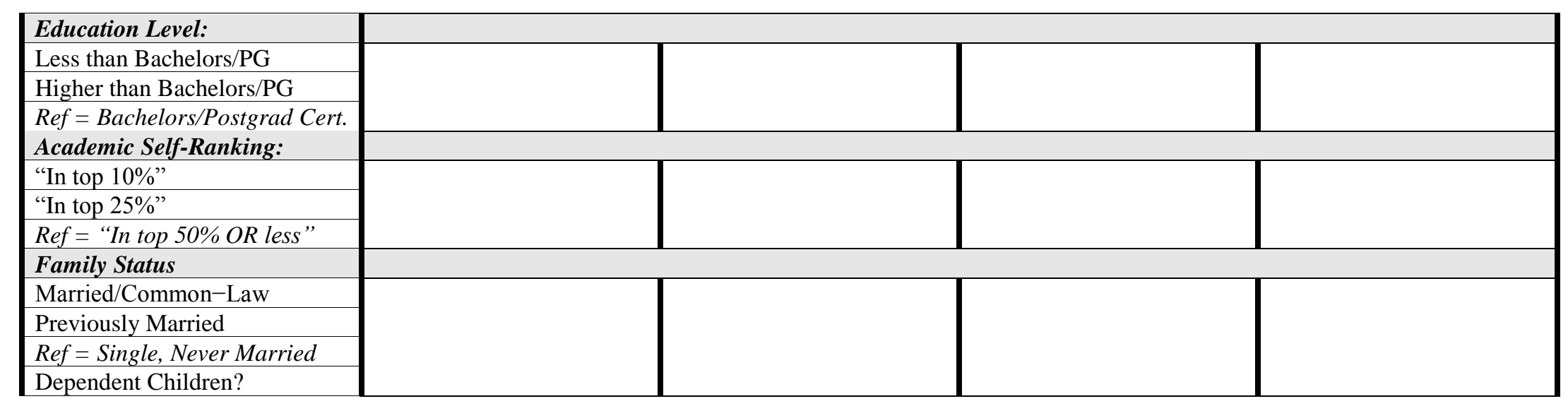

\begin{tabular}{|c|c|c|c|c|c|c|c|c|c|}
\hline \multirow[b]{2}{*}{ Variables } & \multicolumn{3}{|c|}{ Model 5 (Pseudo $\mathrm{R}^{2}=.062$ ) } & \multicolumn{3}{|c|}{ Model 6 (Pseudo $\mathrm{R}^{2}=.063$ ) } & \multicolumn{3}{|c|}{ Model 7 (Pseudo $\left.\mathrm{R}^{2}=.070\right)$} \\
\hline & B & S.E. B & $\operatorname{Exp}(B)$ & B & S.E. B & $\operatorname{Exp}(B)$ & B & S.E. B & $\operatorname{Exp}(B)$ \\
\hline \multicolumn{10}{|l|}{ Male Ethno-Racial Groups: } \\
\hline South Asian Male & 1.512 & 1.512 & $6.228 * * *$ & 1.794 & .201 & $6.014 * * *$ & 1.774 & .201 & $5.893 * * *$ \\
\hline Chinese Male & 1.205 & 1.205 & $2.107 * *$ & .709 & .304 & $2.033 * *$ & .628 & .305 & $1.875 * *$ \\
\hline Black Male & .601 & .601 & 1.786 & .541 & .488 & 1.718 & .497 & .488 & 1.643 \\
\hline Other Male & .890 & .890 & $2.380 * * *$ & .847 & .184 & $2.334 * * *$ & .838 & .184 & $2.312 * * *$ \\
\hline \multicolumn{10}{|l|}{ Female Ethno-Racial Groups: } \\
\hline White Female & -.023 & .094 & .977 & -.026 & .094 & .974 & -.019 & .095 & .981 \\
\hline South Asian Female & .509 & .312 & 1.664 & .472 & .312 & 1.604 & .428 & .313 & 1.535 \\
\hline Chinese Female & -.623 & .517 & .536 & -.658 & .517 & .518 & -.707 & .518 & .493 \\
\hline Black Female & .021 & .392 & 1.021 & .034 & .392 & 1.034 & -.104 & .393 & .901 \\
\hline Other Female & .809 & .169 & $2.245 * * *$ & .787 & .169 & $2.197 * * *$ & .731 & .170 & $2.078 * * *$ \\
\hline Ref $=$ White Male & - & - & - & - & - & - & - & - & - \\
\hline \multicolumn{10}{|l|}{ Employment Controls: } \\
\hline Months FT Experience at Grad & .002 & .000 & $1.002 * * *$ & .002 & .000 & $1.002 * * *$ & .003 & .001 & $1.003 * * *$ \\
\hline FT School After Grad? & .416 & .081 & $1.516 * * *$ & .422 & .081 & $1.525 * * *$ & .389 & .082 & $1.476 * * *$ \\
\hline \multicolumn{10}{|l|}{ Field of Study: } \\
\hline Social Sciences/Law & .014 & .157 & 1.015 & .013 & .157 & 1.013 & .012 & .157 & 1.012 \\
\hline Engineering/Architecture & .480 & .130 & $1.615 * * *$ & .474 & .130 & $1.607 * * *$ & .488 & .131 & $1.629 * * *$ \\
\hline Health & -.301 & .161 & $.740 *$ & -.309 & .161 & $.734 *$ & -.288 & .161 & $.749 *$ \\
\hline Education & 1.204 & .164 & $3.335 * * *$ & 1.213 & .164 & $3.362 * * *$ & 1.233 & .165 & $3.430 * * *$ \\
\hline Physical/Life Sciences & .567 & .173 & $1.763 * * *$ & .566 & .173 & $1.762 * * *$ & .577 & .173 & $1.781 * * *$ \\
\hline
\end{tabular}




\begin{tabular}{|c|c|c|c|c|c|c|c|c|c|}
\hline Math/IT & .276 & .273 & 1.318 & .277 & .273 & 1.319 & .271 & .274 & 1.311 \\
\hline Humanities & .833 & .163 & $2.300 * * *$ & .837 & .163 & $2.310 * * *$ & .848 & .163 & $2.335 * * *$ \\
\hline Visual/Performing Arts & .568 & .191 & $1.765 * * *$ & .562 & .191 & $1.755 * * *$ & .548 & .192 & $1.730 * * *$ \\
\hline Other Fields & .786 & .147 & $2.195 * * *$ & .778 & .147 & $2.177 * * *$ & .781 & .148 & $2.183 * * *$ \\
\hline Ref $=$ Business/Admin & - & - & - & - & - & - & - & - & - \\
\hline \multicolumn{10}{|l|}{ Residence Location: } \\
\hline Atlantic & .433 & .151 & $1.542 * * *$ & .428 & .151 & $1.534 * * *$ & .446 & .152 & $1.562 * * *$ \\
\hline Quebec & .151 & .093 & 1.163 & .129 & .093 & 1.138 & .168 & .094 & $1.182 *$ \\
\hline Prairies & -.500 & .146 & $.606 * * *$ & -.515 & .146 & $.598 * * *$ & -.494 & .146 & $.610 * * *$ \\
\hline British Columbia & -.118 & .146 & .889 & -.114 & .146 & .893 & -.111 & .147 & .895 \\
\hline Northern Territories & -1.215 & 1.521 & .297 & -1.227 & 1.521 & .293 & -1.158 & 1.521 & .314 \\
\hline Ref $=$ Ontario & - & - & - & - & - & - & - & - & - \\
\hline \multicolumn{10}{|l|}{ Education Level: } \\
\hline Less than Bachelors/PG & .390 & .096 & $1.477 * * *$ & .404 & .097 & $1.498 * * *$ & .351 & .098 & $1.421 * * *$ \\
\hline Higher than Bachelors/PG & .018 & .170 & 1.018 & .039 & .170 & 1.039 & .084 & .172 & 1.088 \\
\hline Ref $=$ Bachelors/Postgrad Cert. & - & - & - & - & - & - & - & - & - \\
\hline \multicolumn{10}{|l|}{ Academic Self-Ranking: } \\
\hline "In top $10 \% "$ & & & & -.203 & .105 & $.816^{*}$ & -.194 & .105 & $.824 *$ \\
\hline "In top 25\%" & & & & -.248 & .103 & $.780 * *$ & -.250 & .104 & $.779 * *$ \\
\hline Ref $=$ "In top 50\% OR less" & & & & - & - & - & - & - & - \\
\hline \multicolumn{10}{|l|}{ Family Status } \\
\hline Married/Common-Law & & & & & & & -.495 & .096 & $.610 * * *$ \\
\hline Previously Married & & & & & & & .251 & .206 & 1.286 \\
\hline Ref $=$ Single, Never Married & & & & & & & - & - & - \\
\hline Dependent Children? & & & & & & & .229 & .117 & $1.257 *$ \\
\hline
\end{tabular}

${ }^{*} \mathrm{p}<0.1 ; * * \mathrm{p}<0.05 ; * * * \mathrm{p}<0.01$ 
Appendix 5: Regression 2b: Males'Analysis of Unemployment Odds

Regression 2 (Binary Logistic): Employed $(0) /$ Unemployed (1); Employed (and Self-Employed) $\rightarrow \mathrm{n}=6,099 ;$ Unemployed $\rightarrow \mathrm{n}=394$

\begin{tabular}{|c|c|c|c|c|c|c|c|c|c|c|c|c|}
\hline \multirow[b]{2}{*}{ Variables } & \multicolumn{3}{|c|}{ Model 1 (Pseudo $\mathrm{R}^{2}=.023$ ) } & \multicolumn{3}{|c|}{ Model 2 (Pseudo $\mathrm{R}^{2}=.028$ ) } & \multicolumn{3}{|c|}{ Model 3 (Pseudo $\mathrm{R}^{2}=.052$ ) } & \multicolumn{3}{|c|}{ Model 4 (Pseudo R²= .079) } \\
\hline & B & S.E. B & $\operatorname{Exp}(\mathbf{B})$ & B & S.E. B & $\operatorname{Exp}(B)$ & B & S.E. B & $\operatorname{Exp}(B)$ & B & S.E. B & $\operatorname{Exp}(\mathbf{B})$ \\
\hline \multicolumn{13}{|l|}{ Male Ethno-Racial Groups: } \\
\hline South Asian Male & 1.483 & .189 & $4.406 * * *$ & 1.564 & .192 & $4.779 * * *$ & 1.657 & .196 & $5.245 * * *$ & 1.971 & .213 & $7.181^{* * *}$ \\
\hline Chinese Male & .265 & 294 & 1.304 & .346 & 296 & 1.414 & .514 & .299 & $1.671 *$ & .769 & .313 & $2.158 * *$ \\
\hline Black Male & .518 & .481 & 1.679 & .576 & .482 & 1.778 & .643 & .487 & 1.903 & .713 & .492 & 2.041 \\
\hline Other Male & .604 & .178 & $1.830 * * *$ & .639 & .180 & $1.894 * * *$ & .804 & .183 & $2.233 * * *$ & .961 & .188 & $2.613 * * *$ \\
\hline Ref $=$ White Male & - & - & - & - & - & - & - & - & - & - & - & - \\
\hline \multicolumn{13}{|l|}{ Employment Controls: } \\
\hline Months FT Experience at Grad & & & & .002 & .001 & $1.002 * * *$ & .002 & .001 & $1.002 * * *$ & .002 & .001 & $1.002 * *$ \\
\hline FT School After Grad? & & & & .116 & .110 & 1.123 & .225 & .115 & $1.253 *$ & .220 & .116 & $1.246^{*}$ \\
\hline \multicolumn{13}{|l|}{ Field of Study: } \\
\hline Social Sciences/Law & & & & & & & -.418 & .278 & .659 & -.347 & .279 & .707 \\
\hline Engineering/Architecture & & & & & & & .566 & .163 & $1.761 * * *$ & .543 & .164 & $1.722 * * *$ \\
\hline Health & & & & & & & -.309 & 315 & .734 & -.211 & .316 & .810 \\
\hline Education & & & & & & & 1.211 & .278 & $3.357 * * *$ & 1.336 & .282 & $3.805^{* * *}$ \\
\hline Physical/Life Sciences & & & & & & & .388 & .245 & 1.475 & .461 & .247 & $1.586^{*}$ \\
\hline Math/IT & & & & & & & .295 & .327 & 1.343 & .300 & .328 & 1.349 \\
\hline Humanities & & & & & & & .649 & .261 & $1.913 * *$ & .818 & .265 & $2.267 * * *$ \\
\hline Visual/Performing Arts & & & & & & & .928 & .262 & $2.531 * * *$ & 1.039 & .265 & $2.827 * * *$ \\
\hline Other Fields & & & & & & & .876 & .206 & $2.401 * * *$ & .835 & .207 & $2.306^{* * *}$ \\
\hline Ref $=$ Business $/$ Admin & & & & & & & - & - & - & - & - & - \\
\hline \multicolumn{13}{|l|}{ Residence Location: } \\
\hline Atlantic & & & & & & & & & & .804 & .223 & $2.233 * * *$ \\
\hline Quebec & & & & & & & & & & .687 & .136 & $1.987 * * *$ \\
\hline Prairies & & & & & & & & & & -.841 & .260 & $.431 * * *$ \\
\hline British Columbia & & & & & & & & & & .405 & .186 & $1.499 * *$ \\
\hline Northern Territories & & & & & & & & & & -17.753 & 9630.692 & .000 \\
\hline Ref $=$ Ontario & & & & & & & & & & - & - & - \\
\hline \multicolumn{13}{|l|}{ Education Level: } \\
\hline \multicolumn{13}{|l|}{ Less than Bachelors/PG } \\
\hline \multicolumn{13}{|l|}{ Higher than Bachelors/PG } \\
\hline \multicolumn{13}{|l|}{ Ref $=$ Bachelors $/$ Postgrad Cert. } \\
\hline Academic Self-Ranking: & & & & & & & & & & & & \\
\hline "In top $10 \% "$ & & & & & & & & & & & & \\
\hline
\end{tabular}




\begin{tabular}{|l|l|l|l|l|}
\hline "In top 25\%" & & \multicolumn{1}{|l|}{} & \\
\hline Ref = "In top 50\% OR less" & & & \\
\hline Family Status & & & \\
\hline Married/Common-Law & & & & \\
\hline Previously Married & & & & \\
\hline Ref = Single, Never Married & & & & \\
\hline Dependent Children? & & & & \\
\hline
\end{tabular}

\begin{tabular}{|c|c|c|c|c|c|c|c|c|c|}
\hline \multirow{3}{*}{$\begin{array}{l}\text { Variables } \\
\text { Male Ethno-Racial Groups: }\end{array}$} & \multicolumn{3}{|c|}{ Model $5\left(\right.$ Pseudo $\mathrm{R}^{2}=.088$ ) } & \multicolumn{3}{|c|}{ Model 6 (Pseudo R ${ }^{2}=.092$ ) } & \multicolumn{3}{|c|}{ Model 7 (Pseudo $\mathrm{R}^{2}=.107$ ) } \\
\hline & B & S.E. B & $\operatorname{Exp}(\mathbf{B})$ & B & S.E. B & $\operatorname{Exp}(\mathbf{B})$ & B & S.E. B & $\operatorname{Exp}(\mathbf{B})$ \\
\hline & \multicolumn{9}{|c|}{\begin{tabular}{l|l|l}
\multicolumn{2}{|l}{1} \\
2026
\end{tabular}} \\
\hline South Asian Male & & .215 & $7.659 * * *$ & 1.996 & .217 & $7.361 * * *$ & 1.991 & 217 & $7.324 * * *$ \\
\hline Chinese Male & .855 & .315 & $2.350 * * *$ & .782 & .317 & $2.185 * *$ & .729 & .318 & $2.074 * *$ \\
\hline Black Male & .583 & .494 & 1.791 & .516 & .497 & 1.676 & .511 & .499 & 1.667 \\
\hline Other Male & .976 & .189 & $2.654 * * *$ & .957 & .190 & $2.603 * * *$ & 981 & .191 & $2.667 * * *$ \\
\hline Ref $=$ White Male & - & - & - & - & - & - & - & - & - \\
\hline \multicolumn{10}{|l|}{ Employment Controls: } \\
\hline Months FT Experience at Grad & .001 & .001 & $1.001 *$ & .001 & .001 & $1.001 *$ & .002 & .001 & $1.002 * *$ \\
\hline FT School After Grad? & .259 & .117 & $1.295^{* *}$ & .266 & .117 & $1.305^{* *}$ & 214 & .118 & $1.238^{*}$ \\
\hline \multicolumn{10}{|l|}{ Field of Study: } \\
\hline Social Sciences/Law & -.157 & 284 & .855 & -.170 & .285 & .844 & -.171 & .286 & .843 \\
\hline Engineering/Architecture & .372 & .170 & $1.451 * *$ & .363 & .171 & $1.438^{* * *}$ & .410 & .172 & $1.507 * *$ \\
\hline Health & -.237 & .318 & .789 & -.236 & .318 & .790 & -.298 & .324 & .742 \\
\hline Education & 1.600 & .290 & $4.953 * * *$ & 1.610 & .290 & $5.002 * * *$ & 1.610 & .291 & $5.004 * * *$ \\
\hline Physical/Life Sciences & .474 & .249 & $1.607 *$ & .477 & .249 & $1.611 *$ & .524 & .250 & $1.689 * *$ \\
\hline Math/IT & .221 & .329 & 1.247 & .222 & .329 & 1.248 & .216 & .331 & 1.241 \\
\hline Humanities & .982 & .271 & $2.671 * * *$ & .999 & .272 & $2.716 * * *$ & 1.006 & .273 & $2.736 * * *$ \\
\hline Visual/Performing Arts & .950 & .267 & $2.587 * * *$ & .943 & .267 & $2.567 * * *$ & .919 & .269 & $2.506 * * *$ \\
\hline Other Fields & .626 & .213 & $1.869 * * *$ & .613 & .213 & $1.845 * * *$ & .650 & .215 & $1.916 * * *$ \\
\hline Ref $=$ Business $/$ Admin & - & - & - & - & - & - & - & - & - \\
\hline \multicolumn{10}{|l|}{ Residence Location: } \\
\hline Atlantic & .819 & .224 & $2.267 * * *$ & .794 & .224 & $2.213 * * *$ & .826 & .225 & $2.283 * * *$ \\
\hline Quebec & .645 & .137 & $1.905 * * *$ & .607 & .137 & $1.836 * * *$ & .639 & .139 & $1.894 * * *$ \\
\hline Prairies & -.813 & 261 & $.444 * * *$ & -.848 & .261 & $.428 * * *$ & -.855 & .262 & $.425 * * *$ \\
\hline British Columbia & .407 & .187 & $1.503^{* *}$ & .407 & .187 & $1.502 * *$ & .362 & .189 & $1.436^{*}$ \\
\hline Northern Territories & -17.761 & 9527.933 & .000 & -17.816 & 9462.570 & .000 & -17.709 & 9389.201 & .000 \\
\hline
\end{tabular}




\begin{tabular}{|c|c|c|c|c|c|c|c|c|c|}
\hline Ref $=$ Ontario & - & - & - & - & - & - & - & - & - \\
\hline \multicolumn{10}{|l|}{ Education Level: } \\
\hline Less than Bachelors/PG & .662 & .148 & $1.939 * * *$ & .681 & .150 & $1.975^{* * * *}$ & .605 & .151 & $1.832 * * *$ \\
\hline Higher than Bachelors/PG & .563 & .241 & $1.756^{* *}$ & .600 & .242 & $1.822 * *$ & 707 & .244 & $2.027 * * *$ \\
\hline Ref $=$ Bachelors/Postgrad Cert . & - & - & - & - & - & - & - & - & - \\
\hline \multicolumn{10}{|l|}{ Academic Self-Ranking: } \\
\hline "In top 10\%" & & & & -.282 & .145 & $.754 *$ & -.248 & .145 & $.780^{*}$ \\
\hline "In top 25\%" & & & & -.447 & .145 & $.639 * * *$ & -.447 & .146 & $.639 * * *$ \\
\hline Ref = "In top 50\% OR less" & & & & - & - & - & - & - & - \\
\hline \multicolumn{10}{|l|}{ Family Status } \\
\hline Married/Common-Law & & & & & & & -.518 & .143 & $.596 * * *$ \\
\hline Previously Married & & & & & & & 1.086 & .300 & 2.964 \\
\hline Ref $=$ Single, Never Married & & & & & & & - & - & - \\
\hline Dependent Children? & & & & & & & -.093 & .195 & $.911 * * *$ \\
\hline
\end{tabular}


Appendix 6: Regression 2b: Females' Analysis of Unemployment Odds

Regression 2 (Binary Logistic): Employed(0)/Unemployed(1); Employed (and Self-Employed) $\rightarrow \mathrm{n}=7,588$; Unemployed $\rightarrow \mathrm{n}=376$

\begin{tabular}{|c|c|c|c|c|c|c|c|c|c|c|c|c|}
\hline \multirow[b]{2}{*}{ Variables } & \multicolumn{3}{|c|}{ Model $1\left(\right.$ Pseudo $\left.\mathrm{R}^{2}=.010\right)$} & \multicolumn{3}{|c|}{ Model 2 (Pseudo $\mathrm{R}^{2}=.025$ ) } & \multicolumn{3}{|c|}{ Model 3 (Pseudo $\mathrm{R}^{2}=.052$ ) } & \multicolumn{3}{|c|}{ Model 4 (Pseudo $\mathrm{R}^{2}=.060$ ) } \\
\hline & B & S.E. B & $\operatorname{Exp}(\mathbf{B})$ & B & S.E. B & $\operatorname{Exp}(\mathbf{B})$ & B & S.E. B & $\operatorname{Exp}(B)$ & B & S.E. B & $\operatorname{Exp}(B)$ \\
\hline \multicolumn{13}{|l|}{ Female Ethno-Racial Groups: } \\
\hline South Asian Female & .291 & .303 & 1.337 & .407 & .305 & 1.502 & .435 & 308 & 1.544 & .413 & .311 & 1.511 \\
\hline Chinese Female & -.788 & .511 & .455 & -.716 & .512 & .489 & -.710 & .515 & .491 & -.625 & .517 & .535 \\
\hline Black Female & .082 & .386 & 1.086 & .072 & .387 & 1.075 & .052 & .390 & 1.053 & .012 & .391 & 1.012 \\
\hline Other Female & .800 & .160 & $2.225 * * *$ & .813 & .161 & $2.255 * * *$ & .777 & .164 & $2.176^{* * *}$ & .760 & .166 & $2.138 * * *$ \\
\hline Ref $=$ White Female & - & - & - & - & - & - & - & - & - & - & - & - \\
\hline \multicolumn{13}{|l|}{ Employment Controls: } \\
\hline Months FT Experience at Grad & & & & .003 & .001 & $1.003 * * *$ & .003 & .001 & $1.003 * * *$ & .004 & .001 & $1.004 * * *$ \\
\hline FT School After Grad? & & & & .566 & .109 & $1.762 * * *$ & .565 & .113 & $1.759 * * *$ & .566 & .113 & $1.762 * * *$ \\
\hline \multicolumn{13}{|l|}{ Field of Study: } \\
\hline Social Sciences/Law & & & & & & & .014 & .189 & 1.015 & -.043 & .191 & .958 \\
\hline Engineering/Architecture & & & & & & & .465 & .269 & $1.592^{*}$ & .448 & .270 & $1.565^{*}$ \\
\hline Health & & & & & & & -.304 & .191 & .738 & -.303 & .191 & .739 \\
\hline Education & & & & & & & .946 & .194 & $2.574 * * *$ & .949 & .195 & $2.584 * * *$ \\
\hline Physical/Life Sciences & & & & & & & .487 & 238 & $1.627 * *$ & .464 & .238 & $1.590 * *$ \\
\hline Math/IT & & & & & & & .225 & .516 & 1.253 & 225 & .516 & 1.253 \\
\hline Humanities & & & & & & & .650 & .198 & $1.915 * * *$ & .573 & .201 & $1.773 * * *$ \\
\hline Visual/Performing Arts & & & & & & & .182 & .285 & 1.199 & .180 & .285 & 1.197 \\
\hline Other Fields & & & & & & & 1.032 & .204 & $2.806^{* * * *}$ & 1.013 & .205 & $2.755^{* * * *}$ \\
\hline $\operatorname{Ref}=$ Business $/$ Admin & & & & & & & - & - & - & - & - & - \\
\hline \multicolumn{13}{|l|}{ Residence Location: } \\
\hline Atlantic & & & & & & & & & & .132 & .207 & 1.142 \\
\hline Quebec & & & & & & & & & & -.282 & .133 & $.754 * *$ \\
\hline Prairies & & & & & & & & & & -.315 & .178 & $.730 *$ \\
\hline British Columbia & & & & & & & & & & -.911 & .274 & $.402 * * *$ \\
\hline Northern Territories & & & & & & & & & & -.772 & 1.537 & .462 \\
\hline Ref $=$ Ontario & & & & & & & & & & - & - & - \\
\hline \multicolumn{13}{|l|}{ Education Level: } \\
\hline \multicolumn{13}{|l|}{ Less than Bachelors/PG } \\
\hline \multicolumn{13}{|l|}{ Higher than Bachelors/PG } \\
\hline \multicolumn{13}{|l|}{ Ref $=$ Bachelors/Postgrad Cert. } \\
\hline Academic Self-Ranking: & & & & & & & & & & & & \\
\hline "In top $10 \% "$ & & & & & & & & & & & & \\
\hline
\end{tabular}




\begin{tabular}{|l|l|l|l|l|}
\hline "In top 25\%" & & & \\
\hline Ref= "In top 50\% OR less" & & & \\
\hline Family Status & & & & \\
\hline Married/Common-Law & & & & \\
\hline Previously Married & & & & \\
\hline Ref = Single, Never Married & & & & \\
\hline Dependent Children? & & & & \\
\hline
\end{tabular}

\begin{tabular}{|c|c|c|c|c|c|c|c|c|c|}
\hline \multirow{3}{*}{$\begin{array}{l}\text { Variables } \\
\text { Female Ethno-Racial Groups: }\end{array}$} & \multicolumn{3}{|c|}{ Model 5 (Pseudo $\mathrm{R}^{2}=.062$ ) } & \multicolumn{3}{|c|}{ Model 6 (Pseudo $\mathrm{R}^{2}=.062$ ) } & \multicolumn{3}{|c|}{ Model 7 (Pseudo $\mathrm{R}^{2}=.068$ ) } \\
\hline & B & S.E. B & $\operatorname{Exp}(\mathbf{B})$ & B & S.E. B & $\operatorname{Exp}(\mathbf{B})$ & B & S.E. B & $\operatorname{Exp}(B)$ \\
\hline & \multicolumn{9}{|c|}{20} \\
\hline South Asian Female & & & & .407 & .312 & 1.502 & .367 & .313 & 1.443 \\
\hline Chinese Female & -.570 & .518 & .566 & -.583 & .519 & .558 & -.623 & .519 & .536 \\
\hline Black Female & .006 & .391 & 1.006 & .000 & .392 & 1.000 & -.126 & .393 & .881 \\
\hline Other Female & .766 & .167 & $2.151 * * *$ & .752 & .167 & $2.122 * * *$ & .754 & .168 & $2.126 * * *$ \\
\hline Ref $=$ White Female & - & - & - & - & - & - & - & - & - \\
\hline \multicolumn{10}{|l|}{ Employment Controls: } \\
\hline Months FT Experience at Grad & .004 & .001 & $1.004 * * *$ & .004 & .001 & $1.004 * * *$ & .004 & .001 & $1.004 * * *$ \\
\hline FT School After Grad? & .565 & .114 & $1.759 * * *$ & .572 & .115 & $1.772 * * *$ & .550 & .116 & $1.733 * * *$ \\
\hline \multicolumn{10}{|l|}{ Field of Study: } \\
\hline Social Sciences/Law & .007 & .194 & 1.007 & .004 & .194 & 1.004 & .021 & .195 & 1.021 \\
\hline Engineering/Architecture & .445 & .270 & $1.561 *$ & .443 & .271 & 1.558 & .459 & .271 & $1.582 *$ \\
\hline Health & -.294 & .191 & .745 & -.300 & .192 & .741 & -.294 & .192 & .745 \\
\hline Education & 1.022 & .206 & $2.778 * * *$ & 1.037 & .206 & $2.820 * * *$ & 1.038 & .207 & $2.824 * * *$ \\
\hline Physical/Life Sciences & .536 & .243 & $1.709 * *$ & .539 & .243 & $1.715 * *$ & .566 & .244 & $1.760 * *$ \\
\hline Math/IT & .303 & .518 & 1.354 & .304 & .518 & 1.355 & .348 & .519 & 1.416 \\
\hline Humanities & .633 & .209 & $1.883 * * *$ & .629 & .208 & $1.875 * * *$ & .658 & .209 & $1.931 * * *$ \\
\hline Visual/Performing Arts & .194 & .285 & 1.215 & .192 & .285 & 1.212 & .225 & .287 & 1.252 \\
\hline Other Fields & .955 & .208 & $2.598 * * *$ & .950 & .208 & $2.585 * * *$ & .976 & .209 & $2.653 * * *$ \\
\hline Ref $=$ Business $/$ Admin & - & - & - & 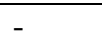 & - & - & - & - & - \\
\hline \multicolumn{10}{|l|}{ Residence Location: } \\
\hline Atlantic & .147 & .208 & 1.158 & .149 & .208 & 1.161 & .160 & 208 & 1.174 \\
\hline Quebec & -.297 & .134 & $.743 * *$ & -.311 & .135 & $.733 * *$ & -.278 & .135 & $.757 * *$ \\
\hline Prairies & -.316 & .178 & $.729 *$ & -.320 & .178 & $726^{*}$ & -.276 & .179 & .758 \\
\hline British Columbia & -.896 & .274 & $408 * * *$ & -.885 & .274 & $413^{* * *}$ & -.868 & .275 & $.420 * * *$ \\
\hline Northern Territories & -.711 & 1.540 & .491 & -.690 & 1.540 & .502 & -.673 & 1.539 & .510 \\
\hline
\end{tabular}




\begin{tabular}{|c|c|c|c|c|c|c|c|c|c|}
\hline Ref $=$ Ontario & - & - & - & - & - & - & - & - & - \\
\hline \multicolumn{10}{|l|}{ Education Level: } \\
\hline Less than Bachelors/PG & .151 & .133 & 1.163 & .172 & .135 & 1.187 & .094 & .137 & 1.098 \\
\hline Higher than Bachelors/PG & -.386 & .249 & .680 & -.364 & .250 & .695 & -.382 & .252 & .683 \\
\hline Ref $=$ Bachelors/Postgrad Cert . & - & - & - & - & - & - & - & - & - \\
\hline \multicolumn{10}{|l|}{ Academic Self-Ranking: } \\
\hline "In top 10\%" & & & & -.166 & .154 & 847 & -.211 & .155 & .810 \\
\hline "In top 25\%" & & & & -.087 & .150 & .917 & -.114 & .150 & .892 \\
\hline Ref = "In top 50\% OR less" & & & & - & - & - & - & - & - \\
\hline \multicolumn{10}{|l|}{ Family Status } \\
\hline Married/Common-Law & & & & & & & -.398 & .130 & $.671 * * *$ \\
\hline Previously Married & & & & & & & -.278 & .291 & .757 \\
\hline Ref $=$ Single, Never Married & & & & & & & - & - & - \\
\hline Dependent Children? & & & & & & & .509 & .149 & $1.663 * * *$ \\
\hline
\end{tabular}




\section{REFERENCES}

Abada, T., Hou, F., \& Ram, B. (2009). Ethnic Differences in Educational Attainment among the Children of Canadian Immigrants. The Canadian Journal of Sociology / Cahiers Canadiens De Sociologie, 34(1), 1-28. Retrieved from: http://www.jstor.org/stable/canajsocicahican.34.1.1

Alesina, A., \& La Ferrara, E. (2005). Ethnic Diversity and Economic Performance. Journal of Economic Literature, 43(3), 762-800. doi:10.1257/002205105774431243

Åslund, O., \& Skans, O. N. (2012). Do Anonymous Job Application Procedures Level the Playing Field? ILR Review, 65(1), 82-107. Retrieved from: https://doi.org/10.1177/001979391206500105

Avery, D. R., \& McKay, P. F. (2006). Target Practice: An Organizational Impression Management Approach to Attracting Minority and Female Job Applicants. Personnel Psychology, 59(1), 157-187. doi:10.1111/j.1744-6570.2006.00807.x

Bernard, A. (2013). Unemployment Dynamics Among Canada's Youth. Economic Insights, 024. (Statistics Canada Catalogue no. 11-626-X). Retrieved from: http://en.copian.ca/library/research/statistics_canada/unemployment_dynamics/unemploy ment_dynamics.pdf

Bertrand, M., \& Mullainathan, S. (2003). Are Emily and Greg More Employable than Lakisha and Jamal? A Field Experiment on Labor Market Discrimination. SSRN Electronic Journal. doi:10.2139/ssrn.422902

Block, S., Galabuzi, G. E., \& Weiss, A. (2014). The colour coded labour market by the numbers. Toronto, ON: Wellesley Institute. Retrieved from:

https://www.wellesleyinstitute.com/publications/the-colour-coded-labour-market-by-thenumbers/

Bolt, G., Phillips, D., \& Van Kempen, R. (2010). Housing policy, (de)segregation and social mixing: An international perspective. Housing Studies, 25(2), 129-135. doi:10.1080/02673030903564838

Boyd, M. (1992). Gender, visible minority, and immigrant earnings inequality. Deconstructing a Nation: Immigration, Multiculturalism and Racism in 90s Canada, edited, 280-321.

Boyd, M. (2002), Educational Attainments of Immigrant Offspring: Success or Segmented Assimilation? International Migration Review, 36, 1037-1060. doi:10.1111/j.17477379.2002.tb00117.x 
Breau, S., Shin, M., \& Burkhart, N. (2017). Pulling apart: new perspectives on the spatial dimensions of neighbourhood income disparities in Canadian cities. Journal of Geographical Systems, 20(1), 1-25. doi:10.1007/s10109-017-0255-0

Bureau of Labor Statistics. (2018). Labor Force Statistics from the Current Population Survey: Household Data - Annual Averages; 22. Persons at work in nonagricultural industries by age, sex, race, Hispanic or Latino ethnicity, marital status, and usual full- or part-time status. Retrieved from: https://www.bls.gov/cps/cpsaat22.htm

Bye, H. H., Horverak, J. G., Sandal, G. M., Sam, D. L., \& van de Vijver, F. J. (2014). Cultural fit and ethnic background in the job interview. International Journal of Cross Cultural Management, 14(1), 7-26. Retrieved from: https://doi.org/10.1177/1470595813491237

Canadian Institute for Health Information (CIHI). (2011). Health Care Cost Drivers: The Facts. Spending and Workforce. Retrieved from: https://secure.cihi.ca/free_products/health_care_cost_drivers_the_facts_en.pdf

Canadian Museum of Immigration. (n.d. -a). Canadian Immigration Acts and Legislation $\mid$ Pier 21. Retrieved from: https://pier21.ca/research/immigration-history/canadian-immigrationacts-and-legislation

Canadian Museum of Immigration. (n.d. -b). Immigration Regulations, Order-in-Council PC 1962-86, 1962 | Pier 21. Retrieved from: https://pier21.ca/research/immigrationhistory/immigration-regulations-order-in-council-pc-1962-86-1962

Canadian Public Health Association (CPHA). (1996). The Health Impact of Unemployment. Retrieved from: https://www.cpha.ca/sites/default/files/assets/resolutions/1996-dp1_e.pdf

Christensen, C. P., \& Weinfeld, M. (1993). The black family in Canada: A preliminary exploration of family patterns and inequality. Canadian Ethnic Studies, 25(3), 26-44. Retrieved from: https://search.proquest.com/docview/215640991?accountid=47455

Christofides, L., \& Swidinsky, R. (1994). Wage Determination by Gender and Visible Minority Status: Evidence from the 1989 LMAS. Canadian Public Policy / Analyse De Politiques, 20(1), 34-51. doi:10.2307/3551834

Clairmont, D. H., \& Wien, F. C. (1976). Race Relations in Canada. Sociological Focus, 9(2), 185-197. doi:10.1080/00380237.1976.10570930

Conway, D. I., Brenner, D. R., McMahon, A. D., Macpherson, L. M., Agudo, A., Ahrens, W. , Bosetti, C. , Brenner, H. , Castellsague, X., Chen, C. , Curado, M. P., Curioni, O. A., Dal Maso, L. , Daudt, A. W., de Gois Filho, J. F., D'Souza, G. , Edefonti, V. , Fabianova, E. , Fernandez, L. , Franceschi, S., Gillison, M., Hayes, R. B., Healy, C. M., Herrero, R. , 
Holcatova, I. , Jayaprakash, V. , Kelsey, K. , Kjaerheim, K. , Koifman, S., La Vecchia, C. , Lagiou, P. , Lazarus, P. , Levi, F. , Lissowska, J. , Luce, D. , Macfarlane, T. V., Mates, D. , Matos, E. , McClean, M. , Menezes, A. M., Menvielle, G. , Merletti, F. , Morgenstern, H. , Moysich, K. , Müller, H. , Muscat, J. , Olshan, A. F., Purdue, M. P., Ramroth, H. , Richiardi, L. , Rudnai, P. , Schantz, S. , Schwartz, S. M., Shangina, O. , Simonato, L. , Smith, E. , Stucker, I. , Sturgis, E. M., Szeszenia-Dabrowska, N. , Talamini, R., Thomson, P. , Vaughan, T. L., Wei, Q. , Winn, D. M., Wunsch-Filho, V. , Yu, G. , Zhang, Z. , Zheng, T. , Znaor, A. , Boffetta, P. , Chuang, S. , Ghodrat, M. , Amy Lee, Y. , Hashibe, M. and Brennan, P. (2015), Estimating and explaining the effect of education and income on head and neck cancer risk: INHANCE consortium pooled analysis of 31 case-control studies from 27 countries. International Journal of Cancer, 136: 1125-1139. doi:10.1002/ijc. 29063

Daenzer, P. (1991). Unemployment and minority immigrants in Canada. International Journal of Sociology and Social Policy, 11(1/2/3), 29-50. doi:10.1108/eb013125

de Kock, F. S., \& Hauptfleisch, D. B. (2018). Reducing racial similarity bias in interviews by increasing structure: A quasi-experiment using multilevel analysis. International Perspectives in Psychology: Research, Practice, Consultation, 7(3), 137-154. Retrieved from: http://dx.doi.org/10.1037/ipp0000091

Denov, M., \& Campbell, K. (2002, February). Casualties of Aboriginal displacement in Canada: children at risk among the Innu of Labrador. Refuge, 20(2), 21+. Retrieved from: http://link.galegroup.com.ezproxy.lib.ryerson.ca/apps/doc/A86388202/CPI?u=rpu_main $\&$ sid=CPI\&xid=e450bbd 4

Department of Finance, Canada. (2014). The State of the Canadian Labour Market. Jobs Report. (Catalogue no. F1-23/3-2014E). Retrieved from:

https://www.budget.gc.ca/2014/docs/jobs-emplois/pdf/jobs-emplois-eng.pdf

Derous, E., Pepermans, R., \& Ryan, A. M. (2017). Ethnic discrimination during résumé screening: Interactive effects of applicants' ethnic salience with job context. Human Relations, 70(7), 860-882. doi:10.1177/0018726716676537

Dollard, M. F., \& Neser, D. Y. (2013). Worker health is good for the economy: Union density and psychosocial safety climate as determinants of country differences in worker health and productivity in 31 European countries. Social Science \& Medicine, 92, 114-123. doi:10.1016/j.socscimed.2013.04.028

Duguet, E. \& Le Clainche, C. (2014). The Effect of Non-Work Related Health Events on Career Outcomes: An Evaluation in the French Labor Market. Revue d'économie politique, vol. 124(3), 437-465. doi:10.3917/redp.243.0437. 
Dunn, A. (2015). The 'choosiness' of the unemployed: evidence on voluntary unemployment in the UK. British Politics and Policy at LSE (22 Jul 2015). Retrieved from: http://eprints.lse.ac.uk/id/eprint/73124

Employment and Social Development Canada. (2015). 2015 Projections, Job Seekers. Retrieved from Canadian Occupational Projection System website:

http://occupations.esdc.gc.ca/sppccops/servlet/copspub?lang=en\&curjsp=1.3bd.2t.1.31s@ _ eng.jsp\&curactn $=$ dwnld $\&$ lid $=63 \&$ fid $=49$

Employment Equity Act (S.C. 1995, c. 44). Retrieved from: https://lawslois.justice.gc.ca/eng/acts/e-5.401/

Esmail, N. (2016). Canada's Physician Supply. Canadian Student Review, 33-41. Retrieved from: https://www.fraserinstitute.org/sites/default/files/canadas-physician-supply-csr-winter2016.pdf

Fan, L., Brownlee, K., Habibov, N. N., \& Neckoway, R. (2017). Returns to education and occupations for Canadian Aboriginal people. International Journal of Social Economics, 44(12), 2224-2237. doi:10.1108/ijse-06-2016-0171

Fortin, B., \& Ragued, S. (2017). Does temporary interruption in postsecondary education induce a wage penalty? Evidence from Canada. Economics of Education Review, 58, 108-122. doi:10.1016/j.econedurev.2017.04.001

Fortin, N., Lemieux, T., \& Torres, J. (2016). Foreign human capital and the earnings gap between immigrants and Canadian-born workers. Labour Economics, 41, 104-119. doi:10.1016/j.labeco.2016.05.021

Francis, D. R. (2006). Why High Earners Work Longer Hours. NBER Digest - National Bureau of Economic Research. Retrieved from: https://www.nber.org/digest/jul06/w11895.html

Frank, K., \& Walters, D. (2012). Exploring the alignment between post-secondary education programs and earnings: An examination of 2005 ontario graduates. The Canadian Journal of Higher Education, 42(3), 93-115. Retrieved from: http://journals.sfu.ca/cjhe/index.php/cjhe/article/view/1866

Gabriel, C. (2015). A different road? canadian immigration policy in the 1960s. Labor: Studies in Working-Class History of the Americas, 12(3), 29-33. doi:10.1215/15476715-2920352

Geel, R., \& Backes-Gellner, U. (2012). Earning While Learning: When and How Student Employment is Beneficial. LABOUR, 26(3), 313-340. doi:10.1111/j.14679914.2012.00548.x 
Gicheva, D. (2013). Working Long Hours and Early Career Outcomes in the High-End Labor Market. Journal of Labor Economics, 31(4), 785-824. doi:10.1086/669971

Girardi Paskulin, L. M., \& Molzahn, A. (2007). Quality of Life of Older Adults in Canada and Brazil. Western Journal of Nursing Research, 29(1), 10-26. Retrieved from: https://doi.org/10.1177/0193945906292550

Giuliano, L., Levine, D., \& Leonard, J. (2011). Racial Bias in the Manager-Employee Relationship: An Analysis of Quits, Dismissals, and Promotions at a Large Retail Firm. The Journal of Human Resources, 46(1), 26-52. Retrieved from: http://www.jstor.org/stable/25764803

Goldman, B. M., Gutek, B. A., Stein, J. H., \& Lewis, K. (2006). Employment Discrimination in Organizations: Antecedents and Consequences. Journal of Management, 32(6), 786830. Retrieved from: https://doi.org/10.1177/0149206306293544

Grayson, J. P. (2004). Social dynamics, university experiences, and graduates' job outcomes. British Journal of Sociology of Education, 25(5), 609-627. doi:10.1080/0142569042000252107

Guo, S. (2009). Difference, deficiency, and devaluation: Tracing the roots of non-recognition of foreign credentials for immigrant professionals in Canada. Canadian Journal for the Study of Adult Education, 22(1), 37-52. Retrieved from: https://cjsae.library.dal.ca/index.php/cjsae/article/view/1002

Halvorsen, R., \& Palmquist, R. (1980). The Interpretation of Dummy Variables in Semilogarithmic Equations. The American Economic Review, 70(3), 474-475. Retrieved from: http://www.jstor.org/stable/1805237

Hancock, J., Allen, D., Bosco, F., McDaniel, K., \& Pierce, C. (2013). Meta-analytic review of employee turnover as a predictor of firm performance. Journal of Management, 39(3), 573-603. doi:10.1177/0149206311424943

Hango, D. (2013). Gender differences in science, technology, engineering, mathematics and computer science (STEM) programs at university. Insights on Canadian Society. Retrieved from: https://www150.statcan.gc.ca/n1/en/pub/75-006x/2013001/article/11874-eng.pdf?st=xZ0B YoRw

Hawkes, N. (2015). People with depression are more likely to commit violent crime, study concludes. BMJ: British Medical Journal, 350, h1083-h1083. doi:10.1136/bmj.h1083 
Headey, B., Muffels, R., \& Wooden, M. (2007). Money Does not Buy Happiness: Or Does It? A Reassessment Based on the Combined Effects of Wealth, Income and Consumption. Social Indicators Research, 87(1), 65-82. doi:10.1007/s11205-007-9146-y

Health Quality Ontario. (2016). Opportunities to achieve health equity in Ontario. Income and Health. Retrieved from: https://www.hqontario.ca/Portals/0/documents/systemperformance/health-equity-report-en.pdf

Herberg, E. N. (1990). The Ethno-Racial Socioeconomic Hierarchy in Canada: Theory and Analysis of the New Vertical Mosaic. International Journal of Comparative Sociology, 31(3-4), 206-221. doi:10.1177/002071529003100305

Hordósy, R., Clark, T., \& Vickers, D. (2018). Lower income students and the 'double deficit' of part-time work: Undergraduate experiences of finance, studying and employability. Journal of Education and Work, 31(4), 353-365. doi:10.1080/13639080.2018.1498068

Hou, F., \& Balakrishnan, T. (1996). The Integration of Visible Minorities in Contemporary Canadian Society. The Canadian Journal of Sociology / Cahiers Canadiens De Sociologie, 21(3), 307-326. doi:10.2307/3341769

Hou, F., \& Coulombe, S. (2010). Earnings Gaps for Canadian-Born Visible Minorities in the Public and Private Sectors. Canadian Public Policy / Analyse De Politiques, 36(1), 2943. Retrieved from: http://www.jstor.org/stable/20695155

Hou, F. (2007). Changes in the Initial Destinations and Redistribution of Canada's Major Immigrant Groups: Reexamining the Role of Group Affinity. International Migration Review, 41(3), 680-705. doi:10.1111/j.1747-7379.2007.00090.x

Howland, J., \& Sakellariou, C. (1993). Wage discrimination, occupational segregation and visible minorities in Canada. Applied Economics, 25(11), 1413-1422. doi:10.1080/00036849300000146

Hum, D., \& Simpson, W. (1999). Wage Opportunities for Visible Minorities in Canada. Canadian Public Policy / Analyse De Politiques, 25(3), 379-394. doi:10.2307/3551526

Hyman, I. (2009). Racism as a determinant of immigrant health. Retrieved from Metropolis Project and Strategic Initiatives and Innovations Directorate (SIID) website: http://www.metropolis.net/pdfs/racism_policy_brief_e.pdf

Immigration, Refugees and Citizenship Canada. (n.d.). Francophone Immigration in Canada: a part of our history. Retrieved from: https://www.canada.ca/en/immigration-refugees- 
citizenship/services/canadians/celebrate-being-canadian/teachers-corner/francophoneimmigration.html

International Organization for Migration (IOM) (2017). World Migration Report 2018. United Nations, New York. Retrieved from: https://doi.org/10.18356/f45862f3-en

Jackson, J., \& Weidman, N. (2005). The Origins of Scientific Racism. The Journal of Blacks in Higher Education, (50), 66-79. Retrieved from http://www.jstor.org/stable/25073379

Jain, H. C., \& Lawler, J. J. (2004). Visible Minorities under the Canadian Employment Equity Act, 1987-1999. Relations Industrielles, 59(3), 585. doi:10.7202/010926ar

Jayasingam, S., Fujiwara, Y., \& Thurasamy, R. (2016). 'I am competent so I can be choosy': choosiness and its implication on graduate employability. Studies in Higher Education, 43(7), 1119-1134. doi:10.1080/03075079.2016.1221918

Johnson, J. S., \& Newport, E. L. (1989). Critical period effects in second language learning: The influence of maturational state on the acquisition of English as a second language. Cognitive Psychology, 21(1), 60-99. doi:10.1016/0010-0285(89)90003-0

Jones, E. B., \& Jackson, J. D. (1990). College Grades and Labor Market Rewards. The Journal of Human Resources, 25(2), 253. doi:10.2307/145756

Kang, S. K., DeCelles, K. A., Tilcsik, A., \& Jun, S. (2016). Whitened Résumés: Race and SelfPresentation in the Labor Market. Administrative Science Quarterly, 61(3), 469-502. Retrieved from: https://doi.org/10.1177/0001839216639577

Kinder, D., \& Winter, N. (2001). Exploring the Racial Divide: Blacks, Whites, and Opinion on National Policy. American Journal of Political Science, 45(2), 439-456. doi: $10.2307 / 2669351$

Krahn, H., \& Maximova, K. (2005). Does race matter? earnings of visible minority graduates from Alberta universities. The Canadian Journal of Higher Education, 35(1), 85-110. Retrieved from: http://journals.sfu.ca/cjhe/index.php/cjhe/article/view/183493

Krivo, L., Peterson, R., \& Kuhl, D. (2009). Segregation, Racial Structure, and Neighborhood Violent Crime. American Journal of Sociology, 114(6), 1765-1802. doi:10.1086/597285

Kustec, S. (2012). The role of migrant labour supply in the Canadian labour market. Research and Evaluation. Citizenship and Immigration Canada. Retrieved from: https://www.canada.ca/en/immigration-refugees-citizenship/corporate/reportsstatistics/research/role-migrant-labour-supply-canadian-labour-market.html 
Lee, D. S., Chiu, M., Manuel, D. G., Tu, K., Wang, X., \& Austin, P. C. (2009). Trends in risk factors for cardiovascular disease in Canada: temporal, socio-demographic and geographic factors. Canadian Medical Association Journal, 181(3-4), E55-E66. doi:10.1503/cmaj.081629

Lemieux, T. (2014). Occupations, fields of study and returns to education. Canadian Journal of Economics/Revue Canadienne d'Economique, 47(4), 1047-1077. doi:10.1111/caje.12116

Li, P. S. (2012). Differences in Employment Income of University Professors. Canadian Ethnic Studies, 44(1), 39-48. doi:10.1353/ces.2012.0012

Lintott, S. (2015). Friendship and Bias: Ethical and Epistemic Considerations. Journal of Social Philosophy, 46(3), 318-339. doi:10.1111/josp.12105

Lix, L. M., Hobson, D. E., Azimaee, M., Leslie, W. D., Burchill, C., \& Hobson, S. (2009). Socioeconomic variations in the prevalence and incidence of Parkinson's disease: a population-based analysis. Journal of Epidemiology \& Community Health, 64(4), 335340. doi:10.1136/jech.2008.084954

Lum, J. M. (1995). The federal employment equity act: Goals vs. implementation. Canadian Public Administration, 38(1), 45-76. doi:10.1111/j.1754-7121.1995.tb01129.x

Lynn, M., \& Sturman, M. (2011). Is the Customer Always Right? The Potential for Racial Bias in Customer Evaluations of Employee Performance. Journal of Applied Social Psychology, 41(9), 2312-2324. Retrieved from: https://doi.org/10.1111/j.15591816.2011.00803.x

Mackenzie King, W. L. (1947). House of Commons Debates, May 1, 1947, 2: 44-2647.

Makarem, S. C., \& Jae, H. (2015). Consumer Boycott Behavior: An Exploratory Analysis of Twitter Feeds. Journal of Consumer Affairs, 50(1), 193-223. doi:10.1111/joca.12080

Manroop, L., Boekhorst, J. A., \& Harrison, J. A. (2013). The influence of cross-cultural differences on job interview selection decisions. International Journal of Human Resource Management, 24(18), 3512-3533. Retrieved from: https://doi.org/10.1080/09585192.2013.777675

Mar, L. R. (2007). Beyond Being Others: Chinese Canadians as National History. BC Studies, 156, 13-34,203. Retrieved from: http://ezproxy.lib.ryerson.ca/login?url=https://search-proquestcom.ezproxy.lib.ryerson.ca/docview/196908236? accountid=13631 
Maxim, P. (1992). Immigrants, Visible Minorities, and Self-Employment. Demography, 29(2), 181-198. Retrieved from: http://www.jstor.org/stable/2061726

McDade, K., \& Institute for Research on Public Policy (1988). Barriers to recognition of the credentials of immigrants in Canada. Ottawa, Ont.: Institute for Research on Public Policy, Studies in Social Policy.

McFarquhar, C. (2007). Blacks in 1880s toronto: The search for equality. Ontario History, 99(1), 64-76,135. Retrieved from: http://ezproxy.lib.ryerson.ca/login?url=https://searchproquest-com.ezproxy.lib.ryerson.ca/docview/208523047?accountid=13631

Mckenzie, S. K., Imlach Gunasekara, F., Richardson, K., \& Carter, K. (2013). Do changes in socioeconomic factors lead to changes in mental health? Findings from three waves of a population based panel study. Journal of Epidemiology and Community Health, 68(3), 253-260. doi:10.1136/jech-2013-203013

Montoya, R. M., \& Horton, R. S. (2012). A meta-analytic investigation of the processes underlying the similarity-attraction effect. Journal of Social and Personal Relationships, 30(1), 64-94. doi:10.1177/0265407512452989

Musterd, S. (2005), Social and Ethnic Segregation in Europe: Levels, Causes, and Effects. Journal of Urban Affairs, 27: 331-348. doi:10.1111/j.0735-2166.2005.00239.x

Nakhaie, M. (2007). Ethnoracial origins, social capital, and earnings. Journal of International Migration and Integration / Revue De l'Integration Et De La Migration Internationale, 8(3), 307-325. doi:10.1007/s12134-007-0024-X

Newton, J. L. (2016). “These French Canadian of the Woods are Half-Wild Folk": Wilderness, Whiteness, and Work in North America, 1840-1955. Labour / Le Travail, 77(1), 121150. doi:10.1353/1lt.2016.0003

Ng, E. S. W., \& Burke, R. J. (2005). Person-organization fit and the war for talent: Does diversity management make a difference? The International Journal of Human Resource Management, 16(7), 1195-1210. doi:10.1080/09585190500144038

OECD. (2014). Improving attraction and retention of labour migrants in Norway, in Recruiting Immigrant Workers: Norway 2014, OECD Publishing, Paris. Retrieved from: https://doi.org/10.1787/9789264226135-9-en.

OHRC - Ontario Human Rights Commission. (n.d.). Racial discrimination, race and racism (fact sheet). Retrieved from: http://www.ohrc.on.ca/en/racial-discrimination-race-and-racismfact-sheet 
Oreopoulos, P. (2011). Why Do Skilled Immigrants Struggle in the Labor Market? A Field Experiment with Thirteen Thousand Resumes. American Economic Journal: Economic Policy, 3(4), 148-171. Retrieved from: http://www.jstor.org/stable/41330445

Pager, D. (2016). Are Firms That Discriminate More Likely to Go Out of Business? Sociological Science, 3, 849-859. doi:10.15195/v3.a36

Peery, D. (2017). (Re)defining race: Addressing the consequences of the law's failure to define race. Cardozo Law Review38(5), 1817-1878.

Pendakur, K., \& Pendakur, R. (1998). The Colour of Money: Earnings Differentials among Ethnic Groups in Canada. The Canadian Journal of Economics / Revue Canadienne D'Economique, 31(3), 518-548. doi:10.2307/136201

Pendakur, K., \& Pendakur, R. (2002). Colour My World: Have Earnings Gaps for CanadianBorn Ethnic Minorities Changed over Time? Canadian Public Policy / Analyse De Politiques, 28(4), 489-512. doi:10.2307/3552211

Pendakur, K., \& Pendakur, R. (2011). Color by Numbers: Minority Earnings in Canada 19952005. Journal of International Migration and Integration / Revue de l'integration et de la migration internationale. doi:10.1007/s12134-010-0160-6

Pendakur, K., \& Pendakur, R. (2016). Which Child Immigrants Face Earnings Disparity? Ageat-immigration, Ethnic Minority Status and Labour Market Attainment in Canada. International Migration, 54(5), 43-58. doi:10.1111/imig.12256

Pharr, J. R., Moonie, S., \& Bungum, T. J. (2012). The Impact of Unemployment on Mental and Physical Health, Access to Health Care and Health Risk Behaviors. ISRN Public Health, 2012, 1-7. doi:10.5402/2012/483432

Plummer, D. L., Stone, R. T., Powell, L., \& Allison, J. (2016). Patterns of adult cross-racial friendships: A context for understanding contemporary race relations. Cultural Diversity and Ethnic Minority Psychology, 22(4), 479-494. doi:10.1037/cdp0000079

Pruegger, V., \& Cook, D. (2009). An Analysis of Immigrant Attraction and Retention Patterns Among Western Canadian CMAs. Our Diverse Cities, 6, 44-49. Retrieved from: http://canada.metropolis.net/pdfs/ODC_vol6_spring09_e.pdf

Raphael, D. (2002). Poverty, Income Inequality, and Health in Canada. The CSJ Foundation for Research and Education: Social Justice Series. Retrieved from: http://www.socialjustice.org/uploads/pubs/PovertyIncomeInequalityandHealthinCanada.p df 
Ravaghi, V., Quiñonez, C., \& Allison, P. J. (2013). The magnitude of oral health inequalities in Canada: findings of the Canadian health measures survey. Community Dentistry and Oral Epidemiology, 41(6), 490-498. doi:10.1111/cdoe.12043

Raver, J. L., \& Nishii, L. H. (2010). Once, twice, or three times as harmful? Ethnic harassment, gender harassment, and generalized workplace harassment. Journal of Applied Psychology, 95(2), 236-254. Retrieved from: https://doi.org/10.1037/a0018377

Raza, M., \& Erfani, A. (2015). Earnings differences among second-generation South Asians. South Asian Diaspora, 7(2), 149-165. doi:10.1080/19438192.2015.1030886

Reardon, S., Fox, L., \& Townsend, J. (2015). Neighborhood income composition by household race and income, 1990-2009. The Annals of the American Academy of Political and Social Science, 660(1), 78-97. doi:10.1177/0002716215576104

Redonnet, B., Chollet, A., Fombonne, E., Bowes, L., \& Melchior, M. (2012). Tobacco, alcohol, cannabis and other illegal drug use among young adults: The socioeconomic context. Drug and Alcohol Dependence, 121(3), 231-239.

doi:10.1016/j.drugalcdep.2011.09.002

Reitz, J. G., Zhang, H., \& Hawkins, N. (2011). Comparisons of the success of racial minority immigrant offspring in the United States, Canada and Australia. Social Science Research, 40(4), 1051-1066. Retrieved from: https://doi.org/10.1016/j.ssresearch.2011.03.009

Richmond, A. H., \& Verma, R. P. (1978). Income inequality in Canada: ethnic and generational aspects. Canadian Studies in Population, 5, 25. doi:10.25336/p6rs48

Roth, P. L., \& Clarke, R. L. (1998). Meta-analyzing the relation between grades and salary. Journal of Vocational Behavior, 53(3), 386-400. doi:10.1006/jvbe.1997.1621

Schmillen, A., \& Umkehrer, M. (2017). The scars of youth: Effects of early-career unemployment on future unemployment experience. International Labour Review, 156(34), 465-494. doi:10.1111/ilr.12079

Segrest Purkiss, S. L., Perrewé, P. L., Gillespie, T. L., Mayes, B. T., \& Ferris, G. R. (2006). Implicit sources of bias in employment interview judgments and decisions. Organizational Behavior and Human Decision Processes, 101(2), 152-167. Retrieved from: https://doi.org/10.1016/j.obhdp.2006.06.005

Seibert, S., Kraimer, M., \& Liden, R. (2001). A Social Capital Theory of Career Success. The Academy of Management Journal, 44(2), 219-237. Retrieved from: http://www.jstor.org/stable/3069452 
Seidel, M. L., Polzer, J. T., \& Stewart, K. J. (2000). Friends in High Places: The Effects of Social Networks on Discrimination in Salary Negotiations. Administrative Science Quarterly, 45(1), 1. doi:10.2307/2666977

Senik, C. (2014). Wealth and happiness. Oxford Review of Economic Policy, 30(1), 92-108. doi:10.1093/oxrep/gru004

Shah, S. J., Krumholz, H. M., Reid, K. J., Rathore, S. S., Mandawat, A., Spertus, J. A., \& Ross, J. S. (2012). Financial Stress and Outcomes after Acute Myocardial Infarction. PLoS ONE, 7(10), e47420. doi:10.1371/journal.pone.0047420

Skuterud, M. (2010). The visible minority earnings gap across generations of Canadians. Canadian Journal of Economics/Revue canadienne d'économique, 43(3), 860-881. doi:10.1111/j.1540-5982.2010.01598.x

Statistics Canada. (n.d.). Table 14-10-0106-01: Employment and unemployment rate, annual, population centres and rural areas. Geography: Canada, Province or territory. Retrieved from: https://www150.statcan.gc.ca/t1/tbl1/en/tv.action?pid=1410010601

Statistics Canada. (2001). 2001 Census of Population, Statistics Canada Catalogue no. 95F0363XCB2001009.

Statistics Canada. (1998). The Daily-1996 Census: Ethnic origin, visible minorities, Tuesday, February 17, 1998. Retrieved from: https://www150.statcan.gc.ca/n1/dailyquotidien/980217/dq980217-eng.htm

Statistics Canada. (2006). Labour Force Activity (8), Visible Minority Groups (14), Immigrant Status and Period of Immigration (9A), Age Groups (9) and Sex (3) for the Population 15 Years and Over of Canada, Provinces, Territories, Census Metropolitan Areas and Census Agglomerations, 1996 to 2006 Censuses - 20\% Sample Data. (Statistics Canada Catalogue no. 97-562-XCB2006013). Retrieved from: https://www12.statcan.gc.ca/census-recensement/2006/dp-pd/tbt/Rpeng.cfm?LANG $=\mathrm{E} \& A P A T H=3 \& D E T A I L=0 \& D I M=0 \& F L=A \& F R E E=0 \& G C=0 \& G I D=$ $0 \& \mathrm{GK}=0 \& \mathrm{GRP}=1 \& \mathrm{PID}=92340 \& \mathrm{PRID}=0 \& \mathrm{PTYPE}=88971,97154 \& \mathrm{~S}=0 \& \mathrm{SHOW} \mathrm{ALL}=0$ $\& S U B=0 \&$ Temporal $=2006 \&$ THEME $=80 \& \mathrm{VID}=0 \& \mathrm{VNAMEE}=\& \mathrm{VNAMEF}=$

Statistics Canada. (2008). 2006 Census: Visible Minority Population and Population Group Reference Guide. (Statistics Canada Catalogue no. 97-562-GWE2006003). Retrieved from: http://www12.statcan.ca/census-recensement/2006/ref/rp-guides/visible_minorityminorites_visibles-eng.cfm

Statistics Canada. (2009). Canadians living in low-income households more likely than those from higher income households to report socially disruptive conditions in their 
neighbourhoods. (Statistics Canada Catalogue no. 85F0033M). Retrieved from:

https://www150.statcan.gc.ca/n1/pub/85f0033m/2009020/findings-resultats/f-r5-eng.htm

Statistics Canada. (2011a). Ethnic diversity and immigration. Statistics Canada Catalogue no. 11402-X. Ottawa, Ontario. Retrieved from: https://www150.statcan.gc.ca/n1/pub/11-402x/2011000/chap/imm/imm-eng.htm

Statistics Canada. (2011b). Labour Force Status (8), Visible Minority (15), Immigrant Status and Period of Immigration (10), Highest Certificate, Diploma or Degree (7), Age Groups (13B) and Sex (3) for the Population Aged 15 Years and Over, in Private Households of Canada, Provinces, Territories, Census Metropolitan Areas and Census Agglomerations, 2011 National Household Survey. (Statistics Canada Catalogue no. 99-012-X2011038). Retrieved from: https://www12.statcan.gc.ca/nhs-enm/2011/dp-pd/dt-td/Rpeng.cfm?LANG $=\mathrm{E} \& A P A T H=3 \& D E T A I L=0 \& D I M=0 \& F L=A \& F R E E=0 \& G C=0 \& \mathrm{GID}=$ $0 \& \mathrm{GK}=0 \& \mathrm{GRP}=0 \& \mathrm{PID}=105611 \& \mathrm{PRID}=0 \& \mathrm{PTYPE}=105277 \& \mathrm{~S}=0 \& \mathrm{SHOWALL}=1 \& \mathrm{~S}$ $\mathrm{UB}=0 \&$ Temporal $=2013 \& \mathrm{THEME}=96 \& \mathrm{VID}=0 \& \mathrm{VNAMEE}=\& \mathrm{VNAMEF}=$

Statistics Canada. (2011c). Analytical document: Immigration and Ethnocultural Diversity in Canada. (Statistics Canada Catalogue no. 99-010-X2011001). Retrieved from: https://www12.statcan.gc.ca/nhs-enm/2011/as-sa/99-010-x/99-010-x2011001-eng.cfm

Statistics Canada. (2013). Labour Force Status (8), Visible Minority (15), Immigrant Status and Period of Immigration (10), Highest Certificate, Diploma or Degree (7), Age Groups (13B) and Sex (3) for the Population Aged 15 Years and Over, in Private Households of Canada, Provinces, Territories, Census Metropolitan Areas and Census Agglomerations, 2011 National Household Survey. (Statistics Canada Catalogue no. 99-012-X2011038).

Retrieved from: https://www12.statcan.gc.ca/nhs-enm/2011/dp-pd/dt-td/Apeng.cfm?LANG $=\mathrm{E} \& A P A T H=3 \& D E T A I L=0 \& D I M=0 \& F L=A \& F R E E=0 \& G C=0 \& \mathrm{GID}=$ $0 \& \mathrm{GK}=0 \& \mathrm{GRP}=0 \& \mathrm{PID}=105611 \& \mathrm{PRID}=0 \& \mathrm{PTYPE}=105277 \& \mathrm{~S}=0 \& \mathrm{SHOWALL}=1 \& \mathrm{~S}$ $\mathrm{UB}=0 \&$ Temporal=2013 \&THEME=96\&VID=0\&VNAMEE=\&VNAMEF $=$

Statistics Canada. (2016). Labour Force Status (8), Visible Minority (15), Immigrant Status and Period of Immigration (11), Highest Certificate, Diploma or Degree (7), Age (13A) and Sex (3) for the Population Aged 15 Years and Over in Private Households of Canada, Provinces and Territories, Census Metropolitan Areas and Census Agglomerations, 2016 Census - 25\% Sample Data. (Statistics Canada Catalogue no. 98-400-X2016286). Retrieved from: https://www12.statcan.gc.ca/census-recensement/2016/dp-pd/dt-td/Rpeng.cfm?LANG $=\mathrm{E} \& A P A T H=3 \& D E T A I L=0 \& D I M=0 \& \mathrm{FL}=\mathrm{A} \& \mathrm{FREE}=0 \& \mathrm{GC}=0 \& \mathrm{GID}=$ $0 \& \mathrm{GK}=0 \& \mathrm{GRP}=1 \& \mathrm{PID}=110692 \& \mathrm{PRID}=10 \& \mathrm{PTYPE}=109445 \& \mathrm{~S}=0 \& \mathrm{SHOW} A L L=0 \&$ $\mathrm{SUB}=0 \&$ Temporal $=2017 \& \mathrm{THEME}=123 \& \mathrm{VID}=0 \& \mathrm{VNAMEE}=\& \mathrm{VNAMEF}=$

Statistics Canada. (2017a). Focus on Geography Series, 2016 Census. Statistics Canada Catalogue no. 98-404-X2016001. Ottawa, Ontario. Data products, 2016 Census. Retrieved from: https://www12.statcan.gc.ca/census-recensement/2016/as-sa/fogsspg/Facts-can-eng.cfm?Lang $=$ Eng $\& \mathrm{GK}=\mathrm{CAN} \& \mathrm{GC}=01 \& \mathrm{TOPIC}=7$ 
Statistics Canada. (2017b). Visible Minority (15), Income Statistics (17), Generation Status (4), Age (10) and Sex (3) for the Population Aged 15 Years and Over in Private Households of Canada, Provinces and Territories, Census Metropolitan Areas and Census Agglomerations, 2016 Census - 25\% Sample Data. (Statistics Canada Catalogue no. 98400-X2016210). Retrieved from: http://www12.statcan.gc.ca/censusrecensemalest/2016/dp-pd/dt-td/Rpeng.cfm?LANG $=\mathrm{E} \& A P A T H=3 \& D E T A I L=0 \& D I M=0 \& F L=A \& F R E E=0 \& G C=0 \& \mathrm{GID}=$ $0 \& \mathrm{GK}=0 \& \mathrm{GRP}=1 \& \mathrm{PID}=110562 \& \mathrm{PRID}=10 \& \mathrm{PTYPE}=109445 \& \mathrm{~S}=0 \&$ SHOWALL $=0 \&$ $\mathrm{SUB}=0 \&$ Temporal=2017 \&THEME $=120 \& \mathrm{VID}=0 \& \mathrm{VNAMEE}=\& \mathrm{VNAMEF}=$

Statistics Canada. (2017c). Labour Force Status (8), Visible Minority (15), Immigrant Status and Period of Immigration (11), Highest Certificate, Diploma or Degree (7), Age (13A) and Sex (3) for the Population Aged 15 Years and Over in Private Households of Canada, Provinces and Territories, Census Metropolitan Areas and Census Agglomerations, 2016 Census - 25\% Sample Data. (Statistics Canada Catalogue no. 98-400-X2016286). Retrieved from: https://www12.statcan.gc.ca/census-recensement/2016/dp-pd/dt-td/Rpeng.cfm?LANG $=\mathrm{E} \& A P A T H=3 \& D E T A I L=0 \& D I M=0 \& F L=A \& F R E E=0 \& G C=0 \& G I D=$ $0 \& \mathrm{GK}=0 \& \mathrm{GRP}=1 \& \mathrm{PID}=110692 \& \mathrm{PRID}=10 \& \mathrm{PTYPE}=109445 \& \mathrm{~S}=0 \& \mathrm{SHOW} \mathrm{ALL}=0 \&$ $\mathrm{SUB}=0 \& \mathrm{Temporal}=2017 \& \mathrm{THEME}=124 \& \mathrm{VID}=0 \& \mathrm{VNAMEE}=\& \mathrm{VNAMEF}=$

Statistics Canada. (2017d). Immigration and Ethnocultural Diversity Highlight Tables - Visible minority (visible minority), both sexes, age (total), Canada, provinces and territories, 2016 Census - 25\% Sample data. (Statistics Canada Catalogue no. 98-316-X2016001). Retrieved from: https://www12.statcan.gc.ca/census-recensement/2016/dp-pd/hltfst/imm/Table.cfm?Lang=E\&T=41\&Geo=00\&SP=1\&vismin=2\&age=1\&sex=1

Statistics Canada. (2017e). Income Highlight Tables - Total population 15 years and over, number of income recipients and median income for total income, both sexes, Canada, provinces and territories, 2016 Census - 100\% Data, 2006 Census - 20\% Sample data. Retrieved from: https://www12.statcan.gc.ca/census-recensement/2016/dp-pd/hlt-fst/increv/Table.cfm?Lang=Eng $\& \mathrm{~T}=201 \& \mathrm{~S}=99 \& \mathrm{O}=\mathrm{A}$

Statistics Canada. (2017f). The Daily_Household income in Canada: Key results from the 2016 Census. Retrieved from: https://www150.statcan.gc.ca/n1/en/dailyquotidien/170913/dq170913a-eng.pdf?st=AcoJ3Nsu

Statistics Canada. (2017g). The Daily-Education in Canada: Key results from the 2016 Census. Retrieved from: https://www150.statcan.gc.ca/n1/daily-quotidien/171129/dq171129aeng.htm

Statistics Canada. (2018). The Daily - Experiences of violent victimization and discrimination reported by minority populations in Canada, 2014. (Statistics Canada Catalogue no. 11001-X). Retrieved from: https://www150.statcan.gc.ca/n1/dailyquotidien/180412/dq180412d-eng.htm 
Stauffer, J. M., \& Buckley, M. R. (2005). The Existence and Nature of Racial Bias in Supervisory Ratings. Journal of Applied Psychology, 90(3), 586-591. Retrieved from: https://doi.org/10.1037/0021-9010.90.3.586

Stelcner, M. (2000). Earnings Differentials among Ethnic Groups in Canada: A Review of the Research. Review of Social Economy, 58(3), 295-317. doi:10.1080/00346760050132346

Stenstrom, D. M., Curtis, M., \& Iyer, R. (2013). School Rankings, Department Rankings, and Individual Accomplishments: What Factors Predict Obtaining Employment After the PhD? Perspectives on Psychological Science, 8(2), 208-217. Retrieved from: https://doi.org/10.1177/1745691612474316

Stumpf, S. A., \& Tymon, W. G. (2012). The effects of objective career success on subsequent subjective career success. Journal of Vocational Behavior, 81(3), 345-353. doi:10.1016/j.jvb.2012.09.001

Swidinsky, R., \& Swidinsky, M. (2002). The Relative Earnings of Visible Minorities in Canada. Relations industrielles, 57(4), 630. doi:10.7202/006904ar

Thornhill, E. M. A. (2008). So seldom for us, so often against us: Blacks and law in canada. Journal of Black Studies, 38(3), 321-337. doi:10.1177/0021934707308258

Tom, M. (2015). Gender-Hours Disparity Across Races. Berkeley Undergraduate Journal, 28(2). Retrieved from: https://escholarship.org/uc/item/8613k4z7

Triadafilopoulos, T. (2010). Global norms, domestic institutions and the transformation of immigration policy in Canada and the US. Review of International Studies, 36(1), 169193. doi:10.1017/S0260210509990556

Triana, M. D., Jayasinghe, M., \& Pieper, J. R. (2015). Perceived workplace racial discrimination and its correlates: A meta-analysis. Journal of Organizational Behavior, 36(4), 491-513. doi:10.1002/job.1988

Turcotte, M. (2011). Women and Education. Women in Canada: A Gender-based Statistical Report, 6. Retrieved from: https://www150.statcan.gc.ca/n1/en/pub/89-503$\mathrm{x} / 2010001 /$ article/11542-eng.pdf?st=7y5Xlnfe

Twa, D. D., Skinnider, M. A., Squair, J. W., \& Lukac, C. D. (2017). Cross-sectional-derived determinants of satisfaction with physician-scientist training among Canadian $\mathrm{MD} / \mathrm{PhD}$ graduates. PLOS ONE, 12(9). doi:10.1371/journal.pone.0185218

Uslaner, E. (2010). Segregation, mistrust and minorities. Ethnicities, 10(4), 415-434. doi:10.1177/1468796810378325 
Van den Broek, T., Langley, D., \& Hornig, T. (2017). The Effect of Online Protests and Firm Responses on Shareholder and Consumer Evaluation. Journal of Business Ethics, 146(2), 279-294. doi:10.1007/s10551-017-3653-9

Varma, A., Toh, S. M., \& Pichler, S. (2006). Ingratiation in job applications: Impact on selection decisions. Journal of Managerial Psychology, 21(3), 200-210. doi:10.1108/02683940610659551

Verbeeten, D. (2007). The Past and Future of Immigration to Canada. Journal of International Migration and Integration / Revue de l'integration et de la migration internationale, 8(1), 1-10. doi:10.1007/s12134-007-0005-0

Verbruggen, M., Van Emmerik, H., Van Gils, A., Meng, C., \& De Grip, A. (2015). Does earlycareer underemployment impact future career success? A path dependency perspective. Journal of Vocational Behavior, 90, 101-110. doi:10.1016/j.jvb.2015.08.002

Walters, D., \& Zarifa, D. (2008). Earnings and employment outcomes for male and female postsecondary graduates of coop and non-coop programmes. Journal of Vocational Education \& Training, 60(4), 377-399. doi:10.1080/13636820802591863

Walters, D., White, J., \& Maxim, P. (2004). Does Postsecondary Education Benefit Aboriginal Canadians? An Examination of Earnings and Employment Outcomes for Recent Aboriginal Graduates. Canadian Public Policy / Analyse De Politiques, 30(3), 283-301. doi: $10.2307 / 3552303$

Wang, J. L., Schmitz, N., \& Dewa, C. S. (2009). Socioeconomic status and the risk of major depression: the Canadian National Population Health Survey. Journal of Epidemiology \& Community Health, 64(5), 447-452. doi:10.1136/jech.2009.090910

Watterson, R. A., A., J. V., Lavorato, D. H., \& Patten, S. B. (2017). Descriptive Epidemiology of Generalized Anxiety Disorder in Canada. The Canadian Journal of Psychiatry, 62(1), 24-29. Retrieved from: https://doi.org/10.1177/0706743716645304

Weisburd, D., Cave, B., Nelson, M., White, C., Haviland, A., Ready, J., ... Sikkema, K. (2018). Mean Streets and Mental Health: Depression and Post-Traumatic Stress Disorder at Crime Hot Spots. American Journal of Community Psychology, 61(3-4), 285-295. doi:10.1002/ajcp.12232

Wilson, R.M., P. Landolt, Y.B. Shakya, G. Galabuzi, Z. Zahoorunissa, D. Pham, F. Cabrera, S. Dahy, and M-P. Joly. (2011). Working Rough, Living Poor: Employment and Income Insecurities Faced by Racialized Groups in the Black Creek Area and their Impacts on Health. Toronto: Access Alliance Multicultural Health and Community Services. Retrieved from: https://www.wellesleyinstitute.com/wp-content/uploads/2011/12/AccessAlliance_Working-Rough-Living-Poor-Final-Report-June-2011-E-version.pdf 
Winn, C. (1985). Affirmative Action and Visible Minorities: Eight Premises in Quest of Evidence. Canadian Public Policy / Analyse De Politiques, 11(4), 684-700. doi:10.2307/3550299

Wright, B. R., Wallace, M., Bailey, J., \& Hyde, A. (2013). Religious affiliation and hiring discrimination in New England: A field experiment. Research in Social Stratification and Mobility, 34, 111-126. doi:10.1016/j.rssm.2013.10.002

Yap, M., \& Konrad, A. M. (2009). Gender and racial differentials in promotions: Is there a sticky floor, a mid-level bottleneck, or a glass ceiling? Relations Industrielles, 64(4), 593-619. doi:http://dx.doi.org.ezproxy.lib.ryerson.ca/10.7202/038875ar

Yu, S. (2018). Visible Minority Wage Gaps for Highly Educated Immigrant and Canadian-born Workers with Canadian Degrees. $u O$ Research. Retrieved from: https://ruor.uottawa.ca/handle/10393/38137

Yuen, J. (2010). Job-education match and mismatch: Wage differentials. Perspectives on Labour and Income, 11(4), 16-26. Retrieved from: https://www150.statcan.gc.ca/n1/pub/75-001x/2010104/article/11149-eng.htm\#a10

Zagorsky, J. L. (2005). Marriage and divorce's impact on wealth. Journal of Sociology, 41(4), 406-424. Retrieved from: https://doi.org/10.1177/1440783305058478

Zalcman, D. (2016). “Kill the indian, save the man". World Policy Journal, 33(3), 72-85. doi:10.1215/07402775-3713029

Zatzick, C. D., Elvira, M. M., \& Cohen, L. E. (2003). When is More Better? The Effects of Racial Composition on Voluntary Turnover. Organization Science, 14(5), 483-496. doi:10.1287/orsc.14.5.483.16768

Zhang, W., McLeod, C., \& Koehoorn, M. (2016). The relationship between chronic conditions and absenteeism and associated costs in Canada. Scandinavian Journal of Work, Environment \& Health, 42(5), 413-422. doi:10.5271/sjweh.3583

Zhang, X. (2009). Earnings of women with and without children. Perspectives on Labour and Income, 10(3), 5-13. Retrieved from: https://www150.statcan.gc.ca/n1/en/pub/75-001x/75-001-x2009103-eng.pdf?st=2nKzovOM 